See discussions, stats, and author profiles for this publication at: https://www.researchgate.net/publication/272162807

\title{
The nonavian theropod quadrate II: systematic usefulness, major trends and cladistic and phylogenetic morphometrics analyses
}

Article · January 2014

DOI: $10.7287 /$ peerj.preprints.380v2

\section{CITATION}

1

3 authors:

(7) Christophe Hendrickx

University of the Witwatersrand

37 PUBLICATIONS 210 CITATIONS

SEE PROFILE

Octávio Mateus

University NOVA of Lisbon

224 PUBLICATIONS 2,205 CITATIONS

SEE PROFILE
READS

90

Ricardo Araujo

Technical University of Lisbon

89 PUBLICATIONS 324 CITATIONS

SEE PROFILE

Some of the authors of this publication are also working on these related projects:

Nature and Time on Earth - Project for a course and a book for virtual visits to past environments in learning programmes for university students (coordinators Edoardo Martinetto, Emanuel Tschopp, Robert A. Gastaldo) View project

Ten Sleep Wyoming Jurassic dinosaurs View project 


\title{
The nonavian theropod quadrate II: systematic usefulness, major trends and cladistic and phylogenetic morphometrics analyses
}

\author{
Christophe Hendrickx ${ }^{1,2}$ \\ ${ }^{1}$ Universidade Nova de Lisboa, CICEGe, Departamento de Ciências da Terra, Faculdade de \\ Ciências e Tecnologia, Quinta da Torre, 2829-516, Caparica, Portugal. \\ ${ }^{2}$ Museu da Lourinhã, 9 Rua João Luis de Moura, 2530-158, Lourinhã, Portugal. \\ chritophe.hendrickx@ hotmail.com
}

\begin{abstract}
Ricardo Araújo $2,3,4,5$
${ }^{2}$ Museu da Lourinhã, 9 Rua João Luis de Moura, 2530-158, Lourinhã, Portugal.

${ }^{3}$ Huffington Department of Earth Sciences, Southern Methodist University, PO Box 750395, 75275-0395, Dallas, Texas, USA.

${ }^{4}$ Instituto de Plasmas e Fusão Nuclear, Instituto Superior Técnico,Universidade de Lisboa, Portugal.

${ }^{3}$ Museum für Naturkunde, Berlin, Germany. rmaraujo@smu.edu
\end{abstract}

Octávio Mateus ${ }^{1,2}$

${ }^{1}$ Universidade Nova de Lisboa, CICEGe, Departamento de Ciências da Terra, Faculdade de Ciências e Tecnologia, Quinta da Torre, 2829-516, Caparica, Portugal.

${ }^{2}$ Museu da Lourinhã, 9 Rua João Luis de Moura, 2530-158, Lourinhã, Portugal. omateus@fct.unl.pt 


\begin{abstract}
The skull-bone quadrate in nonavian theropods is very diverse morphologically alongside the disparity of the group as a whole. However this disparity has been underestimated for taxonomic purposes. In order to evaluate the phylogenetic potential and investigate the evolutionary transformations of the quadrate, we conducted a CatalanoGoloboff phylogenetic morphometric analysis as well as a cladistic analysis using 98 discrete quadrate related characters. The cladistic analysis provides a fully resolved tree mirroring to some degree the classification of nonavian theropods.

The quadrate morphology by its own provides a wealth of data with strong phylogenetic signal and allows inference of major trends in the evolution of this bone. Important synapomorphies include: for Abelisauroidea, a lateral ramus extending to the ectocondyle; for Tetanurae, the absence of the lateral process; for Spinosauridae, a medial curvature of the ventral part of the pterygoid ramus occurring just above the mandibular articulation; for Avetheropoda, an anterior margin of the pterygoid flange formed by a roughly parabolic margin; and for Tyrannosauroidea, a semi-oval pterygoid flange shape in medial view. The Catalano-Goloboff phylogenetic morphometric analysis reveals two main morphotypes of the mandibular articulation of the quadrate linked to function. The first morphotype, characterized by an anteroposteriorly broad mandibular articulation with two ovoid/subcircular condyles roughly subequal in size, is found in Ceratosauria, Tyrannosauroidea and Oviraptorosauria. This morphotype allows a very weak displacement of the mandible laterally. The second morphotype is characterized by an elongate and anteroposteriorly narrow mandibular articulation and a long and parabolic/sigmoid ectocondyle. Present in Megalosauroidea, Carcharodontosauridae and Dromaeosauridae, this morphotype permits the lower jaw rami to be displaced laterally when the mouth opened.
\end{abstract}




\section{INTRODUCTION}

In theropods and non-mammalian tetrapods in general, the quadrate is a paired bone located in the posterior part of the skull, allowing the lower jaw to articulate with the cranium (Brusatte, 2012). The nonavian theropod quadrate always displays a common anatomical architecture: a ventrodorsally elongated body, an anteriorly-oriented pterygoid flange, a mandibular articulation with two condyles separated by a furrow, a lateral articulation with the quadratojugal, and a dorsal condyle, or quadrate head, articulated with the cotylus of the squamosal. Nevertheless, the quadrate morphology and each quadrate sub-units change conspicuously among different clades of theropods (Maryańska and Osmólska, 1997; Sereno et al., 2008) so that this cranial bone shows great taxonomic potential (Elzanowski et al., 2001; Currie, 2006). Yet, no thorough study has tried to evaluate the phylogenetic value of the quadrate bone in nonavian theropods. Quadrate-related cladistic characters are minimal in most cladistic analyses performed in nonavian theropods, with a maximum of eight characters in (Choiniere et al., 2014) data matrices. Maryańska and Osmólska (1997) and Currie (2006) were the first quadrate-driven articles that investigated the morphological differences among nonavian theropod quadrates; however the later considered only five characters in order to determine theropod relationships. In essence, the paucity of characters that have been used underestimates the morphological diversity among the various clades of nonavian theropods. Here, we conduct a cladistic analysis based on a datamatrix of 98 quadrate-related characters coded for 56 taxa belonging to the majority of clades of nonavian theropods. We also performed a phylogenetic morphometric analysis (Catalano et al., 2010; Goloboff and Catalano, 2011) based on quasi homologous landmark configurations of a sub-sample of 23 taxa out of the 56 taxa above.

\section{Institutional Abbreviations}


AMNH FARB, American Museum of Natural History, collection of fossil reptiles, amphibians and birds, New York, USA; BMNH, The Natural History Museum, London, UK; BYUVP, Brigham Young University Vertebrate Paleontology, Provo, Utah, USA; CMNH, Carnegie Museum, Pittsburgh, Pennsylvania, USA; FMNH, Field Museum of Natural History, Chicago, Illinois, USA; FRDC-GS, Fossil Research and Development Center, Gansu Bureau of Geology and Mineral Resources Exploration, Lanzhou, China; GR, Ghost Ranch Ruth Hall Museum of Paleontology, Ghost Ranch, New Mexico, USA; IGM, Mongolian Institute of Geology, Ulaan Bataar, Mongolia; IPFUB, Institute for Paleontology of the Freie Universität, Berlin, Germany; IVPP, Institute for Vertebrate Paleontology and Paleoanthropology, Beijing, China; LACM, Los Angeles County Museum of Natural History, Los Angeles, California, USA; MACN, Museo Argentino de Ciencias Naturales, Buenos Aires, Argentina; MB, Museum für Naturkunde der Humboldt Universität, Berlin, Germany; MCF PVPH, Museo Municipal Carmen Funes, Paleontologia de Vertebrados, Plaza Huincul, Argentina; MCNA, Museo de Ciencias Naturales y Antropológicas de Mendoza, Mendoza, Argentina; MIWG, Dinosaur Isle, Isle of Wight Museum Services, Sandown, UK; ML, Museu da Lourinhã, Lourinhã, Portugal; MNHN, Muséum national d'Histoire naturelle, Paris, France; MNA, Museum of Northern Arizona, Flagstaff, Arizona, USA; MNN, Musée National du Niger, Niamey, Niger; MSNM, Museo di Storia Naturale di Milano, Milan, Italy; MUCPv, Museo de Ciencias Naturales de la Universidad Nacional de Comahue, Neuquén, Argentina; MWC, Museum of Western Colorado, Fruita, Colorado, USA; NCSM, North Carolina Museum of Natural Sciences, Raleigh, NC, USA; OUMNH, Oxford University Museum, Oxford, UK; PIN, Paleontological Institute of the Russian Academy of Sciences, Moscow, Russia; PULR, Paleontología, Universidad Nacional de La Rioja, La Rioja, Spain.; PST, Paleontological and Stratigraphic Section of the Geological Institute, Mongolian Academy of Sciences, Ulaan Baatar, Mongolia; PVSJ, Instituto y Museo de Ciencias 
Naturales, San Juan, Argentina; SMA, Sauriermuseum Aathal, Aathal, Switzerland; SMNS,

Staatliches Museum für Naturkunde, Stuttgart, Germany; IGM, Paleontology and

Stratigraphy Section of the Geological Institute, Ulan Baatar, Mongolia; RTMP, Royal

Tyrrell Museum of Palaeontology, Drumheller, Alberta, Canada; UCMP, University of

California Museum of Paleontology, Berkeley, California, USA; UC, University of Chicago

Paleontological Collection, Chicago, USA; UMNH, Utah Museum of Natural History, Salt

Lake City, Utah, USA; USNM, United State National Museum Vertebrate Paleontology,

Washington D. C., USA; UUVP, Utah Museum of Natural History, Salt Lake City, Utah,

USA; ZPAL, Instytut Paleobiologii PAN, Warsaw, Poland; WDC, Wyoming Dinosaur

Center, Thermopolis, USA

\section{MATERIAL AND METHODS}

Table 1

\section{Cladistic Analysis}

In order to assess the evolution and taxonomic value of the quadrate bone in nonavian theropods, a datamatrix including quadrate-related characters only was created and scored in 55 nonavian theropod taxa and one outgroup taxa (Table 1, Appendix 1). Quadrates pertaining to most clades of nonavian Theropoda have been examined and coded from 1) first-hand observations (35 taxa equivalent to $62.5 \%$ of the dataset) 2) high-resolution photographs (16 taxa equivalent to $28.5 \%$ ), and 3) by using full descriptions and illustrations of the bone in the literature for 5 taxa (Table 1). Most nonavian theropods with well-preserved and well-visible quadrates were included in the analysis and coded at the species level. Due to the weak variation of quadrate morphology among oviraptorid taxa and the exhaustive description of their anatomy in a single paper (Maryańska and Osmólska, 1997), the clade of Oviraptoridae was coded at the "family" level as operational taxonomic units (OTU). 
Likewise, troodontid quadrates were also coded at the "family" level due to the scarcity of information on their morphology, gleaned from several published and unpublished specimens, and the absence of a single complete and well-illustrated troodontid in the literature.

Compsognathidae were not included in the cladistic analysis due to lack of information of the quadrate morphology and bad preservations of this bone. Indeed, the quadrates of all compsognathids such as Compsognathus corallestris (Ostrom, 1978; Peyer, 2006), Juravenator starki (Chiappe and Göhlich, 2010), Scipionyx samniticus (Dal Sasso and Signore, 1998; Dal Sasso and Maganuco, 2011), Huxiagnathus orientalis (Hwang et al., 2004), Sinocalliopteryx gigas (Ji et al., 2007) and Sinosauropteryx prima (Currie and Chen, 2001) have been flattened by post mortem deformation and are either poorly preserved or obscured by other bones.

The data matrix encompasses 98 equally weighted discrete morphological characters related to the quadrate (Appendices $1 \& 2$ ) and allowing to test and propose several quadrate synapomorphies for the 56 taxa coded (Appendix 3.1; Figure S5). A combination of 18 characters are taken from the literature and 80 characters $(81 \%)$ are new. Among the 54 multistate characters, twelve were treated as ordered (Appendix 1), and most quadrate related characters are illustrated in the appendices (Figures S1-S3). Eoraptor lunensis, considered to be either a basal sauropodomorph (Martinez et al., 2011; Sereno et al., 2013) or a basal theropod (e.g., Nesbitt et al., 2009; Nesbitt, 2011; Sues et al., 2011) in the most recent cladistic studies, was treated as the outgroup. In order to constrain all major theropod clades and visualize the quadrate-based synapomorphies for each clades, a second analysis was performed on a supermatrix combining our quadrate-based data matrix to six recent datasets on non-avian theropods based on the whole skeleton (Choiniere, Xu, et al., 2010; Brusatte, Norell, et al., 2010; Martinez et al., 2011; Carrano et al., 2012; Pol and Rauhut, 2012), and from which all quadrate-related characters were removed. The resulting supermatrix includes 
1889 characters and only twelve quadrate related characters were treated as ordered (Appendix 3.2).

TNT v1.1 (Goloboff et al., 2008) was employed to search for most-parsimonious trees (MPTs). The matrix and supermatrix were analyzed under the 'New Technology Search' with the 'driven search' option (TreeDrift, Tree Fusing, Ratchet, and Sectorial Searches selected with default parameters), and stabilizing the consensus twice with a factor of 75 . The consistency and retention indices as well as the Bremer supports (Bremer, 1994) were calculated using the "stats" and "aquickie" commands, respectively, and a bootstrap analysis was performed with the standard options.

The dataset was also analyzed with WinClada 1.00.08 (Nixon, 2002) after making characters non-additive (fitch) and trees were searched for using the Ratchet (Island Hopper) option with default settings.

\section{Phylogenetic Morphometrics Analysis}

The phylogenetic morphometrics (hereinafter phylo-morpho) analysis approach is based on Catalano et al. (2010) and Goloboff and Catalano (2011) method. This method extends the parsimony criteria for characters like landmark data that change in more than one dimension. The method calculates the score of landmark configurations on a tree as the sum of the difference (weighted or not) in landmark position of each of its landmarks along all the branches of the tree. A different landmark configuration (i.e., set of quasi-homologous points that describes the structure under analysis) is therefore regarded as a different character. For example, the same set of landmarks of the anterior view of the quadrate is considered a character. Several configurations can be included in a single phylogenetic analysis and landmark data can also be analyzed in combination with alternative sources of evidence like traditional morphological characters or molecules. In that case the tree score is the sum of the 
scores for each landmark configuration plus the score for each traditional character. We ran two different sets of analyses: 1) each individual phylo-morpho character alone; and 2) a combination of all phylo-morpho characters (Appendices 6-7). This array of analysis allowed us to understand the influence of the phylo-morpho characters on resolving the phylogeny of nonavian theropod quadrates and, to provide a substantial basis for discretization of morphotypes that can be observed with the naked eye, but are hard to define verbally (e.g., outline of the posterior view of the nonavian theropod quadrate).

The phylo-morpho analysis comprised a sample of 23 taxa out of the 56 used in the traditional cladistic analysis (Table 1; Appendix 6). The selection of a smaller sample of nonavian theropod quadrates was based on the following criteria, the quadrate 1) had to be complete, 2) could not be post-mortem deformed, 3) had to be isolated from the cranium, and 4) all views had to be well-preserved. Two quadrate morphotypes were included for Allosaurus (A. fragilis and A. 'jimmadseni') and Ceratosaurus (C. 'magnicornis' and $C$. 'dentisulcatus' sensu Madsen and Welles, 2000). In our analysis we used three different phylo-morpho characters of the quadrate: outline of the medial view (character $1 ; 8$ landmarks), outline of the ventral view (character 2; 8 landmarks) and outline of the posterior view (character 3; 12 landmarks). The rationale for the position of the landmarks is summarized in Appendix 5 Figure S6 and detailed below. The outline of the anterior and dorsal views was not used. Not only some of the landmarks visible anteriorly are also visible posteriorly (i.e., it would imply overweighting certain landmarks) but also, in the dorsal view, because it was hard to find homologous landmarks through taxa due to the lack of reference points of the quadrate head in nonavian theropods. Pictures from different taxa were sorted and compiled for each character individually using tpsUtil (Tps geometric morphometrics software is available for free download at http://life.bio.sunysb.edu/morph/soft-utility.html). The digitization of the landmarks on the pictures was done with tpsDig2. The resulting file 
was taken to tpsRelw were only the alignment was saved by using "Save aligned specimens" option. The resulting *.tps file had to be parsed in order to run in TNT v1.1 (Goloboff et al., 2008). A pre-requisite for the analysis of landmark data is the superimposition of the configurations (= alignment). This is accomplished by superimposition methods, i.e., rotation, translation and sizing. Because different alignments can produce different phylogenetic results, we generated two different dataset, the first aligned using RFTRA (Rho-Theta Resistant-fit Analysis, see Siegel and Benson, 1982; Rohlf and Slice, 1990) and the second performing an ordinary superimposition by minimizing the sum of linear distances of each configuration against a reference configuration (Catalano and Goloboff, 2012).

In order to reconstruct a phylogeny departing from landmark data alone, we used the landsch.run TNT script. To run the combined search we used the TNT script landcombsch.run. The latter allows running a combined analysis of traditional and phylomorpho characters in an analogous way as two (or more) different gene sequences can be analyzed together where each one contributes to the resolution of a phylogeny. Both scripts are available at http://tnt.insectmuseum.org/index.php/Scripts. The phylogenetic searches were re-run considering four different levels of search thoroughness (the scripts pre-defined levels $0,1,2$ and 3). The parameters that define a "level of thoroughness" are: number of replicates, termpoints (i.e., inclusion of the geometric medians as a possible point for an ancestral landmark position), number of cell in the grid (i.e., the higher number of cells the more points available for reconstruction of the ancestral positions), nesting level (i.e., a grid can be nested within another grid in order to allow a more precise, and computationallyefficient, reconstruction of the landmark ancestral positions), and neighbors level (i.e., number of neighboring cells included in the nesting level). The score of each configuration were rescale in all the analysis is such a way that the contribution of one landmark configuration character is similar to a traditional character (TNT default option). For analysis 
3 the driven search option of TNT was used considering Sectorial search, tree drifting, tree fusing, and ratchet algorithms, and finishing the search upon consensus stabilization. The exact same characters used in analysis 4 were used in analysis 3 . For the analysis of the traditional characters TBR (tree bisection and reconnection) and 116 non-additive characters were employed. The resulting tree score is the sum of the tree length and the scaled weighted score for the phylo-morpho characters (see Goloboff and Catalano, 2011, p. 47). On this analysis, both ordinary superimposition minimization and RFTRA datasets, the tree scores converge to an asymptote at the level 2 of thoroughness. This implies that the optimality of the trees can be correctly established with a thoroughness level 2 . Thus, we selected the tree that would mirror more accurately present day knowledge on nonavian theropod phylogeny. A more accurate tree is the one that recovers a higher number of known clades in the analysis. In our analysis that was the case for level 2, re-aligned using RFTRA. The criterion used for picking between different trees was based on the tree score; the lowest the tree scores the more parsimonious the tree topology (see Catalano et al., 2010 for an explanation of the tree score calculation).

Landmark configurations. The landmark configuration schemes chosen (Appendix 5, Figure S6) attempt to capture as much information possible that can depict accurately the evolutionary processes on the nonavian theropod quadrate (Zelditch et al., 2009). The landmarks chosen were selected manually and are all of Bookstein's type 2 , i.e., tip of a bony process or local curvature minima or maxima (Bookstein, 1997).

Medial view (Character 1; Figure S6.1). Landmark 1 is the apex of the curvature of the mandibular articulation. Landmark 2 is the apex of the curvature of the dorsal quadrate head. Landmark 3 is the mid-distance between the apices of the dorsal quadrate head and the mandibular articulation. Landmark 4 is the dorsal intersection between the quadrate ridge and 
the pterygoid flange. Landmark 5 is the dorsal kink of the pterygoid flange. Landmark 6 is the ventral kink of the pterygoid flange. Landmark 7 is the apex of the curvature of the ventral portion of the pterygoid flange. Landmark 8 is the ventral intersection of the quadrate ridge and the pterygoid flange.

Ventral view (Character 2; Figure S6.2). Landmark 1 is the anterior point on the semimajor axis of the ellipse formed by the entocondyle. Landmark 2 is the posterior point on the semi-major axis of the ellipse formed by the entocondyle. Landmark 3 is the medial point on the semi-minor axis of the ellipse formed by the entocondyle. Landmark 4 is the lateral point on the semi-minor axis of the ellipse formed by the entocondyle. Landmark 5 is the medial point on the semi-major axis of the ellipse formed by the ectocondyle. Landmark 6 is the lateral point on the semi-major axis of the ellipse formed by the ectocondyle. Landmark 7 is the anterior point on the semi-minor axis of the ellipse formed by the ectocondyle. Landmark 8 is the posterior point on the semi-minor axis of the ellipse formed by the ectocondyle.

Posterior view (Character 3; Figure S6.3). Landmark 1 is the ectocondyle curvature apex and landmark 2 is the curvature apex of the entocondyle, while landmark 3 is the dorsal quadrate head curvature apex. Landmark 4 is on the lateral margin of the photographic plane at the level of the mid-height of the quadrate, and the landmark 5 is on the medial margin. Landmark 6 is the dorsalmost point of the ventral quadratojugal contact. Landmark 7 is the ventralmost point of the ventral quadratojugal contact. Landmark 8 is the apex of the concavity formed by the quadrate foramen. Landmark 9 is the dorsalmost point of the quadrate foramen. Landmark 10 is the ventralmost point of the quadrate foramen. Landmark 11 is located on the lateral-most point of the posterodorsal margin of the ectocondyle. Landmark 12 is located on the medial-most point of the posterodorsal margin of the entocondyle. 


\section{RESULTS}

Figure 1 and 2

\section{Cladistic Analysis}

The cladistic analysis of the data matrix of quadrate-based characters and including 56 theropod taxa yielded 40 most parsimonious trees (MPTs), in which the strict consensus trees (Length $=592$ steps $; \mathrm{CI}=0.271, \mathrm{RI}=0.536)$ resulted in a few polytomies affecting clades of no more than three taxa (see Appendix 4 Figure S4). Although the consensus tree poorly mirrors the current classification of nonavian theropods, many theropod clades such as Noasauridae, Megalosauridae, Spinosauridae, Allosauridae, Carcharodontosauridae, Tyrannosauridae, Ornithomimosauria, Therizinosauroidea, Oviraptorosauria and Dromaeosauridae were found resolved. As it was noted for teeth (Hwang, 2007; Hendrickx and Mateus, 2014), quadrate-related characters are good at recovering individual clades, but not at resolving the relationship between those clades. Nevertheless, the deletion of Eoraptor, Abelisaurus and Irritator, from which few information on the quadrate can be extracted (55\%, $46 \%$ and $64 \%$ of missing data, respectively), gave a different tree topology. The cladistic analysis performed on the datamatrix of 53 taxa yielded, this time, 19 MPTs in which the consensus tree $($ Length $=580$ steps $; \mathrm{CI}=0.285, \mathrm{RI}=0.554 ;$ Figure 1$)$ recovered to a much better degree the general topology of theropod classification with the usual major clades (e.g., Neotheropoda, Averostra, Ceratosauria, Tetanurae, Megalosauroidea). Indeed, when rooting Herrerasaurus as the outgroup, Eodromaeus, Tawa, Dilophosaurus and the clade of coelophysoids (Liliensternus + Syntarsus) were correctly retrieved as the most-basal theropods, Neotheropoda and Averostra were found monophyletic and the latter includes both Ceratosauria and Tetanurae. Likewise, Megalosauroidea was retrieved as a clade closely related to the basal tetanuran Monolophosaurus (Carrano et al., 2012) and correctly includes Megalosauridae and Spinosauridae. 
Nevertheless, the Tetanurae clade does not correspond to the general idea of the classification of these derived averostrans (Figure 1) as the common clades of Allosauroidea, Avetheropoda, Coelurosauria and Maniraptora were not resolved. For instance, noncarcharodontosaurids allosauroids were found closely related to Therizinosauria, Carcharodontosauridae forms the sister clade of Ornithomimosauria + Dromaeosauridae, and non-tyrannosaurid Tyrannosauroidea, Oviraptorosauria and Troodontidae are gathered in a same clade. In fact, the classification of basal theropods (i.e., non-tetanuran Theropoda) is much better resolved than this of Tetanurae. This can be explained by the large sample of non-coelurosaur theropods in the dataset ( $60 \%$ of the datamatrix), whereas coelurosaurs are under-represented (21 taxa representing 36.5\%) and includes one or two taxa of several coelurosaur clades such as Ornithomimosauria, Alvarezsauroidea and Therizinosauria. Furthermore, the clades of Oviraptoridae and Troodontidae have both been coded as a single OTU and no compsognathid taxa were incorporated in the datamatrix. It is therefore likely that the inclusion of more coelurosaur taxa into the datamatrix of quadrate-based characters in the future will allow mirroring to a better degree the current classification of Tetanurae and Coelurosauria. Interestingly, the quadrate of megalosauroids and allosauroids are relatively similar as members of those two clades were found closely related, giving some support to a monophyletic Carnosauria (Megalosauroidea + Allosauroidea) as it was previously suggested (Kurzanov 1989; Currie 1995; Rauhut 2003).

With a high decay index, Spinosauridae (Bremer support of 5), Allosauridae (Bremer support of 4), Tyrannosauridae (Bremer support of 4) and Ornithomimosauria (Bremer support of 4) are the best supported clades and all possess a highly diagnostic quadrate. The quadrate of non-carcharodontosaurid Allosauroidea (here gathered in a monophyletic group), Therizinosauria and Dromaeosauridae, all with a Bremer support of 3, is also easily recognizable in these theropods. In fact, the cladistic analysis performed on the supermatrix of 
56 taxa, and yielding 34 MPTs (Length $=3616$ steps; $\mathrm{CI}=0.562 ; \mathrm{RI}=0.631$; Figure 2 ), has shown that many theropod clades can be defined by using a combination of ambiguous and unambiguous quadrate-based synapomorphies (Figure 2, Appendix 4 Figures S5A-B). Among the best resolved clades, Spinosauridae are supported by 10 synapomorphies (with five unambiguous), and eight synapomorphies define the clades of Ceratosauria and Carcharodontosauridae. Clades of more than three quadrate synapomorphies include Abelisauroidea (4), Averostra (5), Megalosauridae (5), Avetheropoda (5), Allosauroidea (6), Allosauridae (4), Tyrannosauridae (5) and Ornithomimosauria (6). Coelophysoidea, Abelisauridae and Dromaeosauridae are the only clade of theropods that are not define by a single quadrate synapomorphy.

\section{Figure 3}

\section{Phylogenetic Morphometrics Analysis}

The two most interesting results concerning the phylogenetic morphometric analysis performed character by character is the dichotomy retrieved when character 2 and 3 are run independently (Figure 3; Appendix 6). For the posterior view (character 3; Figure 3.1), this consists essentially on a 'coelurosaurian' (Morphotype A) versus a 'ceratosaurian’ type (Morphotype B). The distinction of these two morphotypes lies essentially on the clear differences of the morphology of the quadrate foramen (landmarks 6-10) and the robustness of the quadrate body (landmarks 1,2 and 3). In morphotype A, the quadrate is low and stout comparatively to the tall and slender bone in morphotype B. Also the quadrate foramen of morphotype A is well-delimited and relatively broad lateromedially, but it is shallow, lateromedially narrow or completely absent in morphotype B. The latter morphotype can be found in ceratosaurian taxa, as well as in megalosaurids and carcharodontosaurids theropods (Appendix 7, Figure S8). On the other hand, morphotype A is present in all coelurosaurians 
and Dilophosaurus, non-carcharodontosaurid allosauroids and Spinosauridae. The basal placement of Sinraptor and Acrocanthosaurus in each 'morphoclade' reveals the clear transition from one morphotype to the other during the evolution of Allosauroidea.

For the ventral view (character 2; Figure 3.2), the dichotomy divides a ceratosaurian versus a megalosauroid type, although this result is more blurred due to the recovery of Afrovenator among the ceratosaurian-dominated clade.

\section{ANATOMY OF THE NONAVIAN THEROPOD QUADRATE}

Figure 4

\section{Non-neotheropod Theropoda}

Eoraptor lunensis (PVSJ 512; Sereno et al., 2013; Figure 4.5), Herrerasaurus ischigualastensis (PVSJ 53 = Frenguellisaurus ischigualastensis; PVSJ 407; Figure 4.2-4.4), Eodromaeus murphi (PVSJ 562; Figure 4.5-4.10); Daemonosaurus chauliodus (Sues et al., 2011); Tawa hallae (Nesbitt et al., 2009; Figure 4.11-4.16).

Although recent discoveries of new basal theropods have increased dramatically in the last five years, information regarding the quadrate anatomy can be improved. The quadrates of many basalmost theropods are still articulated in the cranium and therefore not visible in anterior, ventral and dorsal views. This is the case for Eoraptor lunensis which most of the right quadrate is covered by matrix, and Herrerasaurus ischigualastensis (PVSJ 407) in which the mandibular condyles are still in articulation with the lower jaw (Sereno and Novas, 1994). Likewise, the right quadrate bone of Daemonosaurus chauliodus is not only badly preserved, but also shows the lateral part of the bone only. Fortunately, the left quadrate of Eodromaeus murphi and both left and right quadrates of Frenguellisaurus ischigualastensis (PVSJ 53), now considered to be a junior synonym of Herrerasaurus ischigualastensis (Novas, 1994), and Tawa hallae, the most derived form of non-neotheropod Theropoda 
(sensu Nesbitt et al., 2009), are relatively well preserved and allow a better understanding of the quadrate anatomy in non-neotheropod Theropoda.

The quadrate of these basalmost theropods is tall (strongly elongated ventrodorsally relative to the lateromedial width of the mandibular articulation; ratio corresponding to the lateromedial width of mandibular articulation divided by the ventrodorsal length from entocondyle to quadrate head of less than 0.35 ), lateromedially narrow, and possesses a small quadrate foramen (Figure 4.1, 4.5) at the lower one-third of the quadrate body in E. lunensis and $H$. ischigualastensis (presence of a quadrate foramen in E. murphi, D. chauliodus and $T$. hallae remains unknown). The quadrate foramen of these two taxa is mostly delimited by the quadrate and only the lateral border is formed by the quadratojugal. In $H$. ischigualastensis, the quadrate foramen is adjacent to the quadrate ridge (PVSJ 53, 407; Figure 4.1), whereas the foramen is well-separated from the ridge in E. lunensis (contra Martinez and Alcober, 2009; Figure 4.5) as in the basal sauropodomorph Panphagia protos (PVSJ 874, (Martinez and Alcober, 2009).

The quadrate ridge in $H$. ischigualastensis and E. murphi is prominent, rod-shaped, strongly inclined laterally and get flared above the entocondyle, at one third of the quadrate body (Figure 4.1, 4.8). In E. lunensis, the quadrate ridge is only visible on the dorsal part of the quadrate body, just below the quadrate head. Like in H. ischigualastensis and E. murphi, the ridge reaches the quadrate head but, similar to $T$. hallae, it is straight and not inclined laterally. In lateral view, the posterior margin of the quadrate ridge is concave in E. lunensis (Sereno et al., 2013), E. murphi and T. hallae, but straight in H. ischigualastensis.

In E. murphi and T. hallae, the ventral quadratojugal contact is ovoid to D-shaped, with an irregular articulating surface. It faces postero-laterally in E. murphi (Figure 4.8), and laterally in T. hallae. The ventral quadratojugal contact is wider than the dorsal one in all nonneotheropod theropods, as the dorsal quadratojugal contact corresponds to a thin line on the 
lateral surface of the lateral process in E. lunensis and $H$. ischigualastensis. The ventral quadratojugal contact projects slightly anteriorly in T. hallae (Figure 4.16), unlike $H$. ischigualastensis and E. murphi in which the quadratojugal process is absent (Figure 4.4, 4.10).

Like non-tetanuran theropods, the quadrate of $H$. ischigualastensis possesses a subtriangular lateral process projecting anterolaterally that joins the quadrate body at the foramen level ventrally and the quadrate head dorsally. A lateral process reaching the quadrate head is also present in E. lunensis (Sereno et al., 2013), but its lateral margin is rather parabolic, and the process is relatively short and only projects laterally (Figure 4.5) when compared to $H$. ischigualastensis. A parabolic lateral process also exists in $D$. chauliodus but its dorsal extent terminates well-ventral from the quadrate head. The lateral process of all non-neotheropod theropods contacts the quadratojugal and the squamosal along its lateroventral and laterodorsal rims, respectively. The presence of a lateral process in $E$. murphy and T. hallae cannot be determined as this part of the quadrate body is missing.

The pterygoid flange of basalmost theropods is subtrapezoidal in outline (i.e., the anterior margin of the flange is roughly formed by three sides where the most anterior one is straight and short ventrodorsally), and the most anterior point of the flange appears at midheight of the quadrate. The pterygoid flange meets the quadrate body far above the mandibular condyles in H. ischigualastensis, E. murphi and D. chauliodus, a condition shared by most other non-tetanuran theropods (pers. obs.). The angle formed by the ventral margin of the pterygoid flange and the main axis of the quadrate ridge varies between $60^{\circ}$ and $70^{\circ}$. The flange only projects anteriorly and its anterior part does not curve medially. Nevertheless, there is a weak medial curvature of the ventral margin of the flange ('horizontal shelf' sensu Sereno et al., 2013), and a shallow medial fossa exists in the posteroventral part of the pterygoid flange. 
In D. chauliodus, the quadrate head is an extension of a cylindrical projection of the quadrate shaft. It is single headed, small (Sues et al., 2011) and the posterior margin is convex. The pterygoid flange reaches the quadrate body just below the anteroventral limit of the quadrate head. The same condition occurs in E. murphy where the quadrate head is globular in lateral view, and roughly subtriangular in shape with rounded corner in dorsal view (Figure 4.9). The quadrate head and the dorsalmost part of the quadrate body seem to be slightly posterodorsaly-oriented in E. lunensis but sub-horizontal in $H$. ischigualastensis, $D$. chauliodus and E. murphy (contra Martinez et al., 2011, figure 1B). In H. ischigualastensis, the quadrate head is convex, subtriangular in outline in posterior view and exposed in lateral view, and a flattened medial surface below the quadrate head contacts the paroccipital process (Sereno and Novas, 1994).

Although little information is known about the morphology of the mandibular articulation in the holotypes of E. lunensis and H. ischigualastensis, this part of the quadrate is however well-preserved in a specimen referred to H. ischigualastensis (PVSJ 53; Figure 4.5), and almost complete in E. murphi and T. hallae in which the anterior part of the ectocondyle and entocondyle, respectively, is missing. Both ecto- and entocondyle are subequal in size in H. ischigualastensis but the ectocondyle is longer in E. murphi and $T$. hallae. The ectocondyle is elliptical of H. ischigualastensis and E. murphi whereas it is slightly sigmoid in T. hallae. The entocondyle is elliptical, strongly elongated and does not protrude anteriorly in both H. ischigualastensis (Figure 4.4) and E. murphi (Figure 4.10). The mandibular condyles are separated by a shallow and diagonally-oriented intercondylar sulcus in these two taxa, whereas the sulcus is deep and well-delimited in T. hallae (Figure 4.16). Likewise, the angle between the main axes passing through the intercondylar sulcus and mandibular articulation is lower than $135^{\circ}$ in $H$. ischigualastensis and E. murphi but much higher than this value in T. hallae. 
Although the quadrate height of all basal theropods is subequal or below $80 \%$ of the orbit height within the cranium, the quadrate inclination may have been variable among primitive theropods. Indeed, the mandibular articulation lies anterior to the quadrate head in E. lunensis (Sereno et al., 1993, 2013), at the same level in D. chauliodus (Sues et al., 2011), and posterior to the quadrate head in H. ischigualastensis (Sereno and Novas, 1994).

\section{Figure 5}

\section{Coelophysoidea}

Liliensternus liliensterni (von Huene, 1934; Figure 5.1-5.6); 'Syntarsus' kayentakatae (Rowe, 1989; Figure 5.7-5.9); 'Syntarsus' rhodesiensis (Raath, 1977); Coelophysis bauri (CM 81765; AMNH FARB 7223, 7224,7225, 7227, 7237, 7238); Zupaysaurus rougieri (PULR 076).

As in basal Theropoda, few information of the quadrate anatomy of coelophysoid theropods can be extracted from the literature, as the cranial material of most coelophysoid taxa are still in articulation with the skull, and cannot be observed in all views. This is the case of both quadrates of 'Syntarsus' kayentakatae, Zupaysaurus rougieri (in which the quadrates are mostly covered by the matrix; Arcucci and Coria, 2003; Ezcurra, 2007) and all specimens of Coelophysis bauri examined in this study (CM 81765; AMNH FARB 7223, $7224,7225,7227,7237,7238)$. However, the right quadrate of ' $S$.' kayentakatae is particularly well-visible (Tykoski, 2005) in posterior view (Figure 5.7-5.8), although the pterygoid flange is hidden by matrix and the mandibular articulation is still articulated to the lower jaw. An incomplete non-articulated right quadrate of Liliensternus liliensterni (Figure 5.1-5.6) also gives us the opportunity to have a better understanding of the quadrate anatomy of coelophysoids. 
As seen in the earliest forms of theropods, the quadrate of coelophysoids is elongated and relatively narrow lateromedially, and the posterior margin of the quadrate body is lateromedially concave. A quadrate foramen seems to be present and situated at mid-height of the bone in all coelophysoids. The size and limits of this foramen are however highly variable in this clade, being relatively large, oval and inside the quadrate body in Z. rougieri (Arcucci and Coria, 2003; Ezcurra, 2007), small, deeply recessed and equally surrounded by the quadrate and quadratojugal in 'S.' rhodesiensis (Raath, 1977, figure 3D, 4J; Yates, 2005; Tykoski, 2005) and minute and largely encircled by the quadrate in 'S.' kayentakatae (Tykoski, 2005; Figure 5.7). A quadrate foramen has also been reported in Liliensternus liliensterni (von Huene, 1934), but not in C. bauri (Colbert, 1989); however, according to Tykoski (2005), poor preservation renders its absence uncertain in Coelophysis, an opinion that we also follow for L. liliensterni as some part of the quadrate body are missing in this specimen (Figure 5.3).

The quadrate ridge is subvertical, prominent and particularly narrow, forming a shallow crest in 'S.' kayentakatae (Figure 5.7). In L. liliensterni, the quadrate ridge is rodshaped and strongly laterally inclined (Figure 5.3). Nevertheless, the ridge extends from slightly above the entocondyle in both taxa, and reaches the quadrate head in ' $S$.' kayentakatae. As some basal forms like $H$. ischigualastensis, the quadrate of coelophysoids possesses a subtriangular lateral process (Colbert, 1989) extending anterolaterally from above the quadrate foramen. This process is well-visible in 'S.' kayentakatae, 'S.' rhodesiensis (Raath, 1977, figure 4j), Z. rougieri and L. liliensterni (Figure 5.2) and contacts the quadrate body just beneath the quadrate head at least in ' $S$.' kayentakatae.

Although the dorsal and ventral quadratojugal contacts are not visible or not preserved in most coelophysoids, the ventral quadratojugal contact of L. liliensterni is wide, and much 
larger than the dorsal quadratojugal contact as the latter corresponds to an elongated line on the edge of lateral process (Figure 5.2).

A posterior fossa is well-visible in ' $S$.' kayentakatae (Figure 5.7-5.8) and $L$.

liliensterni. This fossa is relatively small, oval and centered on the quadrate body in both taxa. It does not surround the quadrate foramen at least in 'S.' kayentakatae but may have bordered the quadrate foramen in L. liliensterni.

The mandibular articulation is ventrally visible in ' $S$.' kayentakatae and shows a diagonal intercondylar sulcus separating a lateromedially elongated ectocondyle and a smaller entocondyle. The ectocondyle of ' $S$.' kayentakatae seems to project well-beneath the quadratojugal, a feature only observed in this taxon so far. In L. liliensterni, the entocondyle is ovoid to elliptical in outline and does not protrude anteriorly (Figure 5.6).

The quadrate inclination is quite variable in coelophysoids, as the quadrate is strongly inclined anteriorly in 'S.' kayentakatae (Figure 5.9), subvertical in C. bauri (pers. obs.) and posteriorly inclined in Z. rougieri (Ezcurra, 2007); pers. obs.).

\section{Dilophosauridae}

Dilophosaurus wetherilli (Welles, 1984; Figure 5.10-5.15).

The name of Dilophosauridae was used by Charig and Milner (1990) to contain only the genus type Dilophosaurus. It will also be used here to include this taxon as the morphology of its quadrate differs significantly from this of other coelophysoids and ceratosaurians. Two disarticulated quadrates are available in Dilophosaurus wetherilli and Welles (1984) provided a relatively detailed description of them. However, they are here figured for the first time (Figure 5.10-5.15) and comparison with the quadrate of other theropods is here given. 
Unlike other very basal theropods and coelophysoids, the quadrates of $D$. wetherilli are moderately tall and less ventrodorsally elongated relative to the mandibular articulation (ratio of 0.39). In addition, the quadrate ridge is extremely prominent, rod-shaped, strongly laterally-inclined, and slightly twisted so that both ventromedial and dorsolateral margins of the ridge are convex (Figure 5.12). Nevertheless, the ridge is prominent above the entocondyle and terminates beneath the quadrate head without reaching it. However, the quadrate ridge of $D$. wetherilli is convex in medial view (Figure 5.13), a condition also shared with the megalosaurid Dubreuillosaurus valesdunensis (Allain, 2002).

The pterygoid flange of $D$. wetherilli is straight (not medially bent in its anterior part), subtrapezoidal with the anteriormost margin inclined posteriorly, and does not seem to possess a ventral shelf extending all along the ventral margin of the flange as other taxa such as Ceratosaurus (Figure 6.4) and Allosaurus (SMA 005/02; Figure 10.4). The flange also reaches the quadrate head at its anteroventral margin dorsally, and the quadrate body well above the mandibular condyles ventrally (Figure 5.13). The most anterior point of the pterygoid flange in $D$. wetherilli is situated at two-thirds of the bone and the ventroposterior margin is slightly medially folded (pers. obs.).

Like more basal theropods, $D$. wetherilli possesses a subtriangular lateral process and reaches the quadrate body beneath the quadrate head (Figure 5.11). This lateral process is strongly anteriorly oriented and particularly well-developed in this taxon.

Unlike ceratosaurs and megalosaurids, a quadrate foramen is present in $D$. wetherilli and its shape and position are autapomorphic to this taxon (Figure 5.12). The main axis of the foramen, rather than being subparallel to the long axis of the quadrate, is sub-perpendicular to the quadrate axis and the foramen has an atypical 'keyhole' shape, an autapomorphic character of $D$. wetherilli. The foramen is mostly delimited by the quadrate and surrounded by a deep posterior fossa (Figure 5.12). This fossa is atypical in D. wetherilli as it is 
subtriangular in shape and deep inside the ventral part of the lateral process, delimited by the prominent quadrate ridge medially and by an important bending of the lateral process laterally (Figure 5.12).

Like most basal theropods, the ventral quadratojugal contact is ovoid, almost D-shaped, and much thicker than the dorsal quadratojugal suture which, once again, corresponds to the narrow edge of the lateral process (Figure 5.11). The anterior margin of the ventral contact slightly projects anteriorly.

The mandibular articulation is well-preserved in the left quadrate of $D$. wetherilli. It clearly shows a relatively narrow and sigmoid ectocondyle delimited from a thicker, rather elliptical, and non-protuberant entocondyle by a large and shallow intercondylar sulcus (Figure 5.15). Like megalosauroids, the ectocondyle is much longer than the entocondyle and the angle made by the intercondylar sulcus with the long axis passing through the mandibular articulation is around $130^{\circ}$. These conditions are not shared by any ceratosaurs.

An unnamed clade encompassing D. wetherilli, Dracovenator regenti and Z. rougieri was retrieved in Yates (2005) and later by Smith et al. (2007) which also includes Sinosaurus triassicus (Hu, 1993; Xing, 2012; Xing et al., 2013) and Cryolophosaurus ellioti (Hammer and Hickerson, 1994) but without Z. rougieri. The quadrates of the two latter are indeed quite similar to those of $D$. wetherilli in many aspects such as the shape and inclination of the quadrate ridge and the size and position of the quadrate foramen. However, C. ellioti does not seem to have a lateral process and both $C$. ellioti and Z. rougieri possess a ventrodorsally elongated quadrate foramen and no subtriangular posterior fossa surrounding it. While there is no doubt that $Z$. rougieri is a coelophysoid, $C$. ellioti has also been considered to be a basal tetanuran (Sereno et al., 1994, 1996; Carrano et al., 2012). 


\section{Figure 6}

\section{Ceratosauridae}

Ceratosaurus nasicornis (USNM 4735; MWC 1; Madsen and Welles, 2000; Figure $6.1-6.5)$

Both quadrates of the holotype of Ceratosaurus nasicornis USNM 4735 are in articulation within the cranium and strongly distorted (Gilmore, 1920), yet the disarticulated quadrates of MWC 1 (formerly known as Ceratosaurus 'magnicornis') and UUVP 1646 (formerly known as Ceratosaurus 'dentisulcatus') are relatively complete and slightly deformed (Madsen and Welles, 2000), allowing to propose a full picture of their anatomy. The quadrates of MWC 1 and UUVP 1646 have been briefly described by Madsen and Welles (2000) and a full description of their anatomy is here given for the first time.

As in more basal theropods, the quadrate bone of Ceratosaurus is strongly ventromedially elongated, the mandibular articulation is lateromedially short (Figure 6.3), and the pterygoid flange is straight, subtrapezoidal and reaches the quadrate body well above the mandibular condyles ventrally (Figure 6.4). In addition, the quadrate also possesses a subtriangular lateral process attached to the quadrate body roughly at mid-height of the bone ventrally and far beneath the quadrate head dorsally (Figure 6.3). The latter is prominent, narrow and subtriangular in outline in dorsal view. The quadrate is fused to the quadratojugal (Figure 6.1, 6.3), a condition seen in some derived abelisaurids such as Carnotaurus (Figure 7.14).

The dorsal part of the quadratojugal contact is larger than the ventral one. As in $D$. wetherilli, the ventral margin of the pterygoid flange curves medially and there is a ventral shelf. The most anterior point of the pterygoid flange is situated at two thirds of the quadrate height (Figure 6.4). 
The quadrates of the different species of Ceratosaurus share also together a combination of characters only observed in this genus: the absence of a quadrate foramen, making the quadratojugal contact of the quadrate continuous; a relatively thick, subvertical, and not-well delimited quadrate ridge, becoming visible at one-third of the quadrate, wellabove the entocondyle, but reaching the quadrate head; a deep mesial fossa and a large posterior fossa formed by both quadrate and quadratojugal and centered on the suture of these two bones; a lateral process laterally oriented; and both ecto- and entocondyle are parabolic, subparallel and similar in size in ventral and posterior views. The two mandibular condyles are also separated by a shallow intercondylar sulcus as large as the condyles (Figure 6.5). The ventral quadratojugal contact is lanceolate, and does not possess any anterior projection, whereas the dorsal contact is filiform and follows the edge of the lateral process.

\section{Noasauridae}

Masiakasaurus knopfleri (FMNH PR 2496; Figure 6.6-6.11); Noasaurus leali (PVL 4061; Figure 6.12-6.17).

In noasaurids, only the right quadrates are known in Noasaurus leali and Masiakasaurus knopfleri. The quadrate of the latter is incomplete (ventral part of the lateral and medial rami preserved) and has recently been extensively described by Carrano et al. (2011). The quadrate of $N$. leali has been only figured in medial view and very briefly described by Bonaparte and Powell (1980, figure 7C).

M. knopfleri and N. leali quadrate morphology are similar in many aspects and clearly reflects their ceratosaurian affinity. They are indeed quite similar to the quadrate of Ceratosaurus and only differ from those of Abelisauridae on its derived features. As in Ceratosaurus, the quadrate of M. knopfleri and N. leali possesses a sub-vertical and poorly delimited ridge emerging from above the entocondyle and terminating at the quadrate head 
(Figure 6.8, 6.14). Although incomplete, the lateral process of both noasaurids is also present, mostly laterally-oriented and the dorsal margin of the process reaches the quadrate body wellbelow the quadrate head. As in Abelisauridae, the ventral margin of the process joins the quadrate body at the level of the mandibular articulation (Figure 6.8 and 6.14).

The pterygoid flange is straight and the posteroventral margin is medially folded in $M$. knopfleri (Figure 6.11). A ventral shelf is absent in N. leali and its presence cannot be determined in $M$. knopfleri. The dorsal margin of the flange reaches the quadrate head, and the ventral margin attaches the quadrate body well-above the mandibular articulation in noasaurids (Figure 6.7 and 6.13). Although figured as a subtriangular flange by Bonaparte and Powell (1980, figure 7C), the pterygoid flange of $N$. leali is clearly subtrapezoidal, with a very short anterior margin (Figure 6.15). The medial fossa of the pterygoid flange is very shallow in both noasaurids, and, due to preservation, the existence of a posterior fossa cannot be determined.

Following (Carrano et al., 2011) observation, the presence of the quadrate foramen in M. knofleri cannot be ruled out due to poor preservation of the lateral margin of the quadrate body. Likewise, the presence of a quadrate foramen in N. leali cannot be determined as the lateral margin of the bone is badly preserved, and both ventral and dorsal parts are missing (pers. obs.). Bonaparte and Powell (1980) noted the presence of the quadrate foramen in this taxon and Carrano and Sampson (2008) coded it as absent in their datamatrix, therefore our interpretation contradicts these observations.

The ventral part of the quadratojugal contact of $M$. knopfleri and $N$. leali is similar in shape, and forms a ventrodorsally elongated lanceolate shape facing laterally. Although partly damaged in M. knopfleri and completely absent in N. leali, the dorsal part of the quadratojugal contact was most likely a very narrow line running along the lateral margin of the lateral process, as observed in more basal theropods. 
The quadrate head of $M$. knopfleri is strongly damaged but the head is well-preserved in $N$. leali and corresponds to a semi-spherical condyle with a convex dorsal margin in posterior view (Figure 6.16). The mandibular articulation of $M$. knopfleri is very similar to those of Abelisauridae in possessing a subcircular ectocondyle smaller than the ovoid entocondyle, and a narrow and deep intercondylar sulcus (Figure 6.11), two derived features absent in non-abelisauroids Ceratosauria. In N. leali, although incomplete, the entocondyle was obviously larger than the ectocondyle. The latter corresponds to a subcircular condyle separated from the entocondyle by a shallow and poorly delimited intercondylar sulcus (Figure 6.17).

Figure 7

\begin{abstract}
Abelisauridae
Abelisaurus comahuensis (MPCA 11098); Ilokelesia aguadagrandensis (MCF PVPH 35; Figure 7.1-7.6); Aucasaurus garridoi (MCF-PVPH 236); Majungasaurus crenatissimus (FMNH PR 2100; Figure 7.7-7.12); Carnotaurus sastrei (MACN CH 894; Figure 7.13-7.17).

The quadrates of Abelisaurus comahuensis and Carnotaurus sastrei have only been briefly described in the literature (e.g., Bonaparte and Novas, 1985; Bonaparte, 1991). The quadrate anatomy of Ilokelesia aguadagrandensis, which includes the two portion of a right quadrate, and Majungasaurus crenatissimus, from which the two quadrates are wellpreserved, are well-known as they have been described in detail and are illustrated by Coria and Salgado (1998) and Sampson and Witmer (2007) respectively.
\end{abstract}

Abelisaurid quadrates are easily recognizable by some features present in these derived ceratosaurians such as a lateral process extending below the mid-height of the quadrate body, just above the ectocondyle or reaching the latter, and, in some of them, an anterior and posterior fossae. 
The quadrate is strongly ventrodorsally-elongated with a relatively short mandibular articulation. However, the quadrate body is lateromedially wider than basal ceratosaurians as they possess a lateral process attaching well beneath the quadrate head but almost joining the ectocondyle ventrally, forming a tall and subtriangular flange laterally-oriented ( $I$. aguadagrandensis; Figure 7.2; M. crenatissimus; Figure 7.8) or lateromedially-oriented (C. sastrei; Figure 7.14). Like basal ceratosaurs, there is no quadrate foramen piercing the quadrate body in Abelisauridae.

The quadrate ridge is sub-vertical and only well-delimited at mid-height and twothirds of the quadrate bone in posterior view (Figure 7.3, 7.9, 7.15). The ridge becomes noticeable at one-third of the quadrate body, well above the mandibular condyles, and gets flared below the quadrate head.

As seen in Ceratosaurus, the pterygoid flange of abelisaurids is subtrapezoidal and displays a ventral shelf extending all along the ventral margin of the flange (Figure 7.10, 7.15). The anteriormost point of this flange is situated at about two thirds of the quadrate, and its ventral margin connects the quadrate body well-above the ectocondyle while the dorsal margin gets attached to the quadrate body just under the ventral margin of the quadrate head. The latter is subtriangular in outline in dorsal view and subvertical (no bent medially in its anterior part).

When present, the posterior fossa is small, ovoid and situated at mid-height of the quadrate body, as seen in Aucasaurus garridoi (MCF-PVPH 236) and M. crenatissimus (Figure 7.9). In some abelisaurids, a second fossa occurs on the anterior surface of the quadrate body, lateral to the ventralmost part of the pterygoid flange. This anterior fossa is deep and well-visible in A. comahuensis, M. crenatissimus (Figure 7.7), and C. sastrei (Figure 7.13). 
As observed in other ceratosaurians, the ventral quadratojugal contact of $M$.

crenatissimus is lanceolate and the dorsal quadratojugal contact is an elongated line following the lateral edge of the lateral process (Figure 7.8). On the other hand, the ventral quadratojugal contact of I. aguadagrandensis is hemicircular and placed on the anterolateral part of the ectocondyle (Figure 7.2-7.1). Abelisaurids and noasaurids share a very similar mandibular articulation in which both ecto- and entocondyle are ovoid or subcircular, and the entocondyle is larger than the ectocondyle (Figure 7.6, 7.12, 7.17). The intercondylar sulcus is very narrow in $M$. crenatissimus and $C$. sastrei whereas it is large and shallow in $A$.

comahuensis and I. aguadagrandensis. The first two taxa also possess a deep quadrate notch on the anterior margin of the mandibular articulation (Figure 7L,Q).

\section{Basal Tetanurae}

Cryolophosaurus ellioti (Smith et al., 2007); Monolophosaurus jiangi (Zhao and Currie, 1993; Brusatte, Benson, et al., 2010); Marshosaurus bicentissimus (Madsen, 1976a); Sinosaurus triassicus (Hu, 1993; Xing, 2012).

Recent cladistic analyses performed on tetanurans by Benson (2010) and Carrano et al. (2012) found several theropod taxa placed basally among Tetanurae, but outside the clades of Megalosauria and Allosauroidea. Among those basal tetanurans, Cryolophosaurus ellioti, Marshosaurus bicentissimus, Sinosaurus triassicus and Monolophosaurus jiangi have a quadrate preserved, but this bone has only been well-described in M. jiangi (Brusatte, Benson, et al., 2010). M. jiangi was retrieved at the base of a clade encompassing Megalosauroidea, Allosauroidea, and Dromaeosauridae in the present analysis (Figure 1). Cryolophosaurus ellioti, on the other hand, was found outside Tetanurae, along with Ceratosauria. As noted before, C. ellioti was considered to be closely related to D. wetherilli by Smith et al. (2007) but Carrano et al. (2012) analysis found it as a basalmost Tetanurae. Both quadrates of $C$. 
ellioti (Hammer and Hickerson, 1994) are preserved, and only the right quadrate is wellvisible (Smith et al., 2007), but the mandibular condyles are still in connection with the mandible and only the posterior and the lateral views of the bone can be seen. As for $S$. triassicus, both quadrate are in articulation within the skull of two specimens (KMV 8701; LDM-LCA 10), but the bone has been poorly described by $\mathrm{Hu}$ (1993) and a full picture of the cranial anatomy of this taxon is still waited.

The quadrate body of basal tetanurans are moderately tall (ratio of 0.44 for $M$. jiangi and around 0.36 for $C$. ellioti) and the mandibular articulation is positioned posterior to the quadrate head. A ventrodorsally elongated quadrate foramen is present in all basal tetanurans (e.g., Hue, 1993; Carrano et al., 2012). In C. ellioti, it is small (around 3\% of the dorsoventral depth of the quadrate body) and elliptical, whereas the quadrate bone of $M$. jiangi possesses a large lanceolate quadrate foramen. However, both taxa have their quadrate foramen almost equally delimited by the quadrate and quadratojugal, with the quadrate contributing slightly more to the margin of the foramen than the quadratojugal (pers. obs. for C. ellioti; Zhao and Currie 1993; Brusatte et al. 2010a, figure 1D).

The quadrate ridge of basal tetanurans is rod-shaped, well-delimited, diagonallyoriented and slightly twisted in $C$. ellioti. The ridge seems to reach the entocondyle in $M$. jiangi and gets flared just above the medial condyle in C. ellioti. The quadrate head of $M$. jiangi only contacts the squamosal and is clearly exposed in lateral view rather than being obscured by the squamosal (Zhao and Currie, 1993). The same condition exists in $S$. triassicus (LDM-LCA 10).

Contrarily to most basal theropods and ceratosaurians, there is no lateral process projecting from the quadrate body in S. triassicus, C. ellioti and M. jiangi. The pterygoid flange of $M$. jiangi is moderately expanded anteroposteriorly (ratio of the pterygoid flange, corresponding to the antero-posterior length of the flange divided by the ventrodorsal 
elongation of the quadrate body, of 0.43 ) while the anteroposterior elongation of the pterygoid flange is surprisingly important in C. ellioti (ratio of 0.7). As in megalosaurids and spinosaurids, the anteriormost point of the flange is located at two-thirds of the quadrate in basal tetanurans. However, the most anterior side of the flange is slightly inclined anteriorly in $M$. jiangi and strongly inclined posteriorly in C. ellioti. In both taxa, a posterior fossa is absent and the medial fossa is deep and located in the posteroventral corner of the pterygoid flange. The posteroventral margin of the pterygoid flange deflects medially, and this fold extends well anteriorly in $M$. jiangi, forming a protuberant ventral shelf. In $M$. jiangi, a small concavity just above the boundary between the ento- and ectocondyles appears on the posterior face of the quadrate body (Zhao and Currie, 1993, figure 1D). A concave area seems to be also present at this place in C. ellioti but shallower than in M. jiangi. Similar to the nonaverostran condition, the quadrate of $M$. jiangi and C. ellioti is apneumatic (Smith et al., 2007; Benson, 2010) datamatrix).

According to Benson (2010) datamatrix coding, the quadrate of the basal megalosauroid M. bicentissimus is also apneumatic, lacking a quadrate foramen and possessing "a small circular depression adjacent to the mandibular condyle" (Benson, 2010, p. 35) on the medioventral side of the quadrate and dorsal to the entocondyle. As stated by this author, it "may represent incipient development" (Benson, 2010, p. 35) of the medial foramen existing above the entocondyle and adjacent to the ventral margin of the pterygoid flange in some derived Megalosauridae.

\section{Figure 8}

\section{Megalosauridae}


Eustreptospondylus oxoniensis (OUMNH J.13558; Figure 8.1-8.5); Dubreuillosaurus valesdunensis (Allain, 2002); Torvosaurus tanneri (Britt, 1991; BYUVP 9246; Figure 8.68.11); Afrovenator abakensis (UC OBA1; Figure 8.12-8.17);

The quadrate of Eustreptospondylus oxoniensis and Afrovenator abakensis are complete (Sereno et al., 1994; Sadleir et al., 2008), but the right quadrate of Torvosaurus tanneri has the pterygoid flange missing (Britt, 1991). Only a fossil imprint of pterygoid flange of the left quadrate has been recovered in Dubreuillosaurus valesdunensis (Allain, 2002).

The quadrate is moderately elongated in comparison to the lateromedial width of the mandibular articulation (ratio between $0.35-0.45$ ) and slightly anteriorly-inclined in lateral view. The quadrate body is significantly laterally-inclined from the horizontal axis passing through the mandibular articulation (Figure $8.3,8.8,8.14$ ). It has lateral and medial margins subparallel in posterior view, and the posterior margin is concave except in $D$. valesdunensis in which this margin seems to be convex (Allain, 2002). Like ceratosaurians, the quadrate of megalosaurid taxa lacks a quadrate foramen, therefore the quadratojugal contact extends all the way dorsoventrally. The ventral part of the quadratojugal contact is subtriangular in shape and shows an anterior projection, whereas the dorsal part is an elongated and narrow suture with subparallel anterior and posterior margins (Figure 8.3, 8.8, 8.14). The quadrate ridge is rod-shaped as in ceratosaurians, and can be either shallow and not well-marked (E. oxoniensis; Figure 8.3) or, well-delimited at mid-height of the quadrate body (T. tanneri; Figure 8.8; A. abakensis; Figure 8.14). Nevertheless, the ridge always becomes visible well above the entocondyle, at one third of the bone, and reaches the quadrate head. As all megalosauroids, there is no lateral process of the quadrate body.

The pterygoid flange is straight (no medial curvature of the anterior part), subtrapezoidal and reaches the dorsal margin of the quadrate head dorsally and, not far above 
from the entocondyle ventrally (Figure 8.2, 8.7, 8.15). The posteroventral margin of the flange is medially-folded but there is no ventral shelf in the anteroventral part of the flange. The medial fossa of the quadrate is shallow and there is no distinct posterior fossa, but an depression ventrodorsally elongated along the quadrate body, lateral to the quadrat ridge. The quadrate head projects vertically and its shape is ovoid rather than subtriangular in posterior view as in other non-tetanuran theropods (Figure 8.10, 8.16).

The mandibular articulation is also lateromedially larger than in more basal theropods. In both posterior and ventral views, the ectocondyle is longer than the entocondyle and its ventral margin is slightly sigmoid in T. tanneri in anterior view (Figure 8.6). The ectocondyle is parabolic in T. tanneri (Figure 8.11) and E. oxoniensis (Figure 8.5), but it is rather elliptical in A. abakensis (Figure 8.17). Likewise, the anterior margin of the ectocondyle is concave both in T. tanneri and E. abakensis. The entocondyle is elliptical to oblong in outline, and strongly protrudes anteriorly. The intercondylar sulcus is deep and well-marked in E. oxoniensis (Figure 8.5), but large and shallow in T. tanneri (Figure 8.11) and A. abakensis (Figure 8.17).

In T. tanneri, the ventral margin of the ventral quadratojugal contact and the posteroventral margin of the pterygoid flange are joined together to form a convex arc on the anteroventral side of the quadrate (Figure 8.6). This taxon can also be distinguished from the two other megalosaurids by having a concavity on the anteroventral margin of the quadrate, ventral to the pterygoid flange and anterior to the entocondyle. A similar but larger and deeper concavity has also been noted in some derived Spinosauridae (pers. obs.).

A subtriangular depression with a small foramen inside is present in T. tanneri on the ventromedial part of the quadrate just above the entocondyle (Figure 8.9; Britt, 1991; Benson, 2010; pers. obs.). A shallow concavity with no foramen also exists at the same position in $A$. abakensis but nothing comparable is present in E. oxoniensis (Benson, 2010); pers. obs.). In 
T. tanneri and A. abakensis, a second and larger ovoid foramen also occurs at the ventralmost part of the pterygoid flange, beneath the medial fossa and above the shallow fossa dorsal to the entocondyle (Figure 8.9, 8.15; Benson, 2010, figure 19A). Although a medial pneumatopore was noted by Sadleir et al. (2008) at the base of the pterygoid flange in $E$. oxoniensis, no pneumatopore was observed at this place in this taxon. Instead, there is a groove leading to a small foramen on the anteroventral part of the quadrate, lateral to the ventral part of the pterygoid flange (Figure 8.1) but this structure might be an artifact of preservation. The quadrate of megalosaurids seems therefore to be apneumatic.

Figure 9

\section{Spinosauridae}

Baryonyx walkeri (BMNH R9951; Figure 9.1-9.6); Suchomimus tenerensis (MNN GAD 502; Figure 9.7-9.12); Irritator challengeri (SMNS 58022); Undescribed Spinosaurinae (MSNM V6896; WDC-CSG uncatalogued; Figure 9.13-9.18).

Both quadrates of Baryonyx walkeri provide a good basis to understand the anatomy of this derived clade of Megalosauroidea. An incomplete left quadrate of Suchomimus tenerensis, a small portion of the lateral part of the right quadrate and the quadrate head of the left quadrate in Irritator challengeri (Sues et al., 2002), and six indeterminate spinosaurid quadrates from the Cenomanian of the Kem Kem beds (Morocco) offer further details.

The quadrates of $B$. walkeri have been described in detail by Charig and Milner (1997) but the anatomy of the quadrate of I. challengeri has been very briefly given by Sues et al. (2002) and that of S. tenerensis has not yet been described. A detailed description of the six spinosaurid quadrates from Morocco and comparison with other spinosaurid quadrates will be given elsewhere. 
The Spinosauridae quadrates are highly diagnostic and differ significantly from megalosaurids. The mandibular articulation is very broad lateromedially and the quadrate body is short (ratio more than 0.5). It also seems that the quadrate bone was posteriorly-inclined in the cranium as this configuration appears in I. challengeri, the only reported spinosaurid taxon with an articulated quadrate.

In Baryonychinae, the quadrate foramen is large (thereby called the 'quadrate fenestra' by Sereno et al. (1998), strongly ventrodorsally elongated and predominantly formed by the quadrate (Figure 9.3 and 9.9). Indeed, the dorsal quadratojugal contact possesses a short ventral projection making the dorsolateral margin of the quadrate foramen. Such feature can also be observed in the quadrates of spinosaurid taxa from Morocco (Figure 9.15) but its presence remains uncertain in I. challengeri (pers. obs.). However, the quadrate foramen of Spinosaurinae is slightly to considerably smaller and also subcircular to bean-shaped when compared to Baryonychinae (pers. obs.). As in Megalosauridae, there is no lateral process.

The quadrate ridge of spinosaurids is broad, the broadest among nonavian theropods, and the quadrate body corresponds to the quadrate ridge at the level of the quadrate foramen (Figure 9.3, 9.9, 9.15). The ridge is also strongly inclined laterally, becomes marked just above the entocondyle and flares at two thirds of the quadrate body where, in some derived spinosaurids, it can reappear more dorsally, beneath the quadrate head (pers. obs.).

By having a very long anteriormost margin, the pterygoid flange of the quadrate is sub-rectangular in outline and such morphology is typical of spinosaurid theropods (Figure $9.4,9.16)$. The flange attached dorsally at the level of the quadrate head and descends the quadrate body to meet the entocondyle. A shallow notch occurs at one-fifth of the pterygoid flange and the dorsal margin of the flange is slightly medially-folded from that point (Figure 9.1, 9.7). Unlike Baryonychinae, the flange is strongly medially curved in Spinosaurinae. The 
medial fossa, located ventrally and delimited by the prominent ridge, is particularly deep in comparison to other theropods (Figure 9.4, 9.16).

The shape of the quadrate head is highly variable among spinosaurid theropods: subcircular in B. walkeri (Figure 9.5), subtriangular in S. tenerensis (Figure 9.11), and diamond shaped in I. challengeri and an indeterminate spinosaurine (MSNM V6896; Figure 9.17). There is a small concavity situated on the posterior side of the quadrate body, just beneath the quadrate head, a feature shared among all Spinosauridae (pers. obs.).

The ventral quadratojugal contact is anteroposterioly broad, reniform to D-shaped, and much broader than the dorsal quadratojugal contact which is lanceolate and elongated ventrodorsally (Figure 9.2, 9.8, 9.14). The suture between the quadrate and quadratojugal must have been rigid as the ventral contact is deeply excavated by one or several cavities, and the surface of the dorsal contact is irregular and sometimes shows a central ridge delimited by two elongated grooves. The dorsal quadratojugal contact has an anterior projection and always extents on to the ectocondyle (Figure 9.2, 9.14, 9.14). On the posterior side of the quadrate, a shallow and recurved groove running from above the ventral quadratojugal to the boundary between the ecto- and entocondyles has been observed in B. walkeri and other spinosaurines (pers. obs.).

With a strongly elongated and sigmoid ectocondyle and a short entocondyle, both being delimited by a diagonally-oriented intercondylar sulcus, the mandibular articulation of the quadrate is also typical to the clade of Spinosauridae (Figure 9.6, 9.12, 9.18). The entocondyle is subtriangular and not well-marked and the intercondylar sulcus is shallow in $B$. walkeri, possibly due to the immaturity of the specimen (Charig and Milner, 1997). In more derived spinosaurids, the entocondyle is elliptical in shape and does not protrude anteriorly. The ectocondyle is much larger than the entocondyle in both posterior and anterior views. In 
anterior view, the ventral margin of the condyle is sigmoid. The intercondylar sulcus is deep and well-delimited in mature individuals of Spinosaurine (Hendrickx and Mateus, 2012).

\section{Figure 10}

\section{Non-carcharodontosaurid Allosauroidea}

Allosaurus fragilis (Madsen, 1976b; Bakker, 1998); Allosaurus europaeus (ML 415); Allosaurus 'jimmadseni' (SMA 005/02; Figure 10.1-10.6); Aerosteon riocoloradensis (Sereno et al., 2008; Figure 10.7-10.12); Sinraptor dongi (Currie, 2006; Figure 10M-Q).

The quadrate of non-carcharodontosaurid allosauroids is known in Allosaurus fragilis (Madsen, 1976b), Allosaurus 'jimmadseni' (Chure, 2000), Allosaurus europaeus (Mateus et al., 2006), Sinraptor dongi (Currie, 2006), and Aerosteon riocoloradensis (Sereno et al., 2008). However, the quadrate has only been relatively well-described in A. 'jimmadseni' and S. dongi. Although Allosaurus, Sinraptor and Aerosteon pertain to different clades of allosauroids (sensu Benson et al., 2010; Carrano et al., 2012), they share many features that are not seen in other theropods and Carcharodontosauridae. Thus, the quadrate of Carcharodontosauridae will thereby be described and compared to other theropod taxa in the next chapter.

The quadrate of allosaurids and A. riocoloradensis is moderately elongated (ratio between 0.35 and 0.5 ; Figure 10.3 ) but that of $S$. dongi is notably tall (ratio is approximately 0.3; Figure 10.15) and similar to non-tetanuran theropods. This can be explained by the relatively short mandibular articulation in $S$. dongi, whereas the mandibular articulation of other allosauroids is much broader lateromedially.

The quadrate foramen of allosaurids and $S$. dongi is mostly delimited by the quadrate (Currie, 2006; Figure 10.3), but it is completely enclosed in A. riocoloradensis (Figure 10.7), a feature also present in the coelophysoid Z. rougieri (Ezcurra, 2007). In A. riocoloradensis, 
the quadrate foramen is particularly large, ovoid and situated at mid-height of the bone, while in allosaurids and sinraptorids, the quadrate foramen is more elliptical, smaller, slightly to strongly elongated ventrodorsally, and positioned slightly ventrally from the half of the quadrate body.

The quadrate ridge is prominent, laterally-inclined, and rod-shaped in allosaurids (Figure 10.3, 10.15), and forming almost a broad crest in A. riocoloradensis (Figure 10.9). Interestingly, the ridge is divided in two portions by a groove at one-third or one-fourth of the quadrate body, instead of forming a single structure as in other nonavian theropods. This groove is deep and diagonally-oriented in A. fragilis, A. europaeus and Allosaurus 'jimmadseni' (SMA 0005/02; Figure 10.3) and well-marked but subvertical in A. riocoloradensis (Figure 10.9). In fact, in A. riocoloradensis the ventral part of the ridge butts against the quadrate head while the remaining dorsal portion emerged well beneath the quadrate head laterally, being parallel to the squamosal contact interpreted by Sereno et al. (2008). In S. dongi, however, this feature is more superficial but it seems that the dorsal part of the quadrate ridge deviates laterally beneath the quadrate head (Figure 10.15). A second and much narrower ridge of $S$. dongi becomes distinct more medially at one fourth of the quadrate body, and remains parallel to the other (Figure 10.15). In allosaurids, the ridges forms a convex protuberance at one-third of the quadrate body and well-visible in lateral view (Figure 10.2). This bump on the posterodorsal margin in the quadrate body is not unique to these theropods as it has also been observed in the C. ellioti (Smith et al., 2007, figure 4A-B). A short lateral process is present and projects laterally from the quadrate foramen to the quadrate head in allosaurids (Figure 10.3) and S. dongi (Figure 10.15). The process attaches well-below the quadrate head in these taxa, and its lateral margin is parabolic. In the other hand, the lateral process projects completely anteriorly in A. riocoloradensis, and 
extends entirely on the quadrate body, from the mandibular articulation ventrally to the quadrate head dorsally (Figure 10.7-10.8).

The pterygoid flange is very slightly medially-recurved in allosaurids (Figure 10.1) and S. dongi (Figure 10.13), and strongly arched medially in A. riocoloradensis (Figure 10.7). However, the shape of the flange is quite similar between them, as the flange is parabolic in shape with a rounded anteriormost margin instead of a straight margin present in more basal theropods. The flange meets the quadrate body far above the mandibular condyles ventrally while it reaches the quadrate head just below its ventral margin dorsally. The quadrate head is subcircular in allosauroids and follows the curvature of the quadrate body in allosaurids and S. dongi, whereas the dorsal fourth of the quadrate strongly bends posteriorly in $A$. riocoloradensis (Figure 10.10).

The medial fossa is shallow and roughly centrally positioned in A. riocoloradensis and S. dongi. This fossa is deeper and more ventrally positioned in Allosaurus 'jimmadseni' due to a well-developed ventral shelf in this taxon (Figure 10.4). Such shelf is also present in $S$. dongi but, instead of being projected dorsomedially like in Allosaurus 'jimmadseni', the shelf folds medially (Figure 10.16). A. riocoloradensis does not have such feature. The posterior fossa of $S$. dongi is deep, ventrodorsally-elongated and does not includes the quadrate foramen. No similar fossa exists in allosaurids and A. riocoloradensis, but there is a ventrodorsally-elongated depression surrounding the quadrate foramen in these allosauroids. This concavity is bounded medially by the quadrate ridge and laterally by the quadratojugal contact in allosaurids, and a ridge delimiting posteriorly the lateral process in $A$. riocoloradensis.

The ventral quadratojugal contact of $A$. fragilis is D-shaped and faces laterally whereas it is lanceolate and faces posterolaterally in $S$. dongi (Figure 10.14). Nevertheless, both ventral quadratojugal contacts share a short quadratojugal process projecting anteriorly. 
The dorsal quadratojugal contact is ventrodorsally-elongated and faces anterolaterally or completely anteriorly in these taxa. Although we agree with Sereno et al. (2008) that the lateral contact of $A$. riocoloradensis extends from the ectocondyle to the dorsal margin of the quadrate head along the lateral process (Figure 10.8), we are giving a different interpretation of the morphology of this contact. According to Sereno et al. (2008, figure 4A), the quadratojugal/squamosal contact is broad, its anterior and posterior margins are subparallel, its surface is regular and flattened, and the dorsal part of the lateral contact of $A$. riocoloradensis quadrate would have been connected to the squamosal (Sereno et al., 2008, figure 4). Our observation of the quadrate of $A$. riocoloradensis suggests that only the anterior margin of the lateral process was contacting the quadratojugal anteriorly. The presence of a deep depression on the lateroventral part of the lateral process, here interpreted as an additional pneumatic fossa, seems to support this interpretation. Nevertheless, it is indeed likely that the squamosal was connecting the quadrate on the dorsal surface of the lateral process, as suggested by Sereno et al. (2008, figure 4A).

The mandibular articulation of the allosauroids $S$. dongi (Figure 10.17) and A. riocoloradensis (Figure 10.12) is very similar in shape as both condyles are elliptical, globular and prominent, with a relatively deep intercondylar sulcus separating them. The main axis passing through the ecto- and entocondyles are medially-oriented and the ectocondyle axis is slightly more inclined medially than the entocondyle one, although both axes can be subparallel is some allosaurids (SMA 0005/02; Figure 10.6). All allosaurids, however, show a diagnostic quadrate notch on the posterior side of the mandibular articulation.

Quadrate pneumaticity exists in some non-carcharodontosaurid allosauroids such as $A$. riocoloradensis (Sereno et al., 2008; Figure 10I) where a large and deep pneumatic recess is located on the posterior side of the quadrate body. Currie (2006) estimates that the deep posterior fossa posteromedial to the quadrate foramen in S. dongi (Figure 10.15) was 
presumably pneumatic in origin, an interpretation followed here. A depression also occurs on the lateroventral surface of the lateral process in A. riocoloradensis (Figure 10.8) and was originally pneumatic as well in this taxon.

\section{Figure 11}

\section{Carcharodontosauridae}

Acrocanthosaurus atokensis (NCSM 14345; Figure 11.1-11.5); Shaochilong maortuensis (Brusatte et al., 2009); Giganotosaurus carolinii (MUCPv-CH-1; Figure 11.611.11); Mapusaurus roseae (MCF PVPH-1011.102; Figure 11.12-11.17).

The quadrate of Carcharodontosauridae is relatively well-known due to its detailed description for Acrocanthosaurus atokensis (Eddy and Clarke, 2011), Shaochilong maortuensis (Brusatte, Chure, et al., 2010) and Mapusaurus roseae (Coria and Currie, 2006). The bone is moderately elongated and has an lateral process along the dorsal half of the body and a relatively broad mandibular articulation ventrally. The quadrate ridge is pronounced, strongly laterally-inclined, becomes noticeable at one-third of the quadrate and more dorsally, being completely flared on the first one-third surface of the quadrate body (Figure 11.3, 11.8, 11.14). The ridge varies in width, being lateromedially large at mid-height of the quadrate and reducing in width to form a thin crest below the quadrate head in A. atokensis (Figure 11.3).

The quadrate of the carcharodontosaurids retains many plesiomorphies with basal allosauroids, such as a very small quadrate foramen (less than $7 \%$ of the ventrodorsal height of the quadrate body; Figure 11.3, 11.8, 11.14) mostly delimited by the quadrate, a short lateral process between the quadrate foramen and quadrate head, and a quadrate ridge relatively narrow at two thirds of the quadrate body and divided into ventral and dorsal portions. 
The quadrate body shows a large posterior fossa leading to the quadrate foramen ventrally. This depression is elliptical in shape, poorly-delimited, ventrodorsally elongated and medially inclined in carcharodontosaurids (Figure 11.3, 11.8, 11.14). The narrow quadrate body of S. maortuensis (Brusatte, Chure, et al., 2010, figure 7b) does not show a similar posterior fossa but, according to us, the lateral part of the quadrate body is missing. Unlike more basal allosauroid taxa, the pterygoid flange is straight, with no medial curvature, and the medial fossa is rather sub-circular, centrally positioned on the flange, and very shallow. Furthermore, the flange meets the quadrate body slightly above the entocondyle and well-beneath the ventral margin of the quadrate head. Nevertheless, as other allosauroids, the pterygoid flange is sub-parabolic in medial view, with a large and rounded anterior margin (Figure 11.4). The quadrate head is subcircular in shape in dorsal view in carcharodontosaurids (Figure 11.10) and, subvertical rather than flexing posteriorly as in $A$. riocoloradensis.

Both ventral and dorsal quadratojugal contacts of carcharodontosaurids are morphologically similar to allosaurids and S. dongi (Figure 11.7, 11.13). The dorsal quadratojugal contact is a narrow, elongated, and extends along the lateral process of the quadrate. Except $A$. atokensis, the ventral quadratojugal contact does not show any anterior projection like in more basal allosauroids.

The mandibular articulation is broad, with an ectocondyle always lateromedially larger than the entocondyle in both anterior and posterior views (Figure 11.5, 11.11, 11.17). It is constituted of an elliptical to oblong bulged entocondyle and an elongated parabolic to sigmoid ectocondyle, usually separated by a narrow but deep intercondylar sulcus (Figure $11.5,11.11)$. Although the entocondyle is prominent on both anterior and posterior sides in most carcharodontosaurids, its margins are rather flared in S. maortuensis which also displays a very shallow intercondylar sulcus. 
All carcharodontosaurids but $S$. maortuensis have a pneumatic quadrate. The pneumatic quadrate of carcharodontosaurids possesses a pneumatopore at the base of the pterygoid flange, ventral to the medial fossa (Figure 11.4, 11.9, 11.15). This medial pneumatic recess is large, subcircular and divided by a septum in A. atokensis. In M. roseae, the medial pneumatopore is also relatively large but elliptical and with no septum, like in $G$. carolinii in which this pneumatic opening is relatively small, subcircular and more dorsallysituated on the pterygoid flange. Unlike A. atokensis, Giganotosaurinae taxa do not show any posterior pneumatopore inside the posterior fossa of the quadrate body. However, an anterior pneumatic aperture is present in M. roseae at one third of the bone, lateral to the ventral termination of the pterygoid flange (Figure 11.12).

\section{Basal Coelurosauria}

Bicentenaria argentina (MPCA 865; Figure 14.1-14.6); Zuolong salleei (Choiniere, Clark, et al., 2010); Lourinhanosaurus antunesi (ML 565-10, 565-150; Hendrickx and Mateus, 2012); Aorun zhaoi (Choiniere et al., 2014).

The quadrate of the basal coelurosaurs of Zuolong salleei (Choiniere, Clark, et al., 2010), Lourinhanosaurus antunesi (Hendrickx and Mateus, 2012), and Aorun zhaoi (Choiniere et al., 2014) are relatively well-known as a thorough description has been provided in these taxa. Nevertheless, additional information deserves to be added in Bicentenaria argentina (Novas et al., 2012) as the quadrate of this coelurosaur shows some interesting features not seen in other theropod clades.

Only the ventral half of the left and right quadrates of $B$. argentina are preserved (Figure 14.1-14.6). The quadrate of this taxon displays a prominent and well-defined rodshaped quadrate ridge extending ventro-dorsally, perpendicular to the long axis of the mandibular articulation. The quadrate ridge does not reach the mandibular articulation 
posteriorly but extends to the entocondyle in its medial part (Figure 14.4). The quadrate foramen is strongly ventro-dorsally oriented and ventrolaterally bounded by a short and pointed projection of the basal quadratojugal contact so that the foramen is mostly delimited by the quadrate (Figure 14.3).

As seen in some tyrannosauroids, the pterygoid flange of $B$. argentina extends far anteriorly, its anterior margin is semi-oval, and the ventral margin of the flange forms a right angle with the long axis of the quadrate ridge (Figure 14.4). The pterygoid flange projects anteriorly and does not curve medially. It also reaches the quadrate body slightly above the mandibular articulation, at the level of the entocondyle, and displays a rod-like ventral shelf oriented dorsomedially in its posteroventral margin, so that the medial fossa is relatively deep. In lateral view, the ventral quadratojugal contact is elliptical in shape and slightly anteriorly inclined (Figure 14.2). The contact is concave is posterior view and does not extend on the ectocondyle laterally. The articulating surface of the ventral quadratojugal contact is smooth and slightly excavated in its central part, and its posterodorsal margin is bounded by a wide but short lateral projection.

The mandibular articulation is unique in possessing two well-delimited condyles strongly diagonally oriented in which the ectocondyle is one-third longer than the entocondyle and markedly protrudes laterally in ventral view (Figure 13.6). The mandibular condyles share however a same width and both condyles are separated by a wide and deep intercondylar sulcus. The long axis of the ento-, ectocondyles and intercondylar sulcus is parallel.

The most interesting features in the quadrate of the embryonic specimens of $L$. antunesi are the absence of a quadrate foramen and the poor delimitation of the mandibular articulation, both interpreted as ontogenetical characters. The quadrate shows some similarities with this of B. argentina such as a well-defined rod-shaped quadrate ridge 
('quadrate shaft' sensu Hendrickx and Mateus 2012) almost reaching the entocondyle medially, a ventral quadratojugal not extending on the ectocondyle, and a pterygoid flange projecting mostly anteriorly whose the ventral margin is perpendicular to the long axis passing through the quadrate ridge.

The quadrate of $Z$. salleei shows a combination of features only seen in this taxon, namely: a deep posterior fossa bounded medially by a well-delimited and rod-shaped quadrate ridge, and laterally by a strongly elongated ventral projection of the dorsal quadratojugal contact, a large medially inclined quadrate foramen showing a lenticular outline in posterior view, a ventral quadratojugal contact extending along almost one half of the quadrate body, a dorsal quadratojugal contact facing anteriorly, and two relatively small mandibular condyles separated by a wide intercondylar sulcus. The pterygoid flange projects only anteriorly and possesses a shallow medial fossa and no ventral shelf on its ventral margin. As the two other basal coelurosaurs, the ventral margin of the pterygoid flange extends perpendicular to the long axis of the quadrate shaft but the anterior margin of the flange is parabolic rather that semi-oval.

The quadrate of the basal coelurosaur $A$. zhaoi significantly differs from those of $B$. argentina and $Z$. sallei. The pterygoid flange is autapomorphically triangular and convergently similar to this of dromaeosaurids. A vertically oriented ventral shelf ('sliver of bone' sensu Choiniere et al., 2014) seems to be present on the medial surface of the pterygoid flange, along the posteroventral margin of the flange. The quadrate foramen is large, subcircular, and entirely developed within the quadrate body at one half of the bone (Choiniere et al., 2014). A quadrate foramen with similar size, shape and occupation only occurs in the neovenatorid Aerosteon. Similar to basal coelurosaurs, the lateral process is absent in A. zhaoi, yet no pronounced and well-delimited posterior fossa surrounding the quadrate foramen is present in this taxon (Choiniere et al., 2014). 
Figure 12

\section{Tyrannosauroidea}

Proceratosaurus bradleyi (NHM R 4860; Rauhut et al., 2010; Figure 12.1-12.3);

Eotyrannus lengi (MIWG, 1997.550; Figure 12.4-12.9); Xiongguanlong baimoensis (Li et al., 2010); Alioramus altai (Brusatte et al., 2012; Figure 12.10-12.15); Albertosaurus

sarcophagus (Currie, 2003); Gorgosaurus libratus (AMNH 5336, 5664); Daspletosaurus sp.

(Currie, 2003); Tyrannosaurus rex (FMNH PR2081, AMNH 5027; Molnar, 1991; Brochu, 2003).

Although a significant amount of work has recently been published on tyrannosauroid paleobiology and anatomy due to recent discoveries (e.g., Xu et al., 2004, 2006; Brusatte, Carr, et al., 2009; Ji et al., 2009; Sereno et al., 2009; Carr and Williamson, 2010; Averianov and Sues, 2011; Hone et al., 2011; Loewen et al., 2013), the quadrate anatomy in this important clade of theropods is not particularly well-known. Detailed descriptions are available only for four tyrannosauroid taxa: Proceratosaurus bradleyi (Rauhut et al., 2010), Alioramus altai (Brusatte et al., 2012; Gold et al., 2013), Albertosaurus sarcophagus (Carr, 1996) and Tyrannosaurus rex (Molnar, 1991; Brochu, 2003).

The tyrannosaurid quadrate is particularly short (ratio of more than 0.5 ) while in the basal forms like P. bradleyi and X. baimoensis it is moderately ventrodorsally-elongated (ratio between 0.45 and 0.5 ) like in basal tetanurans (Figure 12.1). In Tyrannosauridae and some basal tyrannosauroids such as X. baimoensis, the mandibular articulation and the quadrate body at the level of the ventral quadratojugal contact are particularly broad (Figure 12.12). However, the quadrate body is strongly constricted at the level of the quadrate foramen, giving the typical axe shape to the quadrate in posterior view (Figure 12.12). 
The quadrate ridge is laterally-inclined and usually distinct, and rod-shaped in basal forms like P. bradleyi (Figure 12.1), but forming a typical crest delimiting the medial margin of the quadrate body in some derived tyrannosauroids like T. rex (AMNH 5027; Larson, 2008). This crest is prominent just dorsal to the entocondyle at the posteromedial portion of the quadrate, and reaches the second third of the quadrate body in A. sarcophagus and Daspletosaurus sp. (Currie, 2003, figures 10, 28) while it extends to the quadrate head in $T$. rex as a narrow crest. The quadrate ridge is straight in most tyrannosauroids but rather biconvex in posterior view, and strongly posteriorly-folded in medial view in A. altai (Figure 12.13) and T. rex. The quadrate ridge of tyrannosaurids is also divided into two ridges separated by a small concavity at the ventral part of the ridge, just above the entocondyle, although the two ridges are rather shallow in A. altai (Figure 12.13) and Daspletosaurus (Currie, 2003, figure 10). The concavity bordered by those two ridges is deep and well-visible in A. sarcophagus (Currie, 2003, figure 10) and T. rex (AMNH 5027), and strongly basoapically elongated, covering the basal half of the quadrate ridge, in the latter.

The quadrate foramen is mostly delimited by the quadrate bone in Tyrannosauroidea (Figure 12.1, 12). In basal forms such as $P$. bradleyi, the quadrate foramen is small, elliptical and strongly ventrodorsally-elongated. It becomes larger in more derived tyrannosauroids like X. baimoensis, G. libratus and T. rex, in which it is lenticular or lanceolate. In tyrannosaurids, a short ventral projection of the dorsal quadratojugal contact delimits the dorsal margin of the quadrate foramen laterally.

Another condition uniting most tyrannosauroid taxa is the semi-oval shape of the pterygoid flange, strongly anteroposteriorly-elongated relative to the height of the quadrate body (ratio of more than 0.8 ). The pterygoid flange forms an elongated subtrapezoidal shape in derived tyrannosaurids like A. altai (Figure 12.13), where both ventral and dorsal margins are concave and the anterior margin is rugged. In tyrannosaurids, the ventral margin of the 
flange is divided into two crests in which the lateral one terminates at the middle of the quadrate body, just above the intercondylar sulcus of the mandibular condyle or reaching them. The medial crest, on the other hand, meets the quadrate body at its medial margin and well-above the entocondyle. A ventral pneumatic recess is found between these two ridges of the pterygoid flange in A. altai (Figure 12.15), A. sarcophagus (Carr, 1996), Daspletosaurus sp. (Currie, 2003, figure 28C) and T. rex (Brochu, 2003). The lateral process of the quadrate body is absent in all tyrannosauroids.

The quadrate head of some tyrannosaurids like Daspletosaurus sp. and A. altai is subcircular (Currie, 2003, figure 28D; Brusatte et al., 2012), but it is slightly biconvex and almost double-headed in T. rex (Figure 12.11) and A. sarcophagus (Currie, 2003, figure 10B), which possess a small concavity centrally-positioned on the quadrate head. The posterior fossa of tyrannosauroids is absent. Nonetheless, the quadrate foramen of some derived tyrannosaurids is bounded by a large depression on the quadrate shaft which is delimited dorsally by the dorsal quadratojugal contact, and laterally by the quadrate ridge. This depression is, however, not considered homologous to the posterior fossa of other theropod taxa.

Most tyrannosauroids have a dorsal quadratojugal contact facing lateroposteriorly (Figure 12.12) or completely posteriorly as in T. rex (Larson, 2008). This feature is difficult to assess in the basal taxon $P$. bradleyi because the descending process of the squamosal covers the posterodorsal side of the quadrate. However, a dorsal quadratojugal contact on the lateroposterior margin of the quadrate body seems to be present in X. baimoensis. Unlike other tyrannosaurids, the ventral quadratojugal contact of the quadrate is broad lateromedially and lanceolate in T. rex, whereas it is more ventrodorsally-elongated and irregularly-shaped in more basal tyrannosaurids. The ventral quadratojugal contact of some Tyrannosauridae such as Eotyrannus lengi (Figure 12.5), A. altai, A. sarcophagus, and T. baatar is also lateroposteriorly-positioned and D-shaped or subquadrangular (Figure 12.11). 
The mandibular articulation in Tyrannosauroidea is composed of two ovoid and subparallel condyles obliquely-oriented, roughly similar in size, and delimited by a very broad and shallow intercondylar sulcus which is parallel to the main axis passing through the mandibular condyles (Figure 12.9, 12.15). Although the ectocondyle of $P$. bradleyi is wider posteriorly than the entocondyle (Rauhut et al., 2010), they are usually subequal in posterior view in other tyrannosauroids taxa like E. lengi and T. rex.

Pneumacity is a common feature among tyrannosaurids and pneumatic foramina can also appear in a pneumatic recess in the medial fossa of the pterygoid flange such as in $A$. sarcophagus (Currie, 2003, figure 10B) and T. rex (Molnar, 1991, figure 7). Also, T. rex and A. sarcophagus possess a pneumatic foramen on the anterodorsal side of the quadrate, beneath the quadrate head (Molnar, 1991; Brochu, 2003, figure 7).

\section{Compsognathidae}

Compsognathus longipes (MNHN CNJ 79; Ostrom, 1978; Peyer, 2006); Scipionyx samnicicus (Dal Sasso and Maganuco, 2011); Juravenator starki (Chiappe and Göhlich, 2010); Sinosauropteryx prima (Currie and Chen, 2001).

The quadrate anatomy of compsognathids is one of poorest known among nonavian theropods. A thorough description of the bone was only given by Dal Sasso and Maganuco (2011) for Scipionyx samnicicus, and the quadrate of other Compsognathidae was either briefly described, as in Compsognathus longipes (Ostrom, 1978; Peyer, 2006), Juravenator starki (Chiappe and Göhlich, 2010), and Sinosauropteryx prima (Currie and Chen, 2001), or not described at all, as in Huxiagnathus orientalis (Hwang et al., 2004) and Sinocalliopteryx gigas (Ji et al., 2007). Although most of compsognathid specimens with cranial material tend to be extremely well preserved and almost complete, their remains are found in two dimensions on slabs of fine grained limestone, usually in articulations with other cranial 
bones, or associated with them. Therefore, due to crushing, missing elements and hidden parts, few information on the compsognathid quadrate can be extracted. This is particularly the case in $J$. starki and $H$. orientalis in which only a small portion of the quadrate is visible.

The quadrate of Compsognathidae is an elongated and slender bone in which the mandibular articulation is relatively narrow, so that the quadrate body is tall both in lateral and posterior views. When articulated, the quadrate lies perpendicular to the ventral margin of the cranium, then gently curves posteriorly with the results that the quadrate head is positioned posteriorly relative to the mandibular articulation. An anterior inclination of the quadrate was proposed by Dal Sasso and Maganuco (2011) for S. samniticus but the quadrate seems to be slightly posteriorly inclined even in articulation, as represented by these authors in the cranial reconstruction of this taxon (Dal Sasso and Maganuco, 2011, figure 175b). The posterior margin of the quadrate body is weakly concave and the lateral margin is sigmoid in S. prima (Currie and Chen, 2001, figure 3f).

A small quadrate foramen exists at one third of the quadrate body in S. samniticus, but its presence cannot be determined in other compsognathids. Nevertheless, the quadrate and quadratojugal tend to be disarticulated instead of fused together, so that the presence of an quadrate foramen between the quadrate and quadratojugal seems to be likely. No quadrate ridge has been illustrated in S. prima, but if present, the ridge was ventro-dorsally oriented rather than medially inclined. The ventral quadratojugal contact corresponds to a lanceolate surface extending on the ectocondyle in S. samniticus, and the shape dorsal quadratojugal contact is unknown of this taxon and other compsognathids.

The quadrate head is single headed and corresponds to a spherical or semi-spherical structure separated from the quadrate shaft by a narrow constriction. The ventral margin of the pterygoid flange attaches to the quadrate body just above the mandibular articulation, as in $S$. samniticus (Dal Sasso and Maganuco, 2011, figure 41) and C. longipes (pers. obs.), or at the 
same level than the mandibular condyles, as it seems to be the case in S. prima (Currie and Chen, 2001, figure 3f). The shape of the pterygoid flange cannot be determined with precision but seems to be roughly parabolic in C. longipes and sub-trapezoidal in S. samniticus. It is unknown whether the dorsal margin of the flange was reaching the quadrate head or not dorsally.

The mandibular articulation includes two condyles in which the ectocondyle is smaller than the entocondyle in posterior view in S. prima (Currie and Chen, 2001, figure 3f). According to Peyer (2006), the reverse condition occurs in C. longipes but the mandibular articulation is not well-preserved enough to support this observation. A pneumatic quadrate is present at least in S. prima which shows a posterior pneumatopore centrally positioned on the quadrate body, at mid-height of the quadrate, and within the ventral part of a large posterior fossa (Currie and Chen, 2001).

Figure 13

\section{Ornithomimosauria}

Garudimimus brevipes (Kobayashi and Barsbold, 2005; Figure 13.6-13.7);

Sinornithomimus dongi (Kobayashi and Lü, 2003; Figure 13.5); Ornithomimus edmontonicus (Tahara and Larsson, 2011; Figure 13.1-13.4); Gallimimus bullatus (IGM 100-1133); Struthiomimus altus (AMNH 5339); Ornithomimosauria gen. et sp. indet. (Makovicky and Norell, 1998).

The quadrate has been described usually briefly for some ornithomimosaurs taxa such as Gallimimus bullatus (Osmólska et al., 1972), Sinornithomimus dongi (Kobayashi and Lü, 2003), Garudimimus brevipes (Kobayashi and Barsbold, 2005), and an indeterminate ornithomimosaur from Mongolia (Makovicky and Norell, 1998). 
The quadrate is slender (ratio of less than 0.35 ) in posterior view with an expanded lateromedially mandibular articulation, the dorsal portion is particularly narrow and elongated (Figure 13.5-13.7), and both lateral and medial margins converge dorsally to the quadrate head. The quadrate of ornithomimosaurs is inclined posteriorly in the cranium so that the mandibular articulation is always anterior relative to the quadrate head.

The quadrate foramen is present in $S$. dongi (Figure 13.5), G. brevipes (the 'paraquadrate foramen' of Kobayashi and Lü 2003 and the 'paraquadrate foramen' or 'paraquadratic foramen' of Kobayashi and Barsbold 2005 respectively; Figure 13.6-13.7), O. edmontonicus (Makovicky et al., 2004, figure 6.2A; Figure 13.3-13.4) and S. Altus (AMNH 5339) and corresponds to a narrow and lenticular aperture positioned at two-fifths of the quadrate body. The quadrate foramen is equally delimited by the quadrate and quadratojugal in basal forms, and mostly bounded by the quadratojugal in derived forms like $O$. edmontonicus.

The quadrate ridge of ornithomimosaurs is not well-defined except when delimited by the deep posterior fossa which forms a narrow rod-shaped structure subparallel to the long axis passing through the quadrate body (Figure 13.5-13.7). The pterygoid flange is wellvisible in G. brevipes in lateral view (Kobayashi and Barsbold, 2005, figure 4A). The flange is parabolic in shape, with a rounded anterior margin in which the most anterior point occurs at mid-height of the quadrate body. The flange is moderately anteroposteriorly elongated (ratio of 0.58 ) but seems to be much larger than the pterygoid flange of $S$. dongi with a ratio of approximately 0.4 (Kobayashi and Lü, 2003). As S. dongi, the ventral margin of the pterygoid flange of G. brevipes seems to meet the quadrate body just above the mandibular condyles, and the dorsal margin reaches the quadrate head at its base. In G. brevipes, the quadrate head is single headed and fits in the quadrate head of the squamosal (Makovicky et al., 2004). The articulation with the squamosal is not exposed in lateral view in 
Shenzhousaurus orientalis, unlike the condition seen in G. bullatus and O. edmontonicus (Ji et al., 2003).

One of the most diagnostic features of most ornithomimosaur quadrate is the deep, lanceolate and well-defined posterior fossa centrally positioned on the quadrate body and including a small pneumatic foramen (Makovicky et al., 2004; Figure 13.1, 13.3-13.7). Such fossa is present in $S$. dongi (the 'quadrate foramen' of Kobayashi and Lü (2003) and includes an ovoid pneumatopore divided by a vertical septum and located within the dorsal part of the fossa. It also exists in G. brevipes (the 'quadrate foramen' of Kobayashi and Barsbold (2005) whose the elliptical foramen is present ventrally in the depression, and an indeterminate ornithomimosaur (IGM 100-987) in which the deep and strongly elongated posterior fossa includes a tiny subcircular foramen at the most dorsal part of the fossa (Makovicky and Norell, 1998). A deep lanceolate posterior fossa is also present in G. bullatus and S. altus at two-thirds of the quadrate body (pers. obs.), yet it is unknown whether this depression was pneumatic or not. According to Makovicky and Norell (1998), a pneumatic and well-defined posterior fossa is not present in some ornithomimids such as O. edmontonicus (ROM 851, ROM 840). Yet, the specimen RTMP 95.110.1 of $O$. edmontonicus does possess a pneumatic foramen on the posteromedial surface of the quadrate, and leading to a vast pneumatic chamber inside the quadrate bone (Tahara and Larsson, 2011; Figure 13.3).

The ventral quadratojugal contact of the quadrate has a unique morphology among ornithomimids. In S. altus, the ventral part of this contact corresponds to a hear-shape depression facing laterally and bounded by a prominent ridge along its ventral and posterior margin (Figure 13.1). The dorsal part of the ventral quadratojugal contact is, however, a line diminishing in width dorsally to meet the quadrate foramen. In O. edmontonicus, the quadratojugal display a dorsal projection which articulates along this articular surface, and delimits the quadrate foramen posteroventrally. The dorsal quadratojugal contact is located on 
the lateral surface of the quadrate body in G. brevipes, and on the anterior margin of the quadrate body in more derived ornithomimids like $S$. altus and $O$. edmontonicus. The quadrate of ornithomimids does not display a lateral process.

The typical mandibular articulation structure of two condyles separated by an intercondylar sulcus is different in derived ornithomimosaurs. According to Kobayashi and Lü (2003) and Kobayashi and Barsbold (2005), the ecto- and entocondyles of S. dongi and G. brevipes are subequal in size and well-separated by an anteroposterior intercondylar sulcus. Yet the entocondyle is protuberant and projected medially in $S$. dongi, whereas there is an accessory condyle lateral to the ectocondyle and dorsally-positioned relative to the two mandibular condyles (Kobayashi and Lü, 2003). The examination of the quadrate of an undescribed skull of Gallimimus bullatus (IGM 100-1133) supports this morphology of the mandibular articulation of ornithomimids. The accessory condyle of Kobayashi and Lü (2003) corresponds in fact to a lateral extension of the ectocondyle, and the ecto- and entocondyle therefore differ significantly in their morphology (Figure 13.2). Indeed, the ectocondyle is parabolic and comma shaped, with a narrow diagonally elongated lateral part and a wide ovoid medial part, whereas the entocondyle is elliptical, almost spherical. This lateral extension of the ectocondyle articulates with a dorsolateral flange of the surangular, just anterior to the mandibular glenoid (Makovicky et al., 2004). Both mandibular condyles are separated by a wide, shallow and poorly delimited intercondylar sulcus which runs anteroposteriorly (Figure 13.2). In basal ornithomimids like Nqwebasaurus thwazi, the quadrate articulation is not as complex and consists of a lateromedially extended hemicylindrical ectocondyle and a hemispherical entocondyle (Choiniere et al., 2012).

Figure 14

\section{Basal Maniraptora}


Ornitholestes hermanni (AMNH FARB 619; Figure 14.7-14.11); Mononykus

olecranus (Chiappe et al., 2002); Shuvuuia deserti (IGM 100-977, Figure 14.12-14.13; IGM

100-1001, Figure 14.14-14.16; Dufeau, 2003).

The quadrate was comprehensively described in the alvarezsaurids Shuvuuia deserti and Mononykus olecranus (Chiappe et al., 2002), but the cranial bone has not received any detailed description in Ornitholestes hermanni. Although all three taxa are basal members of the Maniraptora, O. hermanni is the most primitive maniraptoran (sensu Senter, 2011; Turner et al., 2012) whereas the two alvarezsaurids are derived forms of Alvarezsauroidea (Nesbitt et al., 2011; Xu et al., 2011; Choiniere et al., 2014), so that their quadrates significantly differ in their morphology.

The left quadrate of $O$. hermanni is crushed and fragmented, and only the right quadrate provides data on the anatomy of this bone. The right quadrate is complete, slightly damaged but strongly deformed in its central part. It is preserved in articulation within the cranium, which is crushed and filled with sediment in its internal part so that few information can be extracted in anterior and medial views. Besides, only the ventral part of the bone is visible, the dorsal part other than the quadrate head, being obscured by the squamosal (Figure 14.7).

The quadrate of $O$. hermanni is tall (0.28). Despite some deformation in the central part of the quadrate body, the quadrate displays a quadrate foramen at one-third of the bone, lateral to the prominent quadrate ridge, and open laterally (Figure 14.8-14.10). The quadrate foramen was mostly bordered by the quadrate as a well-developed ventral projection of the dorsal quadratojugal contact seems to have delimited part of the lateral margin of the quadrate foramen (Figure 14.10). A lateral process with a parabolic outline is visible in lateral view. This process projects anteriorly, yet it is unknown whether it was extending mostly laterally or anteriorly before taphonomic deformation. The ventral quadratojugal contact extends along 
the ventral half of the quadrate body and was most likely anteriorly inclined. There is no quadratojugal process extending from the ventral quadratojugal contact. The quadrate head, only visible in lateral view, is single headed and has a rounded dorsal margin. It is weakly oriented anteriorly and the pterygoid flange is not attached to its dorsal margin. The quadrate ridge is prominent, rod-shaped, laterally inclined and reaches the ectocondyle in its medial section.

In $O$. hermanni, the pterygoid flange only projects anteriorly and its anterior extension is relatively limited compared to other basal coelurosaurs. The anterior margin of the pterygoid flange is parabolic and almost subtriangular, and the anteriormost point of the flange is situated at mid-height of the quadrate body. A deep posterior fossa occupies most of the quadrate body in posterior view, and extends from the mandibular articulation ventrally to at least the quadrate foramen. The mandibular articulation encompasses two condyles subequal in shape, size and orientation, and separated by a wide shallowly concave intercondylar sulcus (Figure 14.11). Both ecto- and entocondyles are elliptical and the angle between the long axis of the mandibular articulation and the main axis passing through the condyles and the intercondylar sulcus is approximately $120^{\circ}$.

S. deserti is the only alvarezsauroid preserving a complete quadrate that has been welldescribed in the literature. Both quadrates of the primitive alvarezsauroid Haplocheirus sollers (Choiniere, Xu, et al., 2010) seems to be preserved as well but neither illustrations nor a description have been provided for the quadrate in this taxon. As for M. olecranus, only the quadrate head, which is double headed and contacts both the squamosal and prootic (Perle et al., 1994; Chiappe et al., 2002), is preserved. Access to both articulated skulls of S. deserti (IGM 100-977; IGM 100-1001) allows to provide a list of unique features in this taxon.

The quadrate is remarkably different from this of other theropods in many aspects. Both specimens have been interpreted as belonging to different ontogenetic stages (Dufeau, 
2003), yet the quadrate of each specimens strongly differ in their morphology so much so that the assignation of both specimens to a same species is questionable. The right quadrate of the largest specimen (IGM 100-977) is complete and well-preserved but only its posterior side is well-visible (Figure 14.12-14.13). The most striking features of this bone is the lateral orientation of the quadrate head, the short and parabolic pterygoid flange, and the notch on the dorsal margin of this flange. In this specimen, the quadrate head seems to be single headed and lateromedially wider than the mandibular articulation. There is a faint quadrate ridge in posterior view but the ridge is well-demarcated in medial view. The dorsal margin of the pterygoid flange is unique in possessing a deep notch which does not seem to result from the loss of a fragment. The mandibular articulation is just a prolongation of the quadrate shaft. It is subrectangular, flat and seems to be unicondylar in posterior view. Nonetheless, a fragment of bone lying on the ventrolateral surface of the pterygoid flange may correspond to the lateral part of the mandibular articulation.

The mandibular articulation of IGM 100-1001 is much wider than the quadrate shaft, and the ventral part of the quadrate body is boot-shaped, i.e., the lateroventral margin is convex, almost pointed, and projects far anteriorly. The lateral process is subtriangular and anterolaterally directed. Its anterior corner contacts both the postorbital and the squamosal, a quadrate autapomorphy of $S$. deserti (Chiappe et al., 1998). A small corner marks the ventral limit of the lateral process. The dorsal quadratojugal contact typically extends to that level in many other theropods but the quadratojugal only articulates at the ventrolateral corner of the quadrate body. As a result, the quadrate foramen is merged with the infratemporal fenestra, which is a second quadrate autapomorphy of S. deserti. The quadrate head of IGM 100-1001 clearly displays two condyles, the squamosal capitulum, directed dorsally to contact the squamosal, and the otic capitulum, oriented medially towards the braincase (Chiappe et al., 1998, 2002). 
The pterygoid flange of IGM 100-1001 extends anteromedially and forms a short subtrapezoidal ala in which the anterior margin is long and posteriorly inclined (Figure 14.15). The anteriormost point of the pterygoid flange is located at one fifth of the quadrate body, and the ventral margin of the flange attaches the quadrate flange just above the mandibular articulation. The pterygoid articulates with the medioventral part of the pterygoid flange close to the quadrate body (Figure 14.16). The mandibular articulation clearly shows two condyles in posterior view, and the ectocondyle is lateromedially longer than the entocondyle. In ventral view, the distinction between the two condyles is more subtle, and both ecto- and entocondyles are elliptical and follows the same orientation than the long axis of the mandibular articulation (Figure 14.16), which is also an autapomorphical feature of $S$. deserti.

\section{Therizinosauria}

Falcarius utahensis (Zanno, 2010; Figure 13.8-13.12); Erlikosaurus andrewsi (Clark et al., 1994).

The quadrate of therizinosaurs has been well-described and illustrated in only two taxa: Erlikosaurus andrewsi (Clark et al., 1994) and Falcarius utahensis (Zanno, 2010). The quadrate morphology in these two specialized theropods is significantly different from other closely related coelurosaurs, and both taxa share a combination of apomorphic characters.

Due to the large quadrate foramen, which is deeply positioned inside the quadrate bone, the quadrate body is constricted at mid-height (Figure 13.10). Both ventral and dorsal parts are lateromedially-expanded, roughly making an hourglass shape of the quadrate body in posterior view. The quadrate is a moderately elongated bone (ratio between $0.38-0.4$ ) whose quadrate ridge is shallow in posterior view. It is very well delimited in medial view in F. utahensis but almost unnoticeable in E. andrewsi. As in many tetanurans, the quadrate 
ridge of $F$. utahensis is laterally-inclined and becomes marked just above the entocondyle and reaches the quadrate head (Figure 13.10). The medial margin of the quadrate body of these two therizinosaurs is biconcave, and the convexity separating the two concavities is situated at one third of the quadrate body in E. andrewsi and at two thirds in F. utahensis.

The quadrate foramen is mostly delimited by the quadrate in therizinosaurs, and the ventral projection of the dorsal quadratojugal contacts delimits an important part of the foramen laterodorsally in F. utahensis (Figure 13.10). The shape of the quadrate foramen is lenticular in E. andrewsi and a reversed teardrop in F. utahensis.

The lateral process is here considered as present in F. utahensis (Figure 13.9) and E. andrewsi because there is a short lateral projection of the quadrate body from above the quadrate foramen to the quadrate head in both taxa. The lateral process projects completely laterally in F. utahensis whereas it extends anterolaterally in E. andrewsi, and the lateral margin of this process is parabolic in outline in these two therizinosaurs.

The pterygoid flange is short in therizinosaurs, particularly in F. utahensis (Figure S10K) whose ratio between the anteroposterior width and the ventrodorsal length of the quadrate body is significantly low (0.33). The anterior margin of the flange is M-shaped in $F$. utahensis (Figure $\mathrm{S} 10 \mathrm{~K}$ ) while the pterygoid flange of $E$. andrewsi is parabolic with a small concavity at its anteroventral margin (Clark et al., 1994, figure 2). In both therizinosaurs, the pterygoid flange projects anteromedially but does not curve medially. In addition, the ventral margin of the pterygoid flange meets the quadrate body well-above the entocondyle and the dorsal margin reaches the ventral base of the pterygoid flange. Interestingly, in E. andrewsi the prootic and basipshenoid contact the pterygoid flange posterodorsally. Although the cranium of this taxon has been strongly deformed and this part of the skull has been badly preserved, a contact between the pterygoid flange and the braincase seems to be genuine. A similar contact between those bones also occurs in the oviraptorosaur Avimimus portentosus. 
In therizinosaurs, the dorsal quadratojugal contact is positioned on the anterior side of the short lateral process (Figure 13.8). This contact also possesses a ventral projection widely expanded in F. utahensis whereas such projection is absent in E. andrewsi. The dorsal quadratojugal contact corresponds to an elongated line in F. utahensis (Figure 13.8) and E. andrewsi. The ventral quadratojugal contact is elliptical and situated just above the ectocondyle in F. utahensis (Figure 13.9) and E. andrewsi but this suture with the quadratojugal is much broader anteroposteriorly in the former, and it is narrow and oblong in the latter.

The mandibular articulation is formed by two condyles in F. utahensis (Figure S10L) and by three condyles in E. andrewsi (Clark et al., 1994). The mandibular condyles are ovoid to subcircular in both therizinosaurs. In F. utahensis, the ectocondyle is ovoid and the long axis passing through it is inclined laterally by an angle of $130^{\circ}$ relative to the long axis of the mandibular articulation (Figure 13.12). The entocondyle is protuberant and separated from the ectocondyle by a very broad but shallow intercondylar sulcus, which is parallel to the long axis of the lateral condyle. The three mandibular condyles of E. andrewsi are well developed, with a larger ectocondyle, a medium entocondyle (two thirds of the size of the ectocondyle) and a third much smaller condyle (half of the size of the entocondyle) lying posteriorly between the two (Clark et al., 1994).

A wide pneumatic recess appears in the ventromedial part of the flange in $F$. utahensis (Figure 13.11). This recess of $F$. utahensis penetrates deeply inside the pterygoid flange and quadrate body, and is strongly displaced laterally, contrarily to the medial pneumatopores of other theropods (Figure 13.8). This lateral displacement implies the fact that the ventralmost margin of the pterygoid flange meets the quadrate body at the same level than the intercondylar sulcus rather than close to the entocondyle. Although pneumaticity might have been present in the quadrate of $E$. andrewsi, it is not conspicuously expressed like in $F$. 
utahensis. Clark et al. (1994) inferred the possible existence of a pneumatic foramen in a posteromedial depression near the dorsal margin of the bone, which is not observable due to crushing. Nevertheless, a large medial pneumatic recess is not present in E. andrewsi.

\section{Figure 15}

\section{Oviraptorosauria}

Incisivorosaurus gauthieri (Balanoff et al., 2009); Avimimus portentosus (Kurzanov, 1985; Vickers-Rich et al., 2002; Figure 15.1-15.4); Citipati osmolskae (IGM 100-978; Figure 15.5-15.8); Khaan mckennai (IGM 100-1002; IGM 100-1127; Balanoff and Norell, 2012; Figure 15.9-15.12); Heyuannia huangi (Lü, 2003); Conchoraptor gracilis (Kundrát and Janáček, 2007); Oviraptoridae gen. et sp. indet. (Maryańska and Osmólska, 1997).

The anatomy of the quadrates of some derived oviraptorids (Oviraptor? sp. and Ingenia yanshini or Conchoraptor gracilis) has been comprehensively investigated by Maryańska and Osmólska (1997) and the quadrate anatomy of more basal oviraptorosaurs and other oviraptorids is well-documented in the literature with only good descriptions of the bone in some taxa such as Incisivorosaurus gauthieri (Balanoff et al., 2009), Avimimus portentosus (Kurzanov, 1985; Vickers-Rich et al., 2002), Citipati osmolskae (Chiappe et al., 2002) and Khaan mckennai (Balanoff and Norell, 2012). As noticed by Maryańska and Osmólska (1997), the quadrate of oviraptorids, and to some extend oviraptorosaur theropods, is atypical because of the shape of its mandibular articulation, its contact with the pterygoid and, especially, its quadrate head. In the present paper, the quadrate of the basal oviraptorosaur $A$. portentosus (PIN 3907/1) will be described before summarizing the synapomorphic characters found in Oviraptoridae.

In A. portentosus, the quadrate is uncommonly fused to the braincase and the pterygoid flange (Figure 15.1-15.3). The quadrate body is concave all along the bone and has 
subparallel lateral and medial margins ventrally. Dorsally, the quadrate body enlarges at about two-fifths of the bone height, where the pterygoid flange meets the quadrate body at its medial margin. The ventral part of the pterygoid flange, rather than projecting anteriorly or anteromedially as all nonavian theropods, curves medially to contact the braincase on its posterior side. In ventral view, the dorsal part of the pterygoid flange is oriented anteromedially and fuses to the pterygoid flange anteriorly and the endocranium anterodorsally (Figure 15.4). In lateral view, the anterior margin of the pterygoid flange is parabolic and the most anterior point is situated at one third of the quadrate (Figure 15.1$15.3)$.

What is here interpreted as being a ventral projection of the pterygoid bone contacts the quadrate body on its anteroventral side just above the mandibular articulation (Figure 15.4). If our interpretation is correct, this would be an autapomorphic character for $A$. portentosus. This elongated bone was interpreted by Kurzanov (1985) as being intergrown jugal and quadratojugal bones. However, the presence of a well-visible ventral quadratojugal contact on the lateral side of the left quadrate as well as a pterygoid contact on the anteroventral margin of the right quadrate makes this interpretation doubtful. Due to the absence of both quadratojugals in PIN 3907/1, it is hard to assume the presence of a quadrate foramen. However, the quadratojugal contact of the quadrate seems to form a unique suture along the lateral margin of the quadrate body. The ventral portion of the suture is anteroposteriorly widened and lanceolate, whereas the dorsal part is a very narrow, elongated contact receiving both the quadratojugal and the squamosal. A short anterior projection occurs on the anteroventral part of the quadrate body, at the level of the ectocondyle but just above it. The quadrate head is unfortunately not completely visible in PIN 3907/1, but close observation suggests that the quadrate head was in contact with the squamosal and the braincase (Figure 15.1). The mandibular articulation of A. portentosus is formed by two 
elliptical and subparallel condyles of the same size (Figure 15.4). These two condyles are delimited by a narrow and shallow intercondylar sulcus parallel to the main axis passing through the two condyles and inclined medially. There is no pneumatic foramen in $A$. portentosus and the quadrate is obviously apneumatic in this taxon.

The quadrate of oviraptorid theropods is highly diagnostic given the combination of the following features, namely: an "Eiffel-tower" shape of the quadrate body in posterior view, terminating dorsally by a conical double-headed quadrate head formed by the squamosal and otic capitula; a pterygoid contact on the medial side of the quadrate body and touching the entocondyle (this might not however be the case in C. gracilis, see (Kundrát and Janáček, 2007, figure 2D), and a W-shaped mandibular articulation with a pointing ventromedial margin of the quadrate body in posterior view (Figure 15.6).

The quadrate foramen is medium-sized, lenticular, equally formed by the quadrate and quadratojugal and visible in lateral view (Figure 15.6). The oviraptorid quadrate ridge is not well-delimited in posterior view, but it is strongly inclined laterally and has a biconcave medial margin. As most tetanurans, there is no lateral process projecting from the quadrate body (Figure 15.10). The double-headed quadrate head is tall and conical, with a rounded tip pointing dorsally, and a small constriction separates the head from the rest of the quadrate body.

The pterygoid flange mostly projects anteriorly and slightly curves medially, and in $C$. osmolskae and K. mckennai the flange is subtrapezoidal in shape with a straight (and short in K. mckennai) anteriormost margin inclined posteriorly (Figure 15.9) like in most basal theropods. The ventral quadratojugal contact is broad, lanceolate and extends on the posterior side of the quadrate body. In some oviraptorids such as C. osmolskae, an ventral process projects laterally from the ventral part of this articulation to contact the quadratojugal dorsally (lateral process sensu Maryańska and Osmólska, 1997). Among nonavian theropods, such 
ventral process only exists in oviraptorids. The dorsal quadratojugal contact forms a narrow and elongated line for receiving the dorsal quadratojugal process. The ventral margin of the pterygoid flange meets the quadrate body close to the mandibular articulation, at the level of the entocondyle and just dorsal to the latter (Figure 15.7).

A pneumatic quadrate has been reported in several troodontids, including $K$. mckennai (Balanoff and Norell, 2012), Heyuannia huangi (Lü, 2003), and C. gracilis (Kundrát and Janáček, 2007). No pneumatic foramen is visible in the posterior surface of $K$. mckennai and C. gracilis, however there is indication that the dorsal tympanic recess of $C$. gracilis invades the multichambered quadrate pneumatic sinus through an opening on the medial side of the otic capitulum (Kundrát and Janáček, 2007). In H. huangi, a pneumatic foramen is autapomorphically located on the ventrolateral surface of the pterygoid flange. On the other hand, an elliptical pneumatopore is present on the ventromedial surface of the pterygoid flange in some oviraptorid specimen of Mongolia (Maryańska and Osmólska, 1997). This large and ventrodorsally elongated pneumatic opening is subdivided into numerous hollow compartments and leads into a pneumatic chamber invading the quadrate shaft, mandibular articulation, and ventral part of the pterygoid flange (Maryańska and Osmólska, 1997).

Figure 16

\section{Dromaeosauridae}

Buitreraptor gonzalezorum (MPCA 245); Bambiraptor feinbergi (AMNH FARB 30556; Figure 16.1-16.6); Tsaagan mangas (IGM 100-1015; Figure 16.7-16.11); Dromaeosaurus albertensis (AMNH FARB 5356; Figure 16.12-16.17); Velociraptor mongoliensis (AMNH 6415; Sues, 1977; Barsbold and Osmólska, 1999); Sinornithosaurus millenii (Xu and $\mathrm{Wu}, 2001)$. 
Isolated quadrates of dromaeosaurid theropods have been well-illustrated for Tsaagan mangas (Norell et al., 2006) and Bambiraptor feinbergi (Burnham, 2004), and a detailed description of the bone is given for Tsaagan mangas (Norell et al., 2006), Dromaeosaurus albertensis (Colbert and Russell, 1969; Currie, 1995), Velociraptor mongoliensis (Sues, 1977; Barsbold and Osmólska, 1999), and Sinornithosaurus millenii (Xu and Wu, 2001).

As many other clades of theropods, the quadrate of Dromaeosauridae is highly diagnostic. The quadrate is particularly short (ratio of the elongation of the quadrate body higher than 0.5) due to an important lateromedial expanded mandibular articulation (Figure 16.3-16.7). The quadrate body has a well-marked quadrate ridge laterally-inclined and getting marked from or right above the entocondyle to reach the quadrate head, as in T. mangas, $V$. mongoliensis, and D. albertensis. The quadrate head of derived dromaeosaurid such as $V$. mongoliensis (Barsbold and Osmólska, 1999), D. albertensis (Currie, 1995), B. feinbergis (Burnham, 2004) and T. mangas (Norell et al., 2006) is single-headed and articulates exclusively with the squamosal. A 'bistylic quadrate head' (sensu Turner et al., 2007) is present in the basal dromaeosaurid Mahakala omnogovae and may have been articulated with the squamosal and the prootic of the braincase (Turner et al., 2007, 2011). However, the quadrate head is not double-headed "but the compressed rectangular profile coupled with the abrupt change to a triangular cross section gives the articular portion of the quadrate a medially directed 'head'" (Turner et al., 2011, p.8).

The quadrate foramen is well-visible in lateral view and typically large (Paul, 1988; Barsbold and Osmólska, 1999), forming a lanceolate fenestra equally delimited by the quadrate and quadratojugal. In some dromaeosaurids like T. mangas and B. feinbergis, the quadrate foramen is delimited ventrally by an elongated quadratojugal process, i.e., a welldeveloped projection of the ventral quadratojugal contact of the quadrate (Figure 16.2-16.8). This quadratojugal process is present in many theropods such as Spinosauridae and 
Allosauridae, yet the process does not extend much anteriorly, unlike the condition seen in dromaeosaurids. The quadratojugal process is short in the basal dromaeosaurid Buitreraptor gonzalezorum.

The dorsomedial margin of the quadrate foramen is formed by a subtriangular or parabolic lateral process. This process is particularly well-developed in Buitreraptor gonzalezorum (MPCA 245), B. feinbergi (FIP 001; Figure 16.3), T. mangas (IGM 100-1015; Figure 16.8), and V. mongoliensis (Barsbold and Osmólska, 1999) and much shorter in $D$. albertensis (AMNH 5356; Figure 16.14) and S. millenii (Xu and $\mathrm{Wu}, 2001)$. The orientation of the lateral process is variable among dromaeosaurids, projecting laterally in D. albertensis, and B. gonzalezorum, and being anterolaterally oriented in T. mangas and Adasaurus mongoliensis. The lateral process of the latter is apomorphically displaced dorsally, with the anteriormost point of the process being situated at fourth fifth of the quadrate body, slightly below the quadrate head (Turner et al., 2012). A subtriangular lateral process was previously thought to be unique among Dromaeosauridae but, as noted by Agnolin and Novas (2011), this feature also exists in many basal theropods and basal Avialae such as Archaeopteryx lithographica (Walker, 1985). Nevertheless, the morphology of the lateral process of some dromaeosaurids can be apomorphic in possessing a subrectangular projection receiving the dorsal process of the quadratojugal, as in T. mangas (Figure 16.8).

The atypical pterygoid flange in dromaeosaurid theropods corresponds to a subtriangular flange formed by two elongated sides meeting ventrally in the quadrate body, at one-third or one-fourth of the quadrate bone (Xu and $\mathrm{Wu}, 2001$; Figure 16.4, 15.10, 15.13). The ventral margin of the pterygoid flange meets the quadrate body well-above the entocondyle, whilst the dorsal margin attaches to the quadrate body just beneath the articulating surface of the quadrate head. The dorsal margin of the pterygoid flange is apomorphically columnar in S. millenii (Xu and Wu, 2001), the margin being thickened and 
round along most of the flange, contrasting with the thin dorsal margin of the pterygoid flange of other theropods. However, a columnar posterior margin of the pterygoid flange has also been observed in an undescribed troodontid (IGM 100-1128). The flange can either be straight and projecting anteromedially like in B. feinbergi and D. albertensis (Colbert and Russell, 1969, figure 9), or slightly curved anteromedially as in T. mangas.

The medial fossa, posteroventrally situated on the pterygoid flange, is shallow and does not host a pneumatic recess. A posterior fossa lies on the posterior side of the quadrate body at mid-height of the quadrate body in T. mangas (Norell et al., 2006) and B. feinbergi (FIP 001). The mandibular articulation consists of an ovoid to oblong entocondyle delimited from the elongated, narrow and sigmoid/parabolic ectocondyle by a deep intercondylar sulcus (Figure 16.6, 15.11, 15.17). The intercondylar sulcus is diagonally-oriented and its main axis is sometimes parallel to the main axis passing through the entocondyle. In posterior view, both ecto- and entocondyles are strongly lateromedially-elongated and shortly ventrodorsallyexpanded. They are delimited by the shallow intercondylar sulcus giving sometimes to the mandibular articulation a convex form, rather than a well-marked biconvex shape like in most other nonavian theropods.

A pneumatic quadrate is absent in T. mangas (Norell et al., 2006), B. feinbergi (Burnham, 2004), V. mongoliensis (Barsbold and Osmólska, 1999) and D. albertensis (Currie, 1995) but present in the basal dromaeosaurid B. gonzalezorum (Makovicky et al., 2005) suggesting that the quadrate may have been pleisiomorphically pneumatic in dromaeosaurids. The pneumatopore of B. gonzalezorum is deep and subcircular, and the pneumatic opening is located on the posterolateral side of the quadrate body, at the level of the ventral part of the lateral process (Makovicky et al., 2005, figure 2E).

\section{Troodontidae}


Anchiornis huxleyi (Hu et al., 2009); Xiaotingia zhengi (Xu et al., 2011); Mei long (Xu and Norell, 2004; Gao et al., 2012); Sinovenator changii (Xu et al., 2002); Troodon formosus (Currie and Zhao, 1993a); Saurornithoides mongoliensis (Norell and Hwang, 2004); Troodontidae gen. et sp. indet. (Barsbold et al., 1987); Undescribed Troodontidae (IGM 1001128; IGM 100-1323).

Information regarding quadrate anatomy of Troodontidae (sensu Turner et al., 2012 and Godefroit et al., 2013) is very scarce in the literature because most troodontid taxa such as Saurornithoides mongoliensis (Russell, 1969; Barsbold, 1974; Norell et al., 2009), Zanabazar junior (Norell et al., 2009), Byronosaurus jaffei (Makovicky et al., 2003; Bever and Norell, 2009), Sinovenator changii (Xu et al., 2002), Xixiasaurus henanensis (Lü et al., 2010), and Troodon formosus (Currie, 1985; Currie and Zhao, 1993a) either preserved just a small portion of the quadrate or did not have preserved the bone at all. Nevertheless, the quadrates of Mei long, Anchiornis huxleyi and Xiaotingia zhengi are visible in lateral view; the left quadrate of an indeterminate troodontid lacking the pterygoid flange (IGM 100-44) was briefly described and illustrated in posterior view by Barsbold et al. (1987), and a wellpreserved ventral portion of a right quadrate probably belonging to Saurornithoides mongoliensis has been described by Norell and Hwang (2004). Likewise, the quadrate bone of two undescribed troodontid skulls (IGM 100-1128; IGM 100-1323) from the Upper Cretaceous of Mongolia are also preserved, yet only IGM 100-1128 shows undistorted and relatively complete left and right quadrates.

The troodontid quadrate is moderately, almost strongly elongated (ratio of 0.353 in IGM 100-1128 and 0.4 in IGM 100-44). Both quadrates of IGM 100-1128 are found in articulation within an undistorted skull and their mandibular articulation lies at the same level than the alveolar margin of the upper jaw. This is, however, not the case in M. long and $A$. huxleyi in which the mandibular articulation projects well ventral from the ventral margin of 
the upper jaw. In IGM 100-1128, the ventral half of the quadrate body extends horizontally, perpendicular to the ventral margin of the cranium, whereas the dorsal half is strongly inclined posteriorly so that the quadrate is inclined posteriorly in the cranium and the mandibular articulation is always anterior relative to the quadrate head. A similar condition occurs in A. huxleyi (Hu et al., 2009, figure S2d). The dorsal margin of the quadrate body is parabolic in outline in lateral view in IGM 100-1128, and the medial margin is biconcave. The quadrate ridge is rod-shaped and prominent at one third of the quadrate and along the second third of the quadrate body. The quadrate ridge does not extends to the entocondyle but reaches the quadrate head in a fainted way.

The quadrate head of IGM 100-1128 is clearly monostylic and contacts the braincase medially. This is the case of the quadrate heads of other troodontid taxa which are also single headed (Currie, 1985; Barsbold et al., 1987) and mostly contacts the squamosal (Currie and Zhao, 1993a) and other bones of the braincase (exoccipital/opisthotic and prootic), as noted in T. formosus (Currie and Zhao, 1993a), S. mongoliensis (Norell et al., 2009), the perinate Byronosaurus sp. (Bever and Norell, 2009) and Sinornithoides youngi (Russell and Dong, 1993).

The ventral quadratojugal contact of troodontids is ventro-dorsally elongated, lanceolate, and inclined medially in posterior view. The ventral quadratojugal contact faces posterolaterally in IGM 100-1083, and laterally in IGM 100-1128 and IGM 100-44 (Barsbold et al., 1987, plate 49 figure 4). There is no contact with the quadratojugal along the dorsal part of the quadrate body in $M$. long as the quadratojugal of this taxon only gets attached to the lower part of the quadrate body, at the level of the mandibular articulation. Both quadratojugal and lateral margin of the quadrate are incomplete in IGM 100-1128 and the presence of a quadrate foramen and a dorsal quadratojugal contact cannot be ruled out in this specimen. A large quadrate foramen similar to this of dromaeosaurids has been noted in $X$. 
zhengi (Xu et al., 2011). Likewise, the notched lateral margin of the quadrate has been interpreted as contributing to a large quadrate foramen in A. huxleyi (Hu et al., 2009, figure S2d). The quadrate foramen seems to be equally delimited by the quadrate and quadratojugal in these two taxa. However, there is no evidence of a quadrate foramen, nor a dorsal quadratojugal contact on the quadrate of more derived troodontids hitherto.

The anterior margin of the pterygoid flange of M. long (Xu and Norell, 2004, figure 1B) and IGM 100-1128 is parabolic in outline and almost subrectangular. The most anterior points is situated at one third of the quadrate body in both specimens. Similar to the condition seen in Dromaeosauridae, the ventral margin of the pterygoid flange contacts the quadrate body well-above the entocondyle, and the posterior margin of the flange is strongly inclined anteroventrally. The dorsal margin of the flange meets the quadrate head beneath the articular surface of the head, and the flange is straight and projects only anteriorly. Nevertheless, the pterygoid flange of Troodontidae is particularly short anteroposteriorly (ratio of $0.25-0.3 ; \mathrm{Xu}$ et al., 2011), which is not the case in dromaeosaurids. Some troodontids such as A. huxleyi and $X$. zhengi possess a well-developed lateral process (Hu et al., 2009; Xu et al., 2011). It is however unknown whether this process is present in more derived troodontid taxa.

The mandibular articulation of troodontid quadrates has only been well-illustrated and well-described in IGM 100-1083 by Norell and Hwang (2004). As in some oviraptorids and dromaeosaurids, the medial margin of the mandibular articulation of IGM 100-1083 is pointed in posterior view, but the medial corner is oriented medially. On the other hand, the medial margin of the entocondyle is rounded and does not show this medial corner in IGM 100-44 and IGM 100-1128, yet the ventral margin of the ectocondyle is pointed in posterior view in both specimens. In ventral view, the mandibular articulation of IGM 100-1083 is composed of two condyles separated by a shallow and almost indistinct intercondylar sulcus. The condyles are roughly oval and the entocondyle is larger than the ectocondyle, as observed 
in IGM 100-44 (Barsbold et al., 1987, plate 49 figure 4) and IGM 100-1128 in posterior view. There is no quadratojugal process in IGM 100-1083 and IGM 100-1128.

Quadrate pneumaticity in Troodontidae is well-known (Varricchio, 1997) and has been reported in a Jurassic troodontid (Hartman et al., 2005), T. formosus (Currie and Zhao, 1993a), S. changii (Xu et al., 2002), M. long (Xu and Norell, 2004; Gao et al., 2012) and X. zhengi (Xu et al., 2011) where a posterior pneumatopore has been observed on the quadrate body in the two later taxa. This is also the case of the quadrate described by Barsbold et al. (1987) which displays a small pneumatic foramen positioned medially on the posterior surface of the quadrate body, at mid-height of the bone, and leading to a canal (Barsbold et al., 1987). However, all troodontids may not possess a pneumatic quadrate because no pneumatic chamber has been observed in the broken quadrate of IGM 100-1083 (Norell and Hwang, 2004).

\section{DISCUSSION}

\section{Cladistic Analysis}

This cladistic analysis performed based on a character datamatrix related to one single bone gives strikingly similar results to those from analyses using characters from the entire skeleton (Figures $1 \& 2$ ). The well-resolved tree follows the topology of the classification of nonavian theropods, thus demonstrating the phylogenetic value of the quadrate and offering more quadrate-related characters to be used in future cladistic analyses.

Expectedly, when analyzed in a phylogenetic context, the morphology of the quadrate retrieves all major nonavian theropod clades (Neotheropoda, Ceratosauria, Tetanurae and Avetheropoda) as well as more restricted clades (e.g., Abelisauroidea, Abelisauridae, Megalosauridae, Spinosauridae, Carcharodontosauridae, Tyrannosauridae, Dromaeosauridae) 
supporting the idea that many quadrate synapomorphies contribute to clarifying nonavian theropod relationships.

Although the major clades of nonavian theropods have been found resolved by this analysis, some important discrepancies with the current classification of theropods are apparent. The disparate position of basal and derived Allosauroidea is the most striking and can be explained by the following characters: the shape of the ventral part above the mandibular articulation on the posterior surface of the quadrate body (chars. 8) and the morphology of the mandibular articulation (char., 20, 28, 19) and the quadrate foramen (char. 73, 76). In basal allosauroids (Allosauridae, Sinraptoridae and Neovenatoridae), the posterior surface of the quadrate body dorsal to the mandibular articulation is deeply concave whereas it is strongly convex in Carcharodontosauridae. In addition, the mandibular articulation of carcharodontosaurids is mediolaterally longer than those of basal allosauroids: the ectocondyle is elongated, parabolic and with a sigmoid anterior margin, convergent with the ectocondyle morphology of dromaeosaurids, whereas in other allosauroids, the ectocondyle is shorter, ovoid and with a convex anterior margin in ventral view. As in dromaeosaurids, the quadrate foramen of carcharodontosaurids is also equally delimited by the quadrate and quadratojugal and situated well ventral to the mid-height of the quadrate body. In basal allosauroids, and by convergence with therizinosaurs, the quadrate foramen is roughly positioned at mid-height of the quadrate, mostly delimited by the quadrate and elliptical or bean-shaped in shape.

The results of the phylogenetic analysis allow the identification of evolutionary trends of the quadrate across the clade of Theropoda. Our intention is to propose simple hypotheses as a result of our phylogenetic results and anatomical overview, the understanding of the functional reasons and interdependence of anatomical sub-units will be reserved for another study. The major trends can be summarized as follows: decrease of the elongation of the 
quadrate body and enlargement of the mandibular articulation across the evolution of Theropoda and specifically across the evolution of Megalosauroidea and Tyrannosauroidea; increase of the quadrate ridge width across the evolution of Megalosauroidea and decrease of it in Tyrannosauroidea and Coelophysoidea; loss of the quadrate foramen in Ceratosauria and Megalosauridae; reduction of the size of the quadrate foramen during the evolution of the Spinosauridae and increase of the foramen size in Tyrannosauroidea; increase of the contribution of the quadratojugal in the quadrate foramen during the evolution of Allosauroidea and Coelurosauria; loss of the lateral process in Tetanurae; dorsal displacement of the anteriormost point of the pterygoid flange in Ceratosauria and Megalosauroidea, and ventral displacement of this point during the evolution of Dromaeosauridae and Therizinosauria; development of two capitula in the quadrate head during the evolution of Oviraptorosauria (and convergently in Avialae); lateromedial elongation of the mandibular articulation during the evolution of Megalosauroidea, Allosauroidea and Maniraptoriformes, and increase of the anteroposterior thickness during the evolution of Ceratosauria; development of a sigmoid ectocondyle in Dilophosauridae and Spinosauridae, and an ovoid ectocondyle in Abelisauroidea, Oviraptorosauria, basal Allosauroidea, Tyrannosauroidea and Therizinosauria; and pneumatization of the quadrate in some tetanuran clades.

\section{Major Trends in the Evolution of the Quadrate in Nonavian Theropods}

The results of the phylogenetic analysis allow the identification of evolutionary transformations of the quadrate across the theropod clade which can be summarized as follows:

Quadrate body. Decrease of the elongation of the quadrate body and enlargement of the mandibular articulation across the evolution of Theropoda and specifically across the evolution of Tyrannosauroidea and Megalosauroidea leading to Spinosauridae. Elongated 
quadrates with short mandibular articulation can be seen in ceratosaurs and ornithomimosaurs while short quadrates with broad mandibular articulation are present in spinosaurids, tyrannosaurids and dromaeosaurids.

Quadrate ridge. Increase of the ridge width across the evolution of Megalosauroidea and decrease of it in Tyrannosauroidea and Coelophysoidea. Most of nonavian theropods have rod-shaped ridges but the Coelophysoidea, Tyrannosauridae and the neovenatorid Aerosteon have a narrow crest-like ridge, whereas the Spinosauridae possess a very broad stick-like ridge. The quadrate ridge is usually well delimited in nonavian theropods but a very shallow ridge can be observed in abelisauroids, Eustreptospondylus, ornithomimosaurs, therizinosaurs and oviraptorosaurs. In anterior view, the ridge is only visible in Abelisauridae.

Quadrate foramen. 1) Loss of the quadrate foramen independently in Ceratosauria and Megalosauridae. 2) Reduction of the size of the foramen during the evolution of the Spinosauridae and increase of the foramen size in Tyrannosauroidea. A small quadrate foramen exists in non-tetanuran theropods, spinosaurines and basal Tyrannosauroidea while a large quadrate foramen (or quadrate fenestra) can be observed in some Baryonychinae, Tyrannosauroidea, Alvarezsauroidea and Dromaeosauridae. 3) Increase of the contribution of the quadratojugal in the quadrate foramen during the evolution of Coelurosauria. The quadrate foramen is mostly delimited by the quadrate in all nonavian theropods but Maniraptoriformes (except Falcarius) where the contribution of the quadrate and quadratojugal in the foramen is roughly equal.

Lateral process. 1) Loss of the lateral process in Tetanurae. A lateral process is absent in basal tetanurans, megalosauroids, and some basal averostrans. A very well-developed subtriangular lateral process anterolaterally oriented exists in basal theropods and ceratosaurs but also in alvarezsaurids, derived therizinosauroids, and dromaeosaurids where this structure reappears. 2) Ventral displacement of the ventral margin of the lateral process during the 
evolution of Ceratosauria. In basal-most theropods, coelophysoids (Dilophosauridae + Coelophysidae), some ceratosaurs (Ceratosauridae + Noasauridae), derived therizinosauroids, alvarezsauroids, and dromaeosaurids, the lateral process extends ventrally at mid-height of the quadrate body, from the quadrate foramen when present. However, in Abelisauroidea the lateral process extends ventrally to the mandibular articulation or just above it.

Pterygoid flange. 1) Dorsal displacement of the anteriormost point of the pterygoid flange in Ceratosauria and Megalosauroidea, and ventral displacement of this point during the evolution of Dromaeosauridae and Therizinosauria. The anteriormost point of the pterygoid flange of most nonavian theropod is situated at mid-height of the quadrate in lateral/medial views. On the other hand, this point is situated at two-thirds of the quadrate in ceratosaurs and megalosauroids, and at one-third of the quadrate in Erlikosaurus, Zuolong and some dromaeosaurids. 3) Appearance of a medial fold of the ventral margin of the pterygoid flange in Ceratosauria and disappearance of it in Megalosauridae, derived Carcharodontosauridae and Coelurosauria. A straight ventral margin of the pterygoid flange is present in basal theropods, megalosaurids, derived carcharodontosaurids and coelurosaurs. The ventral margin of this flange is folded medially in ceratosaurs, basal tetanurans, spinosaurids, sinraptorids and neovenatorids, and mediodorsally or dorsally folded in allosaurids and basal carcharodontosaurids.

Quadrate head. 1) Dorsal displacement of the quadrate head to or close to the level of the dorsal margin of the orbit in Ceratosauria and Megalosauridae. A quadrate head at the level or slightly ventral to the dorsal margin of the orbit can be seen in most ceratosaurs and megalosaurids whereas all other nonavian theropods show a quadrate head well ventral to the dorsal margin of the orbit. 2) Decrease of quadrate head width (relative to the width of the mandibular articulation) across the evolution of Allosauroidea and Dromaeosauridae. 3) Development of two capitula in the quadrate head during the evolution of Oviraptorosauria 
and Alvarezsauridae (and convergently in Avialae). The quadrate head is single headed in most nonavian theropods other than oviraptosaurids and the derived alvarezsaurid Shuvuuia which possess two well-distinguished heads contacting the squamosal and the braincase. Mandibular articulation. 1) Ventral displacement of the mandibular articulation in Spinosauridae and Avetheropoda, and dorsal displacement of this articulation at the same level than the alveolar margin of the maxilla in Tyrannosauridae. A mandibular articulation at the level of the ventral margin of the maxilla can be seen in most basal Theropoda, most Ceratosauria, basal Tetanurae, Megalosauridae and Tyrannosauridae. On the other hand, a mandibular articulation projecting well-ventral of the alveolar margin of the cranium exists in Irritator, the coelophysoid Zupaysaurus and most avetheropods. 2) Lateromedial elongation of the mandibular articulation during the evolution of Megalosauroidea, Allosauroidea and Maniraptoriformes, and increase of the anteroposterior thickness during the evolution of Ceratosauria. A very mediolaterally broad mandibular articulation (ratio $>3$ ) exits in Spinosauridae, Carcharodontosauridae and Deinonychosauria whereas a particularly anteroposteriorly broad mandibular articulation (ratio < 2) appears in Ceratosauria. Entocondyle. Increase of the entocondyle width during the evolution of Ceratosauria, Oviraptorosauria and some Megalosauridae. Among nonavian theropods, an entocondyle larger than the ectocondyle exists in Abelisauroidea, Oviraptoridae and the megalosaurid Afrovenator.

Ectocondyle. Development of a sigmoid ectocondyle in Dilophosauridae and Spinosauridae, and an ovoid ectocondyle in Abelisauroidea, Oviraptorosauria, basal Allosauroidea, Tyrannosauroidea, and Therizinosauria.

Pneumacity. 1) Pneumatization of the quadrate independently in Neovenatoridae, Carcharodontosauridae, Tyrannosauridae and Maniraptoriformes. 2) Reduction of the size of the medial pneumatopore in derived Carcharodontosauridae. 


\section{Phylogenetic Morphometrics Analysis}

Phylogenetic morphometrics characters are being proposed for the first time for Dinosauria. By exclusively analyzing the ventral view of the mandibular articulation of nonavian theropods (analysis 2, character 2; Figure 2.2) two distinct 'morphoclades' emerged from the analysis. This presents evidence of two fundamentally distinct morphotypes with possible functional implications.

The first morphotype mandibular articulation (morphotype A) is characterized by: an anteroposteriorly broad mandibular articulation, two ovoid/subcircular ecto- and entocondyles roughly subequal in size, and an intercondylar sulcus in which the angle formed by the main axis of the sulcus and the long axis of mandibular articulation is relatively low $\left(<135^{\circ}\right)$. This morphotype is present in all ceratosaurs but also in oviraptorosaurs, therizinosaurs, tyrannosaurids and some non-carcharodontosaurid allosauroids. Morphotype A is present in a large variety of nonavian theropods, from the small and slender oviraptorosaurs to the large and robust tyrannosaurids. However, all of these taxa share a roughly similar articulation with the lower jaw. In these theropods, the two rami of the mandibles are weakly displaced laterally when the mouth opened, due to the weakly elongated mandibular articulation lateromedially and the ectocondyle, and an angle of the intercondylar sulcus lower than in the second morphotype.

On the other hand, the second morphotype (morphotype B) corresponds to: an elongate and anteroposteriorly narrow mandibular articulation, a long and parabolic/sigmoid ectocondyle much longer than the entocondyle, and an intercondylar sulcus in which the angle between the main axis passing through the sulcus also the long axis of the mandibular articulation is high $\left(>135^{\circ}\right)$. This combination of features allows the lower jaw rami to be slightly to strongly displaced laterally when sliding along the intercondylar sulcus of the 
quadrate. Morphotype B can be seen in a large variety of theropods as they include all megalosauroids but Afrovenator, the dromaeosaurids and the carcharodontosaurids. Once again, although these theropods with morphotype B show some important morphological disparity in their skull and body, it seems that their mandibular articulation was morphofunctionally convergent. These theropods were able to enlarge the pharynx by opening the mouth like some ornithocheiroid pterosaurs and living pelecanid birds (Wellnhofer, 1980; Bennett, 2001; Hendrickx and Buffetaut, 2008).

The presence of Aerosteon and Acrocanthosaurus at the base of each 'morphotypes' clearly demonstrates the transition from one morphotype to the other during the evolution of Allosauroidea. Likewise, the presence of Allosaurus in both morphotypes implies some important variability of the mandibular articulation among this particular taxon.

Although their skull seem to be very disparate, morphotype A includes theropods with either relatively short and broad skulls resisting torsional bending like ceratosaurs, some allosauroids and tyrannosaurids (Rayfield, 2005; Sampson and Witmer, 2007), or beaked skulls like in the herbivorous oviraptorosaurs and therizinosaurs (Zanno et al., 2009). In both case, a broad and latero-medially short articulation of the quadrate was advantageous for either feeding on large prey or on hard plants thanks to a powerful and high efficiency biting (Therrien et al., 2005; Sakamoto, 2010). On the other hand, theropods with a latero-medially elongated mandibular articulation displaying a strongly diagonally oriented intercondylar sulcus where those favoring the deglutition of whole preys, or large chunk of food. They include weak/fast biter theropods with elongated skulls like the Dilophosauridae, Spinosauridae and Dromaeosauridae (Sakamoto, 2010). Those theropods were feeding on relatively small preys they were swallowing in one piece such as fishes (Charig and Milner, 1997; Hendrickx and Buffetaut, 2008) and perhaps insects (Senter, 2009). Morphotype B also includes massive theropods with extremely powerful skulls like Carcharodontosauridae and 
Torvosaurus which must have swallowed large chunk of meet from preys they would easily disarticulate thanks to their strong bite force (Therrien et al., 2005; Sakamoto, 2010).

\section{CONCLUSION}

The present study goes along the lines of other research efforts that recognize that a single bone can bear a wealth of phylogenetic information that cannot be dismissed, such as the quadrate of mosasaurs (Polcyn and Bell, 2005), the ilium of anura (Gardner et al., 2010), the coracoid of eosauropterygian (White, 1940) or the teeth of ornithopods (Araújo et al., 2008). To the eight characters on the quadrate bones used in the most recent publication on a phylogenetic context for nonavian theropod (Choiniere et al., 2014), we increased a number of characters that contribute to describe the disparity and evolutionary transformations of the bone. Many quadrate-related characters are synapomorphic to several major theropod clades such as Neotheropoda, Averostra, Ceratosauria, Tetanurae, Megalosauroidea and Avetheropoda and almost all families of nonavian theropods (e.g., Abelisauridae, Megalosauridae, Spinosauridae, Carcharodontosauridae, Tyrannosauridae, Oviraptoridae and Dromaeosauridae) are retrieved based on the combination of homologous and nonhomologous quadrate related synapomorphies.

The cladistic analysis performed on the datamatrix of 98 quadrate related characters allowed many evolutionary trends for this specific cranial bone to be drawn such as: 1) a decrease of the elongation of the quadrate body and enlargement of the mandibular articulation across the evolution of Theropoda, 2) the loss of the quadrate foramen independently in Ceratosauria and Megalosauridae, 3) the loss of the lateral process in Tetanurae and 4) a reduction of the quadrate ridge width in Tyrannosauridae.

Phylogenetic morphometrics analysis on the quadrate bone in nonavian theropods also highlighted the existence of two different morphotypes in the mandibular articulation. These 
morphotypes are linked to the morphofunctional aspect of the articulation between the lower jaw and the cranium. In morphotype A, characterized by an anteroposteriorly broad mandibular articulation with two ovoid/subcircular condyles roughly subequal in size, the displacement of the mandible laterally was very weak or even inexistent. On the other hand, in morphotype B, characterized by an elongate and anteroposteriorly narrow mandibular articulation and a long and parabolic/sigmoid ectocondyle, the lower jaw rami was displaced laterally when the mouth opened.

\section{ACKNOWLEDGMENTS}

The authors would like to thank E. Buffetaut (CNRS), S. Brusatte (AMNH), M. Mortimer and J. Headden for useful information and discussion regarding the morphology and evolution of the quadrate as well as coding characters. The quadrate of many nonavian theropods were examined at first hand in several institutions and access to the material was possible thanks to P. Sereno (Uni. Chicago), P. Makovicky (FMNH), W. Simpson (FMNH), M. Lamanna (CMNH), A. Henrici (CMNH), M. Carrano (NMNH), M. Brett-Surman (NMNH), S. Chapman (NHM), P. Barrett (NHM), P. Jeffery (OUMNH), S. Hutt (MIW), R. Allain (MNHN), R. Schoch (SMNS), H.-J. Siber (SMA), C. Dal Sasso (MSNM), A. Kramarz (MACN), F. Novas (MACN), R. Barbieri (MPCA), L. Salgado (MUCPv), J. Ignacio Canale (MUCPv-CH), R. Coria (MCF-PVPH), C. Succar (MCF-PVPH), J. Calvo (CePaLB), R. Martínez (PVSJ), C. Mehling (AMNH), M. Norell (AMNH), D. Krauze (SBU), J. Groenke (SBU), P. Brinkman (NCSM) and L. Zanno (NCSM). Photographs of theropod quadrates were kindly shared by M. Lamanna (CMNH), M. Ezcurra (MACNBR), M. Carrano (USNM), E. Buffetaut (CNRS), M. Ellison (AMNH), L. Witmer (Uni. Ohio), S. Brusatte (Uni. Edinburgh), R. Benson (Uni. Cambridge), C. Foth (BSPG), P. Currie (Uni. Alberta), J. Canale (MUCPv-CH), P. Barrett (BMNH), J. Choiniere (Uni. Witwatersrand), D. Eddy (Uni. Texas), 
P. Viscardi (Horniman), S. Nesbitt (Uni. Texas), Y. Kobayashi (HUM), R. Tahara (McGill

Uni.), R. Pei (AMNH), C. Dal Sasso (MSNM), P. Sereno (Uni. Chicago), C. Abraczinskas

(Uni. Chicago), N. Smith (Uni. Chicago), L. Zanno (FMNH), R. Tykoski (MNSD), D.

Burnham (Uni. Kansas), P. Asaroff (MACNBR), R. Irmis (UMNH), V. Shneider (NCMNS),

C. Brochu (Uni. Iowa), S. Lautenschlager (Uni. Bristol), M. Mortimer, K. Peyer (MNHN), R.

Molnar (MNA), and the authors would like to address their sincere thanks to all of these

people. A special thanks to D. Dufeau for sharing his MSc thesis on Shuvuuia. C.H. dedicates this paper to M. Hendrickx-Alexandre and R. Alexandre.

\section{REFERENCES}

Agnolin, F.L. and Novas, F.E. 2011. Unenlagiid theropods: are they members of the Dromaeosauridae (Theropoda, Maniraptora)? Anais da Academia Brasileira de Ciências 83:117-162.

Allain, R. 2002. Discovery of megalosaur (Dinosauria, Theropoda) in the middle Bathonian of Normandy (France) and its implications for the phylogeny of basal Tetanurae. Journal of Vertebrate Paleontology 22:548-563. doi:10.1671/02724634(2002)022[0548:DOMDTI]2.0.CO;2.

Araújo, R., Castahinha, R. and Mateus, O. 2008. Major trends in the evolution of teeth and mandibles in ornithopod dinosaurs. Tercer Congreso Latinoamericano de Paleontología de Vertebrados, Neuquén, Argentina 18.

Arcucci, A.B. and Coria, R.A. 2003. A new Triassic carnivorous dinosaur from Argentina. Ameghiniana 40:217-228.

Averianov, A. and Sues, H.D. 2011. Skeletal remains of Tyrannosauroidea (Dinosauria: Theropoda) from the Bissekty Formation (Upper Cretaceous: Turonian) of Uzbekistan. Cretaceous Research. 
Bakker, R.T. 1998. Brontosaur killers: late Jurassic allosaurids as sabre-tooth cat analogues. Gaia 15:145-158.

Balanoff, A.M. and Norell, M.A. 2012. Osteology of Khaan mckennai (Oviraptorosauria: Theropoda). Bulletin of the American Museum of Natural History 1-77. doi:10.1206/803.1.

Balanoff, A.M., Xu, X., Kobayashi, Y., Matsufune, Y. and Norell, M.A. 2009. Cranial osteology of the theropod dinosaur Incisivosaurus gauthieri (Theropoda: Oviraptorosauria). American Museum Novitates 3651:1-35.

Barsbold, R. 1974. Saurornithoididae, a new family of small theropod dinosaurs from central Asia and North America. Palaeontologia Polonica 30:5-22.

Barsbold, R. 1981. Toothless carnivorous dinosaurs of Mongolia. Trudy Sovmestnoi SovetskoMongol'skoi Paleontologicheskoi Ekspeditsii 15:28-39.

Barsbold, R. 1986. Raubdinosaurier Oviraptoren, p. 210-223. In Vorobyeva, E.I. (ed.), Gerpetologičeskie issledovaniâ v Mongol'skoi Narodnoj Respublike. Moscow.

Barsbold, R. and Osmólska, H. 1999. The skull of Velociraptor (Theropoda) from the Late Cretaceous of Mongolia. Acta Palaeontologica Polonica 44:189-219.

Barsbold, R., Osmólska, H. and Kurzanov, S.M. 1987. On a new troodontid (Dinosauria, Theropoda) from the Early Cretaceous of Mongolia. Acta Palaeontologica Polonica $32: 121-132$.

Barsbold, R. and Perle, A. 1980. Segnosauria, a new infraorder of carnivorous dinosaurs. Acta Palaeontologica Polonica 25:187-195.

Bennett, S.C. 2001. The osteology and functional morphology of the Late Cretaceous pterosaur Pteranodon Part I. General description of osteology. Palaeontographica Abteilung A 260:1-112. 
Benson, R., Carrano, M. and Brusatte, S. 2010. A new clade of archaic large-bodied predatory dinosaurs (Theropoda: Allosauroidea) that survived to the latest Mesozoic. Naturwissenschaften 97:71-78. doi:10.1007/s00114-009-0614-х.

Benson, R.B.J. 2010. A description of Megalosaurus bucklandii (Dinosauria: Theropoda) from the Bathonian of the UK and the relationships of Middle Jurassic theropods. Zoological Journal of the Linnean Society 158:882-935.

Bever, G.S. and Norell, M.A. 2009. The perinate skull of Byronosaurus (Troodontidae) with observations on the cranial ontogeny of paravian theropods. American Museum Novitates 3657:1-52.

Bonaparte, J.F. 1985. A horned Cretaceous carnosaur from Patagonia. National Geographic Research 1:149-151.

Bonaparte, J.F. 1991. The Gondwanian theropod families Abelisauridae and Noasauridae. Historical Biology 5:1-25.

Bonaparte, J.F. and Novas, F.E. 1985. Abelisaurus comahuensis, n.g., Carnosauria del Crétacico Tardio de Patagonia. Ameghiniana 21:259-265.

Bonaparte, J.F. and Powell, J.E. 1980. A continental assemblage of tetrapods from the Upper Cretaceous beds of El Brete, northwestern Argentina (Sauropoda-CoelurosauriaCarnosauria-Aves). Mémoires de la Société Géologique de France, Nouvelle Série 139:19-28.

Bookstein, F.L. 1997. Morphometric Tools for Landmark Data: Geometry and Biology. Cambridge University Press.

Bremer, K. 1994. Branch support and tree stability. Cladistics 10:295-304.

Britt, B.B. 1991. Theropods of Dry Mesa Quarry (Morrison Formation, Late Jurassic), Colorado, with emphasis on the osteology of Torvosaurus tanneri. Brigham Young University Geology Studies 37:1-72. 
Brochu, C.A. 2003. Osteology of Tyrannosaurus rex: Insights from a nearly complete skeleton and high-resolution computed tomographic analysis of the skull. Journal of Vertebrate Paleontology 22:1-138. doi:10.1080/02724634.2003.10010947.

Brusatte, S.L. 2012. Dinosaur Paleobiology. Wiley-Blackwell.

Brusatte, S.L., Benson, R.B.J., Chure, D.J., Xu, X., Sullivan, C. and Hone, D.W.E. 2009. The first definitive carcharodontosaurid (Dinosauria: Theropoda) from Asia and the delayed ascent of tyrannosaurids. Naturwissenschaften 96:1051-1058.

Brusatte, S.L., Benson, R.B.J., Currie, P.J. and Xijin, Z. 2010. The skull of Monolophosaurus jiangi (Dinosauria: Theropoda) and its implications for early theropod phylogeny and evolution. Zoological Journal of the Linnean Society 158:573-607.

Brusatte, S.L., Carr, T.D., Erickson, G.M., Bever, G.S. and Norell, M.A. 2009. A longsnouted, multihorned tyrannosaurid from the Late Cretaceous of Mongolia. Proceedings of the National Academy of Sciences 106:17261-17266.

Brusatte, S.L., Carr, T.D. and Norell, M.A. 2012. The osteology of Alioramus, a gracile and long-snouted tyrannosaurid (Dinosauria: Theropoda) from the Late Cretaceous of Mongolia. Bulletin of the American Museum of Natural History 366:1-197. doi:10.1206/770.1.

Brusatte, S.L., Chure, D.J., Benson, R.B.J. and Xu, X. 2010. The osteology of Shaochilong maortuensis, a carcharodontosaurid (Dinosauria: Theropoda) from the Late Cretaceous of Asia. Zootaxa 2334:1-46.

Brusatte, S.L., Norell, M.A., Carr, T.D., Erickson, G.M., Hutchinson, J.R., Balanoff, A.M., Bever, G.S., Choiniere, J.N., Makovicky, P.J. and Xu, X. 2010. Tyrannosaur paleobiology: new research on ancient exemplar organisms. Science 329:1481-1485. doi:10.1126/science.1193304. 
Burnham, D.A. 2004. New Information on Bambiraptor feinbergi (Theropoda:

Dromaeosauridae) from the Late Cretaceous of Montana, p. 67-111. In Currie, P.J., Koppelhus, E.B., Shugar, M.A., and Wright, J.L. (eds.), Feathered Dragons: Studies on the Transition from Dinosaurs to Birds. Indiana University Press, Bloomington, Indiana.

Burnham, D.A., Derstler, K.L., Currie, P.J., Bakker, R.T., Zhou, Z. and Ostrom, J.H. 2000. Remarkable new birdlike dinosaur (Theropoda: Maniraptora) from the Upper Cretaceous of Montana. The Paleontological Institute, The University of Kansas 13:114.

Carr, T.D. 1996. Cranial osteology and craniofacial ontogeny of Tyrannosauridae: Dinosauria: Theropoda from the Dinosaur Park Formation (Judith River Group, Upper Cretaceous, Campanian) of Alberta. MSc. Dissertation, University of Toronto, Toronto, Ontario, Canada.

Carr, T.D. and Williamson, T.E. 2010. Bistahieversor sealeyi, gen. et sp. nov., a new tyrannosauroid from New Mexico and the origin of deep snouts in Tyrannosauroidea. Journal of vertebrate Paleontology 30:1-16.

Carrano, M.T., Benson, R.B.J. and Sampson, S.D. 2012. The phylogeny of Tetanurae (Dinosauria: Theropoda). Journal of Systematic Palaeontology 10:211-300. doi:10.1080/14772019.2011.630927.

Carrano, M.T., Loewen, M.A. and Sertich, J.J.W. 2011. New materials of Masiakasaurus knopfleri Sampson, Carrano, and Forster, 2001, and implications for the morphology of the Noasauridae (Theropoda: Ceratosauria). Smithsonian Contributions to Paleobiology 95:1-53. 
Carrano, M.T. and Sampson, S.D. 2008. The phylogeny of Ceratosauria (Dinosauria: Theropoda). Journal of Systematic Palaeontology 6:183-236. doi:10.1017/S1477201907002246.

Catalano, S.A. and Goloboff, P.A. 2012. Simultaneously Mapping and Superimposing Landmark Configurations with Parsimony as Optimality Criterion. Systematic Biology 61:392-400. doi:10.1093/sysbio/syr119.

Catalano, S.A., Goloboff, P.A. and Giannini, N.P. 2010. Phylogenetic morphometrics (I): the use of landmark data in a phylogenetic framework. Cladistics 26:539-549.

Charig, A.J. and Milner, A.C. 1986. Baryonyx, a remarkable new theropod dinosaur. Nature $324: 359-361$.

Charig, A.J. and Milner, A.C. 1990. The systematic position of Baryonyx walkeri, in the light of Gauthier's reclassification of the Theropoda, p. 127-140. In Carpenter, K. and Currie, P.J. (eds.), Dinosaur Systematics: Approaches and Perspectives. Cambridge University Press, New York, New York.

Charig, A.J. and Milner, A.C. 1997. Baryonyx walkeri, a fish-eating dinosaur from the Wealden of Surrey. Bulletin of the Natural History Museum 53:11-70.

Chiappe, L.M. and Göhlich, U.B. 2010. Anatomy of Juravenator starki (Theropoda: Coelurosauria) from the Late Jurassic of Germany. Neues Jahrbuch für Geologie und Paläontologie Abhandlungen 258:257-296. doi:10.1127/0077-7749/2010/0125.

Chiappe, L.M., Norell, M.A. and Clark, J.M. 1998. The skull of a relative of the stem-group bird Mononykus. Nature 392:275-278. doi:10.1038/32642.

Chiappe, L.M., Norell, M.A. and Clark, J.M. 2002. The Cretaceous, short-armed Alvarezsauridae: Mononykus and its kin, p. 87-120. In Chiappe, L.M. and Witmer, L.M. (eds.), Mesozoic birds: above the heads of dinosaurs. University of California Press. 
Choiniere, J.N., Clark, J.M., Forster, C.A., Norell, M.A., Eberth, D.A., Erickson, G.M., Chu, H. and Xu, X. 2014. A juvenile specimen of a new coelurosaur (Dinosauria: Theropoda) from the Middle-Late Jurassic Shishugou Formation of Xinjiang, People's Republic of China. Journal of Systematic Palaeontology 12:177-215. doi:10.1080/14772019.2013.781067.

Choiniere, J.N., Clark, J.M., Forster, C.A. and Xu, X. 2010. A basal coelurosaur (Dinosauria: Theropoda) from the Late Jurassic (Oxfordian) of the Shishugou Formation in Wucaiwan, People's Republic of China. Journal of Vertebrate Paleontology 30:17731796. doi:10.1080/02724634.2010.520779.

Choiniere, J.N., Forster, C.A. and de Klerk, W.J. 2012. New information on Nqwebasaurus thwazi, a coelurosaurian theropod from the Early Cretaceous Kirkwood Formation in South Africa. Journal of African Earth Sciences 71-72:1-17. doi:10.1016/j.jafrearsci.2012.05.005.

Choiniere, J.N., Xu, X., Clark, J.M., Forster, C.A., Guo, Y. and Han, F. 2010. A basal alvarezsauroid theropod from the Early Late Jurassic of Xinjiang, China. Science 327:571-574. doi:10.1126/science.1182143.

Chure, D.J. 2000. A new species of Allosaurus from the Morrison Formation of Dinosaur National Monument (Utah-Colorado) and a revision of the theropod family Allosauridae. Ph.D. Dissertation, Columbia University, New York, New York.

Clark, J.M., Norell, M.A. and Rowe, T. 2002. Cranial anatomy of Citipati osmolskae (Theropoda, Oviraptorosauria), and a reinterpretation of the holotype of Oviraptor philoceratops. American Museum Novitates 3364:1-24.

Clark, J.M., Perle, A. and Norell, M. 1994. The skull of Erlicosaurus andrewsi, a late Cretaceous "Segnosaur" (Theropoda, Therizinosauridae) from Mongolia. American Museum Novitates 3115:1-39. 
Colbert, E.H. 1989. The Triassic dinosaur Coelophysis. Museum of Northern Arizona Bulletin $57: 1-174$.

Colbert, E.H. and Russell, D.A. 1969. The small Cretaceous dinosaur Dromaeosaurus. American Museum Novitates 2380:1-49.

Coria, R.A., Chiappe, L.M. and Dingus, L. 2002. A new close relative of Carnotaurus sastrei Bonaparte 1985 (Theropoda: Abelisauridae) from the Late Cretaceous of Patagonia. Journal of Vertebrate Paleontology 22:460-465. doi:10.1671/02724634(2002)022[0460:ANCROC]2.0.CO;2.

Coria, R.A. and Currie, P.J. 2006. A new carcharodontosaurid (Dinosauria, Theropoda) from the Upper Cretaceous of Argentina. Geodiversitas 28:71-118.

Coria, R.A. and Salgado, L. 1995. A new giant carnivorous dinosaur from the Cretaceous of Patagonia. Nature 377:224-226. doi:10.1038/377224a0.

Coria, R.A. and Salgado, L. 1998. A basal Abelisauria Novas, 1992 (Theropoda-Ceratosauria) from the Cretaceous of Patagonia, Argentina. Gaia 15:89-102.

Currie, P.J. 1985. Cranial anatomy of Stenonychosaurus inequalis (Saurischia, Theropoda) and its bearing on the origin of birds. Canadian Journal of Earth Sciences 22:16431658. doi:10.1139/e85-173.

Currie, P.J. 1995. New information on the anatomy and relationships of Dromaeosaurus albertensis (Dinosauria: Theropoda). Journal of Vertebrate Paleontology 15:576-591. doi:10.1080/02724634.1995.10011250.

Currie, P.J. 2003. Cranial anatomy of tyrannosaurid dinosaurs from the Late Cretaceous of Alberta, Canada. Acta Palaeontologica Polonica 48:191-226.

Currie, P.J. 2006. On the quadrate of Sinraptor dongi (Theropoda: Allosauroidea) from the Late Jurassic of China. Mesozoic and Cenozoic Vertebrates and Paleoenvironments. Tributes to the career of Prof. Dan Grigorescu 111-115. 
Currie, P.J. and Chen, P. 2001. Anatomy of Sinosauropteryx prima from Liaoning, northeastern China. Canadian Journal of Earth Sciences 38:1705-1727. doi:10.1139/e01-050.

Currie, P.J. and Zhao, X.-J. 1993a. A new troodontid (Dinosauria, Theropoda) braincase from the Dinosaur Park Formation (Campanian) of Alberta. Canadian Journal of Earth Sciences 30:2231-2247. doi:10.1139/e93-194.

Currie, P.J. and Zhao, X.-J. 1993b. A new carnosaur (Dinosauria, Theropoda) from the Jurassic of Xinjiang, People's Republic of China. Canadian Journal of Earth Sciences 30:2037-2081. doi:10.1139/e93-179.

Dufeau, D.L. 2003. The cranial anatomy of the theropod dinosaur Shuvuuia deserti (Coelurosauria: Alvarezsauridae), and its bearing upon coelurosaurian phylogeny. MSc. Dissertation, University of Texas, Austin, Texas.

Eddy, D.R. and Clarke, J.A. 2011. New information on the cranial anatomy of Acrocanthosaurus atokensis and its implications for the phylogeny of Allosauroidea (Dinosauria: Theropoda). PLoS ONE 6:e17932. doi:10.1371/journal.pone.0017932.

Elzanowski, A., Paul, G.S. and Stidham, T.A. 2001. An avian quadrate from the Late Cretaceous Lance formation of Wyoming. Journal of Vertebrate Paleontology 20:712-719.

Ezcurra, M.D. 2007. The cranial anatomy of the coelophysoid theropod Zupaysaurus rougieri from the Upper Triassic of Argentina. Historical Biology 19:185-202.

Galton, P.M. and Jensen, J.A. 1979. A new large theropod dinosaur from the Upper Jurassic of Colorado. Brigham Young University Geology Studies 26:1-12.

Gao, C., Morschhauser, E.M., Varricchio, D.J., Liu, J. and Zhao, B. 2012. A second soundly sleeping dragon: new anatomical details of the Chinese troodontid Mei long with 
implications for phylogeny and taphonomy. PLOS ONE 7:e45203.

doi:10.1371/journal.pone.0045203.

Gardner, J.L., Trueman, J.W.H., Ebert, D., Joseph, L. and Magrath, R.D. 2010. Phylogeny and evolution of the Meliphagoidea, the largest radiation of Australasian songbirds. Molecular Phylogenetics and Evolution 55:1087-1102.

Gilmore, C.W. 1920. Osteology of the carnivorous Dinosauria in the United State National museum: with special reference to the genera Antrodemus (Allosaurus) and Ceratosaurus. Bulletin of the United States National Museum 110:1-159.

Gilmore, C.W. 1924. On Troodon validus, an ornithopodus dinosaur from the Belly River Cretaceous of Alberta, Canada. Bulletin of the Department of Geology, University of Alberta 1:1-143.

Godefroit, P., Demuynck, H., Dyke, G., Hu, D., Escuillié, F. and Claeys, P. 2013. Reduced plumage and flight ability of a new Jurassic paravian theropod from China. Nature Communications 4:1394. doi:10.1038/ncomms2389.

Gold, M.E.L., Brusatte, S. and Norell, M. 2013. The cranial pneumatic sinuses of the tyrannosaurid Alioramus (Dinosauria, Theropoda) and the evolution of cranial pneumaticity in theropod dinosaurs. American Museum Novitates 3790:1-46.

Goloboff, P.A. and Catalano, S.A. 2011. Phylogenetic morphometrics (II): algorithms for landmark optimization. Cladistics 27:42-51.

Goloboff, P.A., Farris, J.S. and Nixon, K.C. 2008. TNT, a free program for phylogenetic analysis. Cladistics 24:774-786. doi:10.1111/j.1096-0031.2008.00217.x.

Hammer, W.R. and Hickerson, W.J. 1994. A crested theropod dinosaur from Antarctica. Science 264:828-830.

Hartman, S., Lovelace, D. and Wahl, W. 2005. Phylogenetic assessment of a maniraptoran from the Morrison Formation. Journal of Vertebrate Paleontology 25:67A-68A. 
Hendrickx, C. and Buffetaut, E. 2008. Functional interpretation of spinosaurid quadrates (Dinosauria: Theropoda) from the Mid-Cretaceous of Morocco. 56th Annual Symposium of Vertebrate Palaeontology and Comparative Anatomy. Dublin (September 2nd-6th 2008) 25-26.

Hendrickx, C. and Mateus, O. 2012. Ontogenetical changes in the quadrate of basal tetanurans, p. 20, 101-104. In Royo-Torres, R., Gascó, F., and Alcalá, L. (eds.), 10th Annual Meeting of the European Association of Vertebrate Palaeontologists. ¡Fundamental!

Hendrickx, C. and Mateus, O. 2014. Abelisauridae (Dinosauria: Theropoda) from the Late Jurassic of Portugal and dentition-based phylogeny as a contribution for the identification of isolated theropod teeth. Zootaxa 3759:1-74. doi:10.11646/zootaxa.3759.1.1.

Hone, D.W.E., Wang, K., Sullivan, C., Zhao, X., Chen, S., Li, D., Ji, S., Ji, Q. and Xu, X. 2011. A new, large tyrannosaurine theropod from the Upper Cretaceous of China. Cretaceous Research 32:495.

Hu, D., Hou, L., Zhang, L. and Xu, X. 2009. A pre-Archaeopteryx troodontid theropod from China with long feathers on the metatarsus. Nature 461:640-643. doi:10.1038/nature08322.

Hu, S. 1993. A new theropoda (Dilophosaurus sinensis sp. nov.) from Yunnan, China. Vertebrata PalAsiatica 31:65-69.

Von Huene, F.R. 1926. LX.- On several known and unknown reptiles of the order Saurischia from England and France. Journal of Natural History Series 9 17:473-489. doi:10.1080/00222932608633437.

Von Huene, F.R. 1934. Ein neuer Coelurosaurier in der thüringischen Trias. Paläontologische Zeitschrift 16:145-170. doi:10.1007/BF03042684. 
Hutt, S., Naish, D., Martill, D.M., Barker, M.J. and Newbery, P. 2001. A preliminary account of a new tyrannosauroid theropod from the Wessex Formation (Early Cretaceous) of southern England. Cretaceous Research 22:227-242. doi:10.1006/cres.2001.0252.

Hwang, S.H. 2007. Phylogenetic patterns of enamel microstructure in dinosaur teeth. Ph.D. Dissertation, Columbia University, New York, New York.

Hwang, S.H., Norell, M.A., Qiang, J. and Keqin, G. 2004. A large compsognathid from the Early Cretaceous Yixian Formation of China. Journal of Systematic Palaeontology 2:13-30. doi:10.1017/S1477201903001081.

Ji, Q., Ji, S., Lü, J. and Yuan, C. 2007. A new giant compsognathid dinosaur with long filamentous integuments from lower Cretaceous of Northeastern China. Acta Geologica Sinica 81:8-15.

Ji, Q., Ji, S.A. and Zhang, L.J. 2009. First large tyrannosauroid theropod from the Early Cretaceous Jehol Biota in northeastern China. Geological Bulletin of China 28:13691374.

Ji, Q., Norell, M.A., Makovicky, P.J., Gao, K.-Q., Ji, S. and Yuan, C. 2003. An early ostrich dinosaur and implications for ornithomimosaur phylogeny. American Museum Novitates 3420:1-19. doi:10.1206/0003-0082(2003)420<0001:AEODAI>2.0.CO;2.

Kirkland, J.I., Zanno, L.E., Sampson, S.D., Clark, J.M. and DeBlieux, D.D. 2005. A primitive therizinosauroid dinosaur from the Early Cretaceous of Utah. Nature 435:84-87.

Kobayashi, Y. and Barsbold, R. 2005. Reexamination of a primitive ornithomimosaur, Garudimimus brevipes Barsbold, 1981 (Dinosauria: Theropoda), from the Late Cretaceous of Mongolia. Canadian Journal of Earth Sciences 42:1501-1521. doi:10.1139/e05-044.

Kobayashi, Y. and Lü, J.-C. 2003. A new ornithomimid dinosaur with gregarious habits from the Late Cretaceous of China. Acta Palaeontologica Polonica 48:235-259. 
Kundrát, M. and Janáček, J. 2007. Cranial pneumatization and auditory perceptions of the oviraptorid dinosaur Conchoraptor gracilis (Theropoda, Maniraptora) from the Late Cretaceous of Mongolia. Naturwissenschaften 94:769-778. doi:10.1007/s00114-0070258-7.

Kurzanov, S.M. 1981. An unusual theropod from the Upper Cretaceous of Mongolia. Joint Soviet-Mongolian Paleontological Expedition 15:39-49.

Kurzanov, S.M. 1985. The skull structure of the dinosaur Avimimus. Paleontological Journal 1985:92-99.

Larson, P.L. 2008. Atlas of the skull bones of Tyrannosaurus rex, p. 233-243. In Larson, P.L. and Carpenter, K. (eds.), Tyrannosaurus rex, the Tyrant King. Indiana University Press, Bloomington, Indiana.

Lavocat, R. 1955. Sur une portion de mandibule de théropode provenant du Crétacé supérieur de Madagascar. Bulletin du Muséum National d'Histoire Naturelle 27:256-259.

Li, D., Norell, M.A., Gao, K.Q., Smith, N.D. and Makovicky, P.J. 2010. A longirostrine tyrannosauroid from the Early Cretaceous of China. Proceedings of the Royal Society B: Biological Sciences 277:183-190.

Loewen, M.A., Irmis, R.B., Sertich, J.J.W., Currie, P.J. and Sampson, S.D. 2013. Tyrant dinosaur evolution tracks the rise and fall of Late Cretaceous oceans. PLoS ONE 8:e79420. doi:10.1371/journal.pone.0079420.

Lü, J. 2003. A new oviraptorosaurid (Theropoda: Oviraptorosauria) from the Late Cretaceous of southern China. Journal of Vertebrate Paleontology 22:871-875. doi:10.1671/0272-4634(2002)022[0871:ANOTOF]2.0.CO;2.

Lü, J., Xu, L., Liu, Y., Zhang, X., Jia, S. and Ji, Q. 2010. A new troodontid theropod from the Late Cretaceous of central China, and the radiation of Asian troodontids. Acta Palaeontologica Polonica 55:381-388. 
Madsen, J.H. 1976a. A second new theropod dinosaur from the Late Jurassic of east central Utah. Utah geology 3:51-60.

Madsen, J.H. 1976b. Allosaurus fragilis: A Revised Osteology. Utah Geological Survey Bulletin 109:1-177.

Madsen, J.H. and Welles, S.P. 2000. Ceratosaurus (Dinosauria, Theropoda): a revised osteology. Utah Geological Survey, Miscellaneous Publication 00-2:1-89.

Makovicky, P.J., Apesteguía, S. and Agnolín, F.L. 2005. The earliest dromaeosaurid theropod from South America. Nature 437:1007-1011. doi:10.1038/nature03996.

Makovicky, P.J., Kobayashi, Y. and Currie, P.J. 2004. Ornithomimosauria, p. 137-150. In Weishampel, D.B., Dodson, P., and Osmólska, H. (eds.), The Dinosauria, Second Edition. University of California Press, Berkeley/Los Angeles/London.

Makovicky, P.J. and Norell, M. 1998. A partial ornithomimid braincase from Ukhaa Tolgod (Upper Cretaceous, Mongolia). American Museum Novitates 3247:1-16.

Makovicky, P.J., Norell, M.A., Clark, J.M. and Rowe, T. 2003. Osteology and relationships of Byronosaurus jaffei (Theropoda: Troodontidae). American Museum Novitates 3402:1-32. doi:10.1206/0003-0082(2003)402<0001:OAROBJ>2.0.CO;2.

Marsh, O.C. 1877. Notice of new dinosaurian reptiles from the Jurassic Formation. American Journal of Science 14:14-516.

Marsh, O.C. 1884. Principal characters of the American Jurassic dinosaurs. Part VIII. The order Theropoda. American Journal of Science, Series 3 27:329-340.

Martill, D.M., Cruickshank, A.R.I., Frey, E., Small, P.G. and Clarke, M. 1996. A new crested maniraptoran dinosaur from the Santana Formation (Lower Cretaceous) of Brazil. Journal of the Geological Society 153:5-8. doi:10.1144/gsjgs.153.1.0005. 
Martinez, R.N. and Alcober, O.A. 2009. A basal sauropodomorph (Dinosauria: Saurischia) from the Ischigualasto Formation (Triassic, Carnian) and the early evolution of Sauropodomorpha. PLoS ONE 4:e4397. doi:10.1371/journal.pone.0004397.

Martinez, R.N., Sereno, P.C., Alcober, O.A., Colombi, C.E., Renne, P.R., Montañez, I.P. and Currie, B.S. 2011. A basal dinosaur from the dawn of the dinosaur era in southwestern Pangaea. Science 331:206-210. doi:10.1126/science.1198467.

Maryańska, T. and Osmólska, H. 1997. The quadrate of oviraptorid dinosaurs. Acta Palaeontologica Polonica 42:361-371.

Mateus, O., Walen, A. and Antunes, M.T. 2006. The large theropod fauna of the Lourinhã Formation (Portugal) and its similarity to the Morrison Formation, with a description of a new species of Allosaurus. New Mexico Museum of Natural History and Science Bulletin 36:123-129.

Matthew, W.D. and Brown, B. 1922. The family Deinodontidae, with notice of a new genus from the Cretaceous of Alberta. Bulletin of the American Museum of Natural History $46: 367-385$

Molnar, R.E. 1991. The cranial morphology of Tyrannosaurus rex. Palaeontographica Abteilung A 217:137-176.

Nesbitt, S.J. 2011. The early evolution of archosaurs: relationships and the origin of major clades. Bulletin of the American Museum of Natural History 1-292. doi:10.1206/352.1.

Nesbitt, S.J., Clarke, J.A., Turner, A.H. and Norell, M.A. 2011. A small alvarezsaurid from the eastern Gobi Desert offers insight into evolutionary patterns in the Alvarezsauroidea. Journal of Vertebrate Paleontology 31:144-153. doi:10.1080/02724634.2011.540053. 
Nesbitt, S.J., Smith, N.D., Irmis, R.B., Turner, A.H., Downs, A. and Norell, M.A. 2009. A complete skeleton of a Late Triassic saurischian and the early evolution of dinosaurs. Science 326:1530-1533. doi:10.1126/science.1180350.

Nixon, K.C. 2002. WinClada, version 1.00.08. Published by the author, Ithaca, New York.

Norell, M.A., Clark, J.M., Turner, A.H., Makovicky, P.J., Barsbold, R. and Rowe, T. 2006. A new dromaeosaurid theropod from Ukhaa Tolgod (Ömnögov, Mongolia). American Museum Novitates 3545:1-51. doi:10.1206/00030082(2006)3545[1:ANDTFU]2.0.CO;2.

Norell, M.A. and Hwang, S.H. 2004. A troodontid dinosaur from Ukhaa Tolgod (Late Cretaceous Mongolia). American Museum Novitates 3446:1-9.

Norell, M.A., Makovicky, P.J., Bever, G.S., Balanoff, A.M., Clark, J.M., Barsbold, R. and Rowe, T. 2009. A review of the Mongolian Cretaceous dinosaur Saurornithoides (Troodontidae: Theropoda). American Museum Novitates 3654:1-63. doi:10.1206/648.1.

Novas, F.E. 1994. New information on the systematics and postcranial skeleton of Herrerasaurus ischigualastensis (Theropoda: Herrerasauridae) from the Ischigualasto Formation (Upper Triassic) of Argentina. Journal of Vertebrate Paleontology 13:400423. doi:10.1080/02724634.1994.10011523.

Novas, F.E., Ezcurra, M.D., Agnolin, F.L., Pol, D. and Ortíz, R. 2012. New Patagonian Cretaceous theropod sheds light about the early radiation of Coelurosauria. Revista del Museo Argentino de Ciencias Naturales 14:57-81.

Osborn, H.F. 1903. Ornitholestes hermanni, a new compsognathoid dinosaur from the Upper Jurassic. Bulletin of the American Museum of Natural History 19:459-464.

Osborn, H.F. 1905. Tyrannosaurus and other Cretaceous carnivorous dinosaurs. Bulletin of the American Museum of Natural History 21:259-265. 
Osborn, H.F. 1912. Crania of Tyrannosaurus and Allosaurus. Memoirs of the American Museum of Natural History. New Series 1:1-30.

Osmólska, H., Roniewicz, E. and Barsbold, R. 1972. A new dinosaur, Gallimimus bullatus n. gen., n. sp.(Ornithomimidae) from the Upper Cretaceous of Mongolia. Palaeontologia Polonica 27:103-143.

Ostrom, J.H. 1978. The osteology of Compsognathus longipes Wagner. Zitteliana 4:73-118.

Paul, G.S. 1988. Predatory Dinosaurs of the World: A Complete Illustrated Guide. Simon \& Schuster.

Perle, A., Chiappe, L.M. and Barsbold, R. 1994. Skeletal morphology of Mononykus olecranus (Theropoda: Avialae) from the Late Cretaceous of Mongolia. American Museum Novitates 3105:1-29.

Peyer, K. 2006. A reconsideration of Compsognathus from the upper Tithonian of Canjuers, southeastern France. Journal of Vertebrate Paleontology 26:879-896. doi:10.1671/0272-4634(2006)26[879:AROCFT]2.0.CO;2.

Pol, D. and Rauhut, O.W.M. 2012. A Middle Jurassic abelisaurid from Patagonia and the early diversification of theropod dinosaurs. Proceedings of the Royal Society B: Biological Sciences 279:3170-3175. doi:10.1098/rspb.2012.0660.

Polcyn, M.J. and Bell, G.L. 2005. Russellosaurus coheni n. gen., n. sp., a 92 million-year-old mosasaur from Texas (USA), and the definition of the parafamily Russellosaurina. Netherlands Journal of Geosciences 84:321-333.

Raath, M.A. 1977. The anatomy of the Triassic theropod Syntarsus rhodesiensis (Saurischia: Podokesauridae) and a consideration of its biology. Ph.D. Dissertation, Department of Zoology and Entomology, Rhodes University, Salisbury, Rhodesia.

Rauhut, O.W.M., Milner, A.C. and Moore-Fay, S. 2010. Cranial osteology and phylogenetic position of the theropod dinosaur Proceratosaurus bradleyi (Woodward, 1910) from 
the Middle Jurassic of England. Zoological Journal of the Linnean Society 158:155195. doi:10.1111/j.1096-3642.2009.00591.x.

Rayfield, E.J. 2005. Aspects of comparative cranial mechanics in the theropod dinosaurs Coelophysis, Allosaurus and Tyrannosaurus. Zoological Journal of the Linnean Society 144:309-316. doi:10.1111/j.1096-3642.2005.00176.x.

Reig, O.A. 1963. La presencia de dinosaurios saurisquios en los "Estratos de Ischigualasto" (Mesotriásico Superior) de las provincias de San Juan y La Rioja (República Argentina). Ameghiniana 3:3-20.

Rohlf, F.J. and Slice, D. 1990. Extensions of the procrustes method for the optimal superimposition of landmarks. Systematic Biology 39:40-59. doi:10.2307/2992207.

Rowe, T. 1989. A new species of the theropod dinosaur Syntarsus from the Early Jurassic Kayenta Formation of Arizona. Journal of Vertebrate Paleontology 9:125-136. doi:10.1080/02724634.1989.10011748.

Russell, D.A. 1969. A new specimen of Stenonychosaurus from the Oldman Formation (Cretaceous) of Alberta. Canadian Journal of Earth Sciences 6:595-612. doi:10.1139/e69-059.

Russell, D.A. 1970. Tyrannosaurs from the Late Cretaceous of western Canada. National Museum of Natural Sciences Publications in Paleontology 1:1-34.

Russell, D.A. and Dong, Z.-M. 1993. A nearly complete skeleton of a new troodontid dinosaur from the Early Cretaceous of the Ordos Basin, Inner Mongolia, People's Republic of China. Canadian Journal of Earth Sciences 30:2163-2173. doi:10.1139/e93-187.

Sadleir, R., Barrett, P.M. and Powell, H.P. 2008. The anatomy and systematics of Eustreptospondylus oxoniensis, a theropod dinosaur from the Middle Jurassic of 
Oxfordshire, England. Monograph of the Palaeontographical Society, London 160:182.

Sakamoto, M. 2010. Jaw biomechanics and the evolution of biting performance in theropod dinosaurs. Proceedings of the Royal Society B: Biological Sciences 277:3327-3333. doi:10.1098/rspb.2010.0794.

Sampson, S.D. and Witmer, L.M. 2007. Craniofacial anatomy of Majungasaurus crenatissimus (Theropoda: Abelisauridae) from the Late Cretaceous of Madagascar. Journal of Vertebrate Paleontology 27:32-104. doi:10.1671/02724634(2007)27[32:CAOMCT]2.0.CO;2.

Dal Sasso, C. and Maganuco, S. 2011. Scipionyx samniticus (Theropoda: Compsognathidae) from the Lower Cretaceous of Italy: osteology, ontogenetic assessment, phylogeny, soft tissue anatomy, taphonomy and palaeobiology. Memorie della Società Italiana di Scienze Naturali e del Museo Civico di Storia Naturale di Milano 37:1-281.

Dal Sasso, C. and Signore, M. 1998. Exceptional soft-tissue preservation in a theropod dinosaur from Italy. Nature 392:383-387. doi:10.1038/32884.

Senter, P. 2009. Pedal function in deinonychosaurs (Dinosauria: Theropoda): a comparative study. Bulletin of the Gunma Museum of Natural History 13:1-14.

Senter, P. 2011. Using creation science to demonstrate evolution 2: morphological continuity within Dinosauria. Journal of Evolutionary Biology 24:2197-2216. doi:10.1111/j.1420-9101.2011.02349.x.

Sereno, P.C., Beck, A.L., Dutheil, D.B., Gado, B., Larsson, H.C.E., Lyon, G.H., Marcot, J.D., Rauhut, O.W.M., Sadleir, R.W., Sidor, C.A., Varricchio, D.D., Wilson, G.P. and Wilson, J.A. 1998. A long-snouted predatory dinosaur from Africa and the evolution of spinosaurids. Science 282:1298-1302. doi:10.1126/science.282.5392.1298. 
Sereno, P.C., Dutheil, D.B., Larochene, M., Larsson, H.C.E., Lyon, G.H., Magwene, P.M., Sidor, C.A., Varricchio, D.J. and Wilson, J.A. 1996. Predatory dinosaurs from the Sahara and Late Cretaceous faunal differentiation. Science 272:986-991. doi:10.1126/science.272.5264.986.

Sereno, P.C., Forster, C.A., Rogers, R.R. and Monetta, A.M. 1993. Primitive dinosaur skeleton from Argentina and the early evolution of Dinosauria. Nature 361:64-66. doi:10.1038/361064a0.

Sereno, P.C., Martínez, R.N. and Alcober, O.A. 2013. Osteology of Eoraptor lunensis (Dinosauria, Sauropodomorpha). Journal of Vertebrate Paleontology 32:83-179. doi:10.1080/02724634.2013.820113.

Sereno, P.C., Martinez, R.N., Wilson, J.A., Varricchio, D.J., Alcober, O.A. and Larsson, H.C.E. 2008. Evidence for avian intrathoracic air sacs in a new predatory dinosaur from Argentina. PLoS ONE 3:e3303. doi:10.1371/journal.pone.0003303.

Sereno, P.C. and Novas, F.E. 1994. The skull and neck of the basal theropod Herrerasaurus ischigualastensis. Journal of Vertebrate Paleontology 13:451-476. doi:10.1080/02724634.1994.10011525.

Sereno, P.C., Tan, L., Brusatte, S.L., Kriegstein, H.J., Zhao, X. and Cloward, K. 2009. Tyrannosaurid skeletal design first evolved at small body size. Science 326:418-422. doi:10.1126/science.1177428.

Sereno, P.C., Wilson, J.A., Larsson, H.C.E., Dutheil, D.B. and Sues, H.-D. 1994. Early Cretaceous dinosaurs from the Sahara. Science 266:267-271. doi:10.1126/science.266.5183.267.

Siegel, A.F. and Benson, R.H. 1982. A Robust Comparison of Biological Shapes. Biometrics 38:341. doi:10.2307/2530448. 
Smith, N.D., Makovicky, P.J., Hammer, W.R. and Currie, P.J. 2007. Osteology of Cryolophosaurus ellioti (Dinosauria: Theropoda) from the Early Jurassic of Antarctica and implications for early theropod evolution. Zoological Journal of the Linnean Society 151:377-421. doi:10.1111/j.1096-3642.2007.00325.x.

Stovall, J.W. and Langston Jr, W. 1950. Acrocanthosaurus atokensis, a new genus and species of Lower Cretaceous Theropoda from Oklahoma. American Midland Naturalist 696-728.

Sues, H.-D. 1977. The skull of Velociraptor mongoliensis, a small Cretaceous theropod dinosaur from Mongolia. Paläontologische Zeitschrift 51:173-184. doi:10.1007/BF02986567.

Sues, H.-D., Frey, E., Martill, D.M. and Scott, D.M. 2002. Irritator challengeri, a spinosaurid (Dinosauria: Theropoda) from the Lower Cretaceous of Brazil. Journal of Vertebrate Paleontology 22:535-547. doi:10.1671/02724634(2002)022[0535:ICASDT]2.0.CO;2.

Sues, H.-D., Nesbitt, S.J., Berman, D.S. and Henrici, A.C. 2011. A late-surviving basal theropod dinosaur from the latest Triassic of North America. Proceedings of the Royal Society B: Biological Sciences 278:3459-3464. doi:10.1098/rspb.2011.0410.

Tahara, R. and Larsson, H.C.E. 2011. Cranial pneumatic anatomy of Ornithomimus edmontonicus (Ornithomimidae: Theropoda). Journal of Vertebrate Paleontology 31:127-143. doi:10.1080/02724634.2011.539646.

Therrien, F., Henderson, D.M. and Ruff, C.B. 2005. Bite me: biomechanical models of theropod mandibles and implications for feeding behavior, p. 179-237. In Carpenter, K. (ed.), The Carnivorous Dinosaurs. Indiana University Press, Bloomington, Indiana.

Turner, A.H., Hwang, S.H. and Norell, M.A. 2007. A small derived theropod from Öösh, Early Cretaceous, Baykhangor Mongolia. American Museum Novitates 3557:1-27. 
Turner, A.H., Makovicky, P.J. and Norell, M. 2012. A review of dromaeosaurid systematics and paravian phylogeny. Bulletin of the American Museum of Natural History 371:1206.

Turner, A.H., Pol, D. and Norell, M.A. 2011. Anatomy of Mahakala omnogovae (Theropoda: Dromaeosauridae), Tögrögiin Shiree, Mongolia. American Museum Novitates 3722:166. doi:10.1206/3722.2.

Tykoski, R.S. 2005. Anatomy, ontogeny, and phylogeny of coelophysoid theropods. Ph.D. Dissertation, The University of Texas, Austin, Texas.

Varricchio, D.J. 1997. Troodontidae, p. 749-754. In Currie, P.J. and Padian, K. (eds.), Encyclopedia of Dinosaurs. Academic Press, San Diego, California.

Vickers-Rich, P., Chiappe, L.M. and Kurzanov, S. 2002. The enigmatic birdlike dinosaur Avimimus portentosus, p. 65-86. In Chiappe, L.M. and Witmer, L.M. (eds.), Mesozoic birds: above the heads of dinosaurs. University of California Press, Berkeley/Los Angeles/London.

Walker, A.D. 1964. Triassic reptiles from the Elgin Area: Ornithosuchus and the origin of carnosaurs. Philosophical Transactions of the Royal Society of London. Series B, Biological Sciences 248:53-134. doi:10.1098/rstb.1964.0009.

Walker, A.D. 1985. The braincase of Archaeopteryx, p. 123-134. In Hecht, M.K., Ostrom, J.H., Viohl, G., and Wellnhofer, P. (eds.), The Beginnings of Birds. Freunde des JuraMuseums Eichstätt, Germany.

Welles, S.P. 1954. New Jurassic Dinosaur from the Kayenta Formation of Arizona. Geological Society of America Bulletin 65:591-598. doi:10.1130/00167606(1954)65[591:NJDFTK]2.0.CO;2.

Welles, S.P. 1984. Dilophosaurus wetherilli (Dinosauria, Theropoda). Osteology and comparisons. Palaeontographica Abteilung A 185:85-180. 
Wellnhofer, P. 1980. Flugsaurierreste aus der Gosau-Kreide von Muthmannsdorf (Niederösterreich)-ein Beitrag zur Kiefermechanik der Pterosaurier. Mitteilungen der Bayerischen Statssammlung fur Paleontologie und historische Geologie 20:95112.

White, T.E. 1940. Holotype of Plesiosaurus longirostris Blake and classification of the plesiosaurs. Journal of Paleontology 451-467.

Xing, L. 2012. Sinosaurus from southwestern China. MSc. Dissertation, University of Alberta, Edmonton, Alberta, Canada.

Xing, L., Bell, P.R., Rothschild, B.M., Ran, H., Zhang, J., Dong, Z., Zhang, W. and Currie, P.J. 2013. Tooth loss and alveolar remodeling in Sinosaurus triassicus (Dinosauria: Theropoda) from the Lower Jurassic strata of the Lufeng Basin, China. Chinese Science Bulletin 58:1931-1935. doi:10.1007/s11434-013-5765-7.

Xu, X., Clark, J.M., Forster, C.A., Norell, M.A., Erickson, G.M., Eberth, D.A., Jia, C. and Zhao, Q. 2006. A basal tyrannosauroid dinosaur from the Late Jurassic of China. Nature 439:715-718. doi:10.1038/nature04511.

Xu, X. and Norell, M.A. 2004. A new troodontid dinosaur from China with avian-like sleeping posture. Nature 431:838-841. doi:10.1038/nature02898.

Xu, X., Norell, M.A., Kuang, X., Wang, X., Zhao, Q. and Jia, C. 2004. Basal tyrannosauroids from China and evidence for protofeathers in tyrannosauroids. Nature 431:680-684. doi:10.1038/nature02855.

Xu, X., Norell, M.A., Wang, X., Makovicky, P.J. and Wu, X. 2002. A basal troodontid from the Early Cretaceous of China. Nature 415:780-784. doi:10.1038/415780a.

Xu, X. and Wu, X.-C. 2001. Cranial morphology of Sinornithosaurus millenii Xu et al. 1999 (Dinosauria: Theropoda: Dromaeosauridae) from the Yixian Formation of Liaoning, China. Canadian Journal of Earth Sciences 38:1739-1752. doi:10.1139/e01-082. 
Xu, X., You, H., Du, K. and Han, F. 2011. An Archaeopteryx-like theropod from China and the origin of Avialae. Nature 475:465-470. doi:10.1038/nature10288.

Yates, A.M. 2005. A new theropod dinosaur from the Early Jurassic of South Africa and its implications for the early evolution of theropods. Palaeontologia Africana 41:105122.

Zanno, L.E. 2010. Osteology of Falcarius utahensis (Dinosauria: Theropoda): characterizing the anatomy of basal therizinosaurs. Zoological Journal of the Linnean Society 158:196-230. doi:10.1111/j.1096-3642.2009.00464.x.

Zanno, L.E., Gillette, D.D., Albright, L.B. and Titus, A.L. 2009. A new North American therizinosaurid and the role of herbivory in "predatory" dinosaur evolution. Proceedings of the Royal Society B: Biological Sciences 276:3505-3511. doi:10.1098/rspb.2009.1029.

Zelditch, M.L., Wood, A.R. and Swiderski, D.L. 2009. Building Developmental Integration into Functional Systems: Function-Induced Integration of Mandibular Shape. Evolutionary Biology 36:71-87. doi:10.1007/s11692-008-9034-7.

Zhao, X.-J. and Currie, P.J. 1993. A large crested theropod from the Jurassic of Xinjiang, People's Republic of China. Canadian Journal of Earth Sciences 30:2027-2036. doi:10.1139/e93-178. 


\section{FIGURE CAPTIONS}

FIGURE 1. Strict consensus cladogram from 13 most parsimonious trees. Initial analysis was a New Technology Search using TNT v.1.1 of a data matrix comprising 98 quadrate based characters for one outgroup (Herrerasaurus ischigualastensis) and 54 nonavian theropod taxa. Tree length $=589$ steps $\mathrm{CI}=0.282 ; \mathrm{RI}=0.556$. Bremer support values are in bold and bootstrap values are in italic.

FIGURE 2. Strict consensus cladogram from 34 most parsimonious trees. Initial analysis was a New Technology Search using TNT v.1.1 of a supermatrix comprising 98 quadrate based characters combined with six recent datasets based on the whole skeleton (Choiniere, $\mathrm{Xu}$, et al., 2010; Brusatte, Norell, et al., 2010; Martinez et al., 2011; Carrano et al., 2012; Pol and Rauhut, 2012) for one outgroup (Eoraptor lunensis) and 54 nonavian theropod taxa. Tree length $=3616$ steps $; \mathrm{CI}=0.562 ; \mathrm{RI}=0.63113$. Bremer support values are in bold and bootstrap values are in italic.

FIGURE 3. 1, Cladogram resulting from the phylogenetic morphometrics analysis of the quadrate body shape in posterior view using 12 landmarks (tree score: 3.25, by using RFTRA) and revealing two morphotypes: low and stout quadrate with well-delimited and relatively broad lateromedially quadrate foramen (morphotype A; Spinosauridae and Coelurosauria) versus tall and slender quadrate with a lateromedially narrow or completely absent quadrate foramen (morphotype B; Ceratosauria and Megalosauridae); 2, Cladogram resulting from the phylogenetic morphometrics analysis of the mandibular articulation in ventral view using 8 landmarks (tree score: 2.92; by using RFTRA) and revealing two morphotypes: anteroposteriorly broad mandibular articulation with two ovoid/subcircular condyles roughly subequal in size (morphotype A; Ceratosauria, Tyrannosauroidea and Oviraptorosauria) 
versus elongate and anteroposteriorly narrow mandibular articulation with a long and parabolic/sigmoid ectocondyle (morphotype B; Megalosauroidea, Carcharodontosauridae and Dromaeosauridae).

FIGURE 4. Quadrate diversity in non-neotheropod Theropoda. Right quadrate (1-4) of Herrerasaurus ischigualastensis (PVSJ 53, formerly Frenguellisaurus ischigualastensis) in (1) posterior, (2) medial, (3) anterior and (4) ventral views. Right quadrate (5) of Eoraptor lunensis (PVSJ 512) in posterolateral view. Left quadrate (5-10) of Eodromaeus murphi (PVSJ 562) in (6) lateral, (7) medial, (8) posterior, (9) dorsal, and (10) ventral views. Left (11-13) and right (14-16) quadrates of Tawa hallae (GR 241) in (11) lateral, (12,14) posterior, $(\mathbf{1 3}, \mathbf{1 5})$ medial and $(\mathbf{1 6})$ ventral views (courtesy of Sterling Nesbitt). Abbreviations: ecc, ectocondyle; enc, entocondyle; lpq, lateral process; mfq, medial fossa; pfl, pterygoid flange; pfq, posterior fossa; qf, quadrate foramen; q.jp, quadratojugal process; qr quadrate ridge; vsh, ventral shelf of the pterygoid flange.

FIGURE 5. Quadrate diversity in Coelophysoidea. Right quadrate (1-6) of Liliensternus liliensterni (MB R.2175) in (1) anterior, (2) lateral, (3) posterior, (4) medial, (5) dorsal, and (6) ventral views (courtesy of Martín Ezcurra). Right (7-8) and left (8-9) quadrates of 'Syntarsus' kayentakatae (MNA V2623) in (9) lateral and $(\mathbf{7 , 8})$ posterior views (courtesy of Ronald Tykoski). Left $(\mathbf{1 0}, \mathbf{1 2}, \mathbf{1 5})$ and right $(\mathbf{1 1}, \mathbf{1 3 - 1 4})$ quadrates of Dilophosaurus wetherilli (UCMP 37302) in (10) anterior, (11) lateral, (12) posterior, (13) medial, (14) dorsal and (15) ventral views (courtesy of Randall Irmis). Abbreviations: ecc, ectocondyle; enc, entocondyle; lpq, lateral process; mfq, medial fossa; pfl, pterygoid flange; pfq, posterior fossa; qf, quadrate foramen; qh, quadrate head; qjp, quadratojugal process; qr quadrate ridge; vsh, ventral shelf of the pterygoid flange. 
FIGURE 6. Quadrate diversity in Ceratosauridae and Noasauridae. Coosified right $(\mathbf{1}, \mathbf{3})$ and left $(\mathbf{2}, \mathbf{4 - 5})$ quadrates and quadratojugals of Ceratosaurus nasicornis (MWC 1; formerly known as C. 'magnicornis') in (1) anterior, (2) lateral, (3) posterior, (4) medial and (5) ventral views. Right quadrate (6-9) of Masiakasaurus knopfleri (FMNH PR 2496) in (6) lateral, (7) posterior, (8) medial and (9) ventral views (courtesy of Matthew Carrano). Right quadrate (10-15) of Noasaurus leali (PVL 4061) in (10) anterior, (11) lateral, (12) posterior, (13) medial, dorsal (14), and (15) ventral views. Abbreviations: ecc, ectocondyle; enc, entocondyle; ics, intercondylar sulcus; lpq, lateral process; mfq, medial fossa; ptf, pterygoid flange; qh, quadrate head; qje, quadratojugal contact; qr quadrate ridge; vsh, ventral shelf of the pterygoid flange; pfq, posterior fossa.

FIGURE 7. Quadrate diversity in Abelisauridae. Right quadrate (1-6) of Ilokelesia aguadagrandensis (PVPH 35) in (1) anterior, (2) lateral, (3) posterior, (4) medial, (5) dorsal and (6) ventral views (courtesy of Matthew Lamanna). Right quadrate (7-12) of Majungasaurus crenatissimus (FMNH PR 2100) in (7) anterior, (8) lateral, (9) posterior, (10) medial, (11) dorsal and (12) ventral views (courtesy of Lawrence Witmer). Right $(\mathbf{1 3}, \mathbf{1 4}, \mathbf{1 5}$, 16) and left $(\mathbf{1 5}, \mathbf{1 7})$ quadrates of Carnotaurus sastrei (MACN CH 894) in (13) anteroventral, (14) lateral, (15) posterior, (16) anteromedial and (17) ventral views (courtesy of Pablo Asaroff). Abbreviations: ecc, ectocondyle; enc, entocondyle; icn, intercondylar notch; ics, intercondylar sulcus; lpq, lateral process; mfq, medial fossa; pfq, posterior fossa; qh, quadrate head; qjc, quadratojugal contact; qr quadrate ridge; ri, ridge on the ventrolateral surface of the quadrate body; vsh, ventral shelf of the pterygoid flange. 
FIGURE 8. Quadrate diversity in Megalosauridae. Right quadrate (1-5) of Eustreptospondylus oxoniensis (OUMNH J.13558) in (1) anterior, (2) lateral, (3) posterior, (4) medial and (5) ventral views (courtesy of Paul Barrett). Right quadrate (6-11) of Torvosaurus tanneri (BYUVP 9246) in (6) anterior, (7) lateral, (8) posterior, (9) medial, (10) dorsal and (11) ventral views (courtesy of Matthew Lamanna). Left quadrates (12-17) of Afrovenator abakensis (UC OBA1) in (12) anterior, (13) lateral, (14) posterior, (15) medial, (16) dorsal and (17) ventral views (courtesy of Roger Benson). Abbreviations: ecc, ectocondyle; enc, entocondyle; fo1, medial foramen 1; fo2, medial foramen 2; ics, intercondylar sulcus; mfq, medial fossa; pfq, posterior fossa; qh, quadrate head; qjc, quadratojugal contact; q.jp, quadratojugal process; vmfo, ventromedial foramen.

FIGURE 9. Quadrate diversity in Spinosauridae. Left quadrate (1-6) of Baryonyx walkeri (BMNH R9951) in (1) anterior, (2) lateral, (3) posterior, (4) medial, (5) dorsal and (6) ventral views. Left quadrate (7-12) of Suchomimus tenerensis (MNN GAD 502) in (7) anterior, (8) lateral, (9) posterior, (10) medial, (11) dorsal and (12) ventral views. Left quadrate (13-18) of and indeterminate Spinosaurinae from the Kem Kem beds (MSNM V6896) in (13) anterior, (14) lateral, (15) posterior, (16) medial, (17) dorsal and (18) ventral views. Abbreviations: ecc, ectocondyle; enc, entocondyle; icp, intercondylar pit; lfo, lateral foramen; mfq, medial fossa; ptf, pterygoid flange; qf, quadrate foramen; qh, quadrate head; q.jp, quadratojugal process; qr, quadrate ridge; vpdq, ventral projection of the dorsal quadratojugal contact; vsh, ventral shelf of the pterygoid flange.

FIGURE 10. Quadrate diversity in non-carcharodontosaurid Allosauroidea. Left (1-6) coosified quadrate and quadratojugal of Allosaurus 'jimmadseni'. (SMA 005/02) in (1) anterior, (2) lateral, (3) posterior, (4) medial, (5) dorsal, and (6) ventral views. Left quadrate 
(7-12) of Aerosteon riocoloradensis (MCNA-PV-3137) in (7) anterior, (8) lateral, (9)

posterior, (10) medial, (11) dorsal, and (12) ventral views (courtesy of Martin Ezcurra). Right quadrate (13-17) of Sinraptor dongi (IVPP 10600) in (13) anterior, (14) lateral, (15) posterior, (16) medial, and (17) ventral views (Currie, 2005 for 13, 16-17; courtesy of Philip Currie for 14-15). Abbreviations: ecc, ectocondyle; enc, entocondyle; dqje, dorsal quadratojugal contact; icp, intercondylar pit; lpq, lateral process; pfq, posterior fossa; ppne, posterior pneumatopore; qf, quadrate foramen; qr, quadrate ridge; qrg, quadrate ridge groove; vqje, ventral quadratojugal contact; vsh, ventral shelf of the pterygoid flange.

FIGURE 11. Quadrate diversity in Carcharodontosauridae. Right $(\mathbf{1 , 5})$ and left $(\mathbf{2}-\mathbf{4})$ coosified quadrate and quadratojugal of Acrocanthosaurus atokensis (NCSM 14345) in (1) anterior, (2) lateral, (3) posterior, (4) medial, and (5) ventral views (courtesy of Drew Eddy and Vince Shneider). Right quadrate (6-11) of Shaochilong moartuensis (IVPP V2885.3) in (6) anterior, (7) lateral, (8) posterior, (9) medial, (10) dorsal and (11) ventral views (courtesy of Steve Brusatte). Left quadrate (12-17) of Mapusaurus rosea (MCFPVPH-108.102) in (12) anterior, (13) lateral, (14) posterior, (15) medial, (16) dorsal, and (17) ventral views (courtesy of Matthew Lamanna). Abbreviations: apne, anterior pneumatopore; lpq, lateral process; mfq, medial fossa; mpne, medial pneumatopore; pfq, posterior fossa; ppne, posterior pneumatopore; qf, quadrate foramen; qrg, quadrate ridge groove; vsh, ventral shelf of the pterygoid flange.

FIGURE 12. Quadrate diversity in Tyrannosauroidea. Left and right (1-3) quadrates of Proceratosaurus bradleyi (NHM R 4860) in (1) posterior and (2-3) posteromedial views. Ventral part of the right quadrate (4-9) of Eotyrannus lengi (MIWG 1997.550) in (4) anterior, (5) lateral, (6) posterior, (7) medial, (8) dorsal and (9) ventral views. Left quadrate (10-15) of 
Alioramus altai (IGM 100-1844) in (10) anterior, (11) lateral, (12) posterior, (13) medial, (14) dorsal, and (15) ventral views (courtesy of Mike Ellison (C AMNH). Abbreviations: dqje, dorsal quadratojugal contact; ecc, ectocondyle; enc, entocondyle; mfq, medial fossa; pfl, pterygoid flange; pfq, posterior fossa; qf, quadrate foramen; qh, quadrate head; qr, quadrate ridge; vqje, ventral quadratojugal contact; vpne, ventral pneumatopore.

FIGURE 13. Quadrate diversity in Ornithomimosauria and Therizinosauria. Left quadrate (1) of Struthiomimus altus (AMNH 5339) in lateral view. Left quadrate (2) of Gallimimus bullatus (IGM 100-1133) in ventral view. Right coosified quadrates and quadratojugal (3-4) of Ornithomimus edmontonicus (RTMP 95.110.1) in $(\mathbf{1}, \mathbf{3})$ lateral and $(\mathbf{2}, \mathbf{4})$ lateroposterior views (courtesy of Rui Tahara and Yoshitsugu Kobayashi). Left coosified quadrate and quadratojugal (5) of Sinornithomimus dongi (IVPP-V11797-10) in posterior view (courtesy of Yoshitsugu Kobayashi, modified). Left (6) and right (7) coosified quadrates and quadratojugals of Garudimimus brevipes (IGM 100-13) in (6-7) posterior view (courtesy of Yoshitsugu Kobayashi, modified). Right quadrate (8-12) of Falcarius utahensis (UMNH VP 14559) in (8) anterior, (9) lateral, (10) posterior, (11) medial, and (12) ventral views (courtesy of Lindsay Zanno). Abbreviations: dqje, dorsal quadratojugal contact; ecc, ectocondyle; enc, entocondyle; exo, exoccipital; j, jugal; la, lacrimal; mpne, medial pneumatopore; pfq, posterior fossa; po, postorbital; ppne, posterior pneumatopore; qf, quadrate foramen; qh, quadrate head; qj, quadratojugal; pfq, posterior fossa; ppne, posterior pneumatopore; sq, squamosal; vqje, ventral quadratojugal contact.

FIGURE 14. Quadrate diversity in basal Coelurosauria and Alvarezsauroidea. Right (1-2, 6) and left (3-5) quadrates of Bicentenaria argentina (MPCA 865) in (1) anterior, (2) lateral, (3) posterior, (4) medial, (5) dorsal, and (6) ventral views. Right quadrate (7-8) of Ornitholestes 
hermanni (AMNH FARB 619) in (7) lateral, $(\mathbf{8 , 1 0})$ posterior, $(\mathbf{9})$ posterolateral, and (11) ventral views, (10) with details of the central part of the quadrate body (photo courtesy shared by Mickey Mortimer). Right (12-13) and left (14-16) quadrates of Shuvuuia deserti (12-13: IGM 100-977; 14-16: IGM 100-1001) in $(\mathbf{1 2}, \mathbf{1 4})$ posterior, (13) posteromedial, (15) lateral, and (16) ventral views. Abbreviations: dpvq, dorsal projection of the ventral quadratojugal contact; ecc, ectocondyle; enc, entocondyle; ics, intercondylar sulcus; lpr, lateral process; mfq, medial fossa; oca, ootic capitulum; pfl, pterygoid flange; pfq, posterior fossa; po, postorbital; poc, postorbital contact; pt, pterygoid; ptc, pterygoid contact; qf, quadrate foramen; qh, quadrate head; qj, quadratojugal; qje, quadratojugal contact; qr, quadrate ridge; sca, squamosal capitulum; sq, squamosal; vpdq, ventral projection of the dorsal quadratojugal contact; vpne, ventral pneumatopore; vqje, ventral quadratojugal contact; vsh, ventral shelf.

FIGURE 15. Quadrate diversity in Oviraptorosauria. Occipital part of the cranium (1-4) of Avimimus portentosus (cast of PIN 3907/1) in (1) lateral, (2) posterior, (3) anterolateral, and (4) ventral views (courtesy of Lawrence Witmer). Right quadrate (5-8) of Citipati osmolskae (IGM 100-978) in (5) lateral, (6) posterior, (7) medioposterior, and (8) ventral views. Right quadrate (9-12) of Khaan mckennai (IGM 100-1127 for 9-11, IGM 100-1002 for 12) in (9, 12) lateral, (10) posterolateral, and (11) anterolateral views. Abbreviations: brc, braincase contact; dptc, dorsal pterygoid contact; dqje, dorsal quadratojugal contact; ecc, ectocondyle; enc, entocondyle; pfl, pterygoid flange; pfq, posterior fossa; pt, pterygoid; ptc, pterygoid contact; qf, quadrate foramen; qj, quadratojugal; qje, quadratojugal contact; qr, quadrate ridge; sq, squamosal; sqc, squamosal contact; vptc, ventral pterygoid contact; vqje, ventral quadratojugal contact. 
FIGURE 16. Quadrate diversity in Dromaeosauridae. Left quadrate (1-6) of Bambiraptor feinbergi (AMNH 30556) in (1) anterior, (2) lateral, (3) posterior, (4) medial, (5) dorsal, and (6) ventral views. Right quadrate (7-11) of Tsaagan mangas (IGM 100-1015) in (7) anterior, (8) lateral, (9) posterior, (10) medial, and (11) ventral views (courtesy of Mick Ellison). Right quadrate (12-17) of Dromaeosaurus albertensis (AMNH 5356) in (12) anterior, (13) lateral, (14) posterior, (15) medial, (16) dorsal, and (17) ventral views. Abbreviations: dqje, dorsal quadratojugal contact; ecc, ectocondyle; enc, entocondyle; ics, intercondylar sulcus; lpq, lateral process; mfq, medial fossa; pfl, pterygoid flange; pfq, posterior fossa; pt, pterygoid; qf, quadrate foramen; qh, quadrate head; q.jp, quadratojugal process; qr, quadrate ridge; sqc, squamosal contact; vqje, ventral quadratojugal contact; vptc, anteroventral pterygoid contact. 


\section{TABLE}

TABLE 1. Nonavian theropod specimens and clades examined and scored in the cladistic analysis. Taxa and clades with an asterisk were used in the phylogenetic morphometric analysis. Abbreviations: Y, Yes; N, No.

\begin{tabular}{|c|c|c|c|c|}
\hline \multirow[b]{2}{*}{ Taxon } & \multicolumn{3}{|c|}{ Exami } & \multirow[b]{2}{*}{ Literature } \\
\hline & Specimens & ned & Photo credits & \\
\hline Eoraptor lunensis Sereno et & PVSJ 512 & $\mathrm{Y}$ & Martín Ezcurra & Sereno et al., \\
\hline al., 1993 & & & & 2013 \\
\hline Herrerasaurus & PVSJ 53, & $\mathrm{Y}$ & Martín Ezcurra & \\
\hline ischigualastensis Reig, & 407 & & & \\
\hline \multicolumn{5}{|l|}{1963} \\
\hline Eodromaeus murphi & PVSJ 562 & $\mathrm{Y}$ & Carol Abraczinskas & \\
\hline \multicolumn{5}{|l|}{ Martinez et al., 2011} \\
\hline Tawa hallae* Nesbitt et al., & GR 241 & $\mathrm{~N}$ & Sterling Nesbitt & Nesbitt et al., \\
\hline 2009 & & & & 2009 \\
\hline 'Syntarsus' kayentakatae & MNA & $\mathrm{N}$ & Ronald Tykoski; & Rowe, 1989 \\
\hline Rowe, 1989 & V2623 & & Randall Irmis & \\
\hline Liliensternus liliensterni & MB R.2175 & $\mathrm{N}$ & Martín Ezcurra & von Huene, 1934 \\
\hline \multicolumn{5}{|l|}{ von Huene, 1934} \\
\hline Dilophosaurus wetherilli* & UCMP & $\mathrm{N}$ & Randall Irmis; & Welles, 1984 \\
\hline Welles, 1954 & 37302 & & Martín Ezcurra; & \\
\hline & & & Mathew Carrano & \\
\hline Ceratosaurus nasicornis* & USNM & $\mathrm{Y}$ & Mathew Carrano & (Madsen and \\
\hline Marsh, 1884 & 4735 & & & Welles, 2000) \\
\hline
\end{tabular}




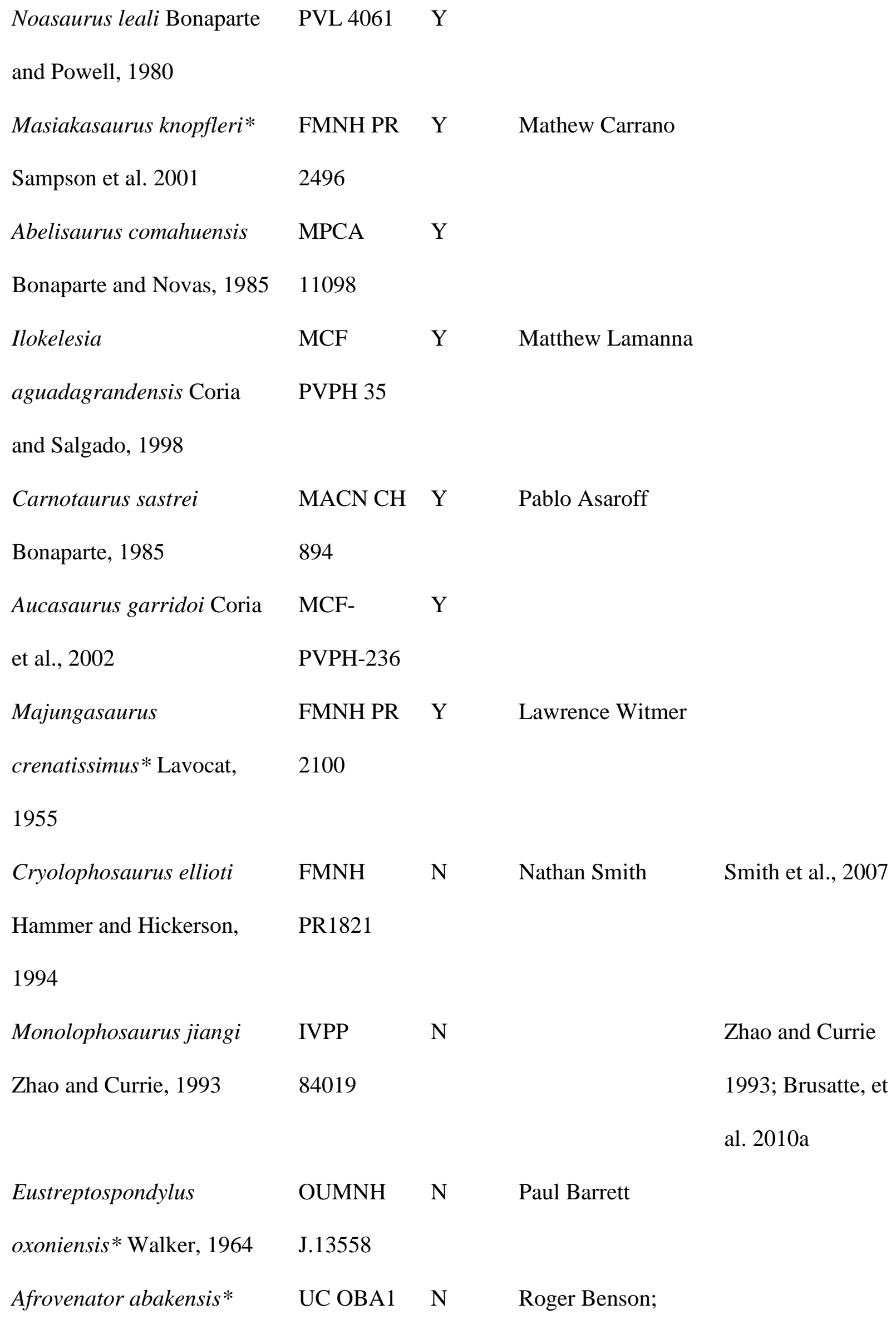


Sereno et al., 1994

Torvosaurus tanneri Galton BYUVP $\quad$ Y $\quad$ Matthew Lamanna

and Jensen, 1979

Baryonyx walkeri* Charig

and Milner, 1986

Suchomimus tenerensis

Sereno et al., 1998

Irritator challengeri Martill

et al., 1996

Spinosaurinae morphotype

$I^{*}$

Spinosaurinae morphotype

II

Allosaurus fragilis* Marsh,

1877

Allosaurus europaeus

Mateus et al., 2006

Allosaurus 'jimmadseni’*
Juan Canale;

Mathew Carrano

9246

BMNH $\quad \mathrm{Y} \quad$ Eric Buffetaut

R9951

MNN GAD Y Steve Brusatte

502

SMNS Y

58022

MSNM Y

V6896;

WDC-CSG

uncatalogu

ed

WDC-CSG Y

uncatalogu

ed

BYU Y

Osborn, 1912;

Gilmore, 1920;

Madsen, 1976b;

Chure, 2000 
Chure, 2000

Aerosteon riocoloradensis*

Sereno et al., 2008

PV-3137

Sinraptor dongi $*$ Currie and IVPP

10600

Zhao, 1993b

Acrocanthosaurus

atokensis* Stovall and

Langston Jr, 1950

Shaochilong maortuensis*

Brusatte, Benson, et al.,

2009

IVPP

V2885.3

$\mathrm{N}$

Steve Brusatte

Brusatte, Benson,

et al., 2009;

Brusatte, Chure,

et al., 2010

Mapusaurus roseae Coria

MCF

Y

Matthew Lamanna

and Currie, 2006

\section{PVPH}

108.102

Giganotosaurus carolinii*

$\mathrm{MUCPV}$

Y

Matthew Lamanna

Coria and Salgado, 1995

$\mathrm{CH}-1$

Ornitholestes hermanni

AMNH

Y

Mickey Mortimer

Osborn, 1903

FARB 619

Bicentenaria argentina

MPCA $865 \quad \mathrm{Y}$

Novas et al., 2012

Zuolong salleei Choiniere,

IVPP

$\mathrm{N}$

Choiniere, Clark,

Clark, et al., 2010

V15912

Proceratosaurus bradleyi

et al., 2010

Rauhut et al., 
von Huene, 1926

4860

2010

Eotyrannus lengi Hutt et al., MIWG Y Parren Naish

2001

1997.550

Xionggualong baimoensis

FRDC-GS N

Li et al., 2010

Li et al., 2010

JB16-2-1

Alioramus altai Brusatte,

IGM 100- $\quad \mathrm{N}$

Mick Ellison

Brusatte et al.,

Carr, et al., 2009

1844

2012; Gold et al.,

2013

Albertosaurus sarcophagus RTMP

Carr, 1996;

Osborn, 1905

81.10.1;

Currie, 2003

FMNH

PR308;

CMN 12;

CMN 2120

Daspletosaurus sp. Russell,

RTMP

$\mathrm{N}$

Currie, 2003

1970

94.143 .1

Tyrannosaurus rex*

AMNH

Y

Mickey Mortimer

Molnar, 1991;

Osborn, 1905

5027 ;

Brochu, 2003;

FMNH

Larson, 2008

PR2081

Garudimimus brevipes

IGM 100- N

Yoshitsugu

Kobayashi and

Barsbold, 1981

13

Kobayashi

Barsbold, 2005

Sinornithomimus dongi

IVPP-V11 N

Yoshitsugu

Kobayashi and

Kobayashi and Lü, 2003

797-10

Kobayashi

Lü, 2003

Shuvuuia deserti Chiappe et IGM 100- Y

Dufeau, 2003 
al., 1998

977, 100-

1001

Falcarius utahensis*

Kirkland et al., 2005

Erlikosaurus andrewsi

Barsbold and Perle, 1980

Avimimus portentosus

Kurzanov, 1981

Oviraptoridae* Barsbold,

1986

Buitreraptor gonzalezorum

Makovicky et al., 2005

Bambiraptor feinbergi*

Burnham et al., 2000

Tsaagan mangas* Norell et

al., 2006

Dromaeosaurus albertensis

Matthew and Brown, 1922

Troodontidae Gilmore,

14559

PST 100

FARB

$100-978$

FIN 001

1015

5356
UMNH VP N

$\mathrm{N}$

Stephan

Lautenschlager

PIN 3907/1 N

Lawrence Witmer

Kurzanov, 1985;

Vickers-Rich et

al., 2002

Maryańska and

AMNH $\quad \mathrm{Y}$

6517; IGM

100-1002;

IGM 100-

1127; IGM

MPCA $245 \quad \mathrm{Y}$

$\mathrm{Y}$

David Burnham

Martín Ezcurra
Osmólska, 1997;

Clark et al.,

2002; Kundrát

and Janáček,

2007; Balanoff

and Norell, 2012

IGM 100- Y Mick Ellison

AMNH $\quad \mathrm{Y}$

IGM 100- Y Rui Pei

Barsbold et al., 
100-1128;

Hwang, 2004; Xu

IGM 100-

and Norell, 2004;

1323

Hu et al., 2009;

Xu et al., 2011;

Gao et al., 2012 